\title{
A co-operative trial in the primary prevention of ischaemic heart disease using clofibrate Report ${ }^{1}$ from the Committee of Principal Investigators
}

SUMMARY A double-blind intervention trial was started in 1965 to test the hypothesis that the incidence of ischaemic heart disease in middle-aged men can be reduced by lowering raised serum cholesterol levels. It was carried out in 3 European centres-Edinburgh, Budapest, and Prague. Serum cholesterol was to be lowered by the drug clofibrate (ethyl chlorophenoxyisobutyrate) which was considered to be free from serious side effects.

Studies were carried out on 15745 males, aged 30 to 59 at entry, for an average of 5.3 years, accumulating 83534 years of experience. The treatment group, of about 5000, Group I, was a randomly chosen half of the men in the upper third of the serum cholesterol distribution in some 30000 volunteers. The comparable control group, Group II, comprised the other 5000 men of the upper third of the cholesterol distribution, and these were given a placebo. A further control group, Group III, of 5000 men, was selected randomly from the lower third of the cholesterol distribution. These numbers were chosen in order to be 90 per cent certain of detecting a 30 per cent reduction in the incidence of ischaemic heart disease should this occur. Subjects with manifest heart or other major disease were excluded from the trial. No attempt was made to correct other 'risk factors' for IHD, but their presence was monitored and considered in the analysis. Investigators and participants in the trial were unaware of the groups to which individual men belonged.

A mean reduction of approximately 9 per cent of the initial serum cholesterol levels was achieved in the treatment group (ranging from 7 to $11 \%$ in the 3 centres); this was less than the 15 per cent fall expected. In Edinburgh, during treatment, serum triglyceride concentrations in Group I resembled those naturally occurring in Group III.

The incidence of IHD was lower by 20 per cent in the clofibrate group compared with the high cholesterol controls $(P<0.05)$; this fall was confined to non-fatal myocardial infarcts which were reduced by 25 per cent. The incidence of fatal heart attacks was similar in the 2 high cholesterol groups and there was no significant difference in the incidence of angina. Group III showed substantially lower rates of ischaemic heart disease.

The reduction of myocardial infarction in the clofibrate-treated group was greatest in men with the highest levels, and greatest reduction in serum cholesterol. Men with a substantial reduction of cholesterol concentration, who smoked, and also had above average blood pressure levels showed the most benefit.

The numbers of deaths, and crude mortality rates from all causes in the clofibrate-treated group significantly exceeded those in the high cholesterol control group $(P<0.05)$, though the age-standardised mortality rates did not differ significantly between the 3 groups. The numbers of deaths from 'other

\footnotetext{
1 Prepared by-

M. F. Oliver, J. A. Heady, J. N. Morris, J. Cooper

Principal Investigators-

H. Geizerova, Institute for Clinical and Experimental Medicine, Prague (J. Fodor: 1966-1968)

I. Gyarfas, Hungarian Institute of Cardiology, Budapest (G. Lamm: 1966-1974)

K. G. Green, ICI, Macclesfield

J. A. Heady and J. N. Morris, MRC Social Medicine Unit, London

M. F. Oliver, The Royal Infirmary of Edinburgh

T. Strasser, WHO, Geneva (Z. Fejfar: 1966-1973)
}

Investigators-

Edinburgh: W. G. Macfie, E. Scott

Budapest: M. Czukas, J. Duba, E. Östor

Prague: D. Grafnetter, Z. Hejl

London: J. Cooper

WHO, Geneva: Z. Pisa, K. Uemura Copenhagen: G. Lamm (from 1974)

ICI: J. M. Thorp 
vascular causes' and from 'accidents' as well as IHD were similar in Groups I and II. Excluding these, the excess of deaths in the clofibrate-treated over the high cholesterol control group was $77 v 47(\mathrm{P}<0.01)$. The subgroup with the greatest proportionate excess of deaths is that of conditions related to the liver, the biliary, and intestinal systems, with 19 deaths in Group I $v 7$ in Group II $(P<0.05)$. Deaths from these conditions were commoner, however, in Group III than in Group II (age-standardised rates for the 3 groups being $0.75,0 \cdot 17$, and 0.65 , respectively), and it is possible that Group II had fortuitously low rates. The cholecystectomy rate for gall stones was higher in Group I than in Groups II and III $(\mathrm{P}<0.001)$.

The results of the trial confirm the basic hypothesis that reduction of high serum cholesterol levels, even in middle-age, can reduce the incidence of IHD. However, the fact that clofibrate increases the incidence of gall stones, and the possibility that it may have even more serious local pathological consequences, indicate that it cannot be recommended as a lipid-lowering drug for community-wide primary prevention of ischaemic heart disease.

By 1965, the association of raised serum lipids, particularly cholesterol, with an increased risk of developing ischaemic heart disease, was well established (e.g. Kannel et al., 1964). Whether raised serum cholesterol actually was causative or, simply, the indication of an underlying metabolic disorder was not known. But on general principles, medical opinion held that it was desirable to reduce serum lipids towards accepted normal levels as far as possible. The means of achieving this were largely based on alterations in diet, and experience at that time suggested that the measures thought necessary were impracticable on any wide scale and were unlikely to be adhered to by most individuals in an affluent society. The possibility of using a cholesterol-lowering drug had been considered but until ethyl chlorophenoxyisobutyrate (later called clofibrate) was introduced (Oliver, 1962; Thorp, 1962; Thorp and Waring, 1962; Symposium on Atromid, 1963) none available satisfied the prerequisites of effectiveness and safety. Clofibrate was known to be capable of reducing plasma concentrations of low density, and very low density, lipoproteins, and thus cholesterol and triglyceride. It was decided, therefore, to initiate a trial in healthy volunteers to find out whether reducing plasma lipids, using clofibrate, would result in a decreased incidence of ischaemic heart disease. No deliberate attempt would be made to change the life style of participants or to rectify other risk factors. A full account of design and procedure has already been published (Heady, 1973). The trial has now been completed, as planned; the present paper summarises the main points of methodology and gives the results.

\section{Trial design-procedure}

15745 healthy men, aged $30-59$, selected on the basis of a preliminary determination of serum cholesterol level were assigned to 3 groups as follows: half of the men in the upper third of the distribution of serum cholesterol values were assigned at random to a clofibrate-treated group (Group I) taking $1.6 \mathrm{~g}$ clofibrate daily; the other half of the upper third constituted a control group (Group II) taking identical capsules containing olive oil. A second control group of similar size (Group III), chosen at random from the lowest third of the serum cholesterol distribution, also received the olive oil capsules (Fig. 1).

Allocation to the high and low cholesterol groups was carried out every one or two months at each centre, from volunteers 'screened' during the period concerned. Thus, the cut-off levels into thirds varied chronologically.

The essential part of the trial was, thus, the double-blind comparison of the two randomly selected high serum cholesterol groups. The low serum cholesterol group served as a comparison (also double-blind) between men whose untreated cholesterol levels were 'naturally' low and those in Group I whose cholestero! levels fell under treat-

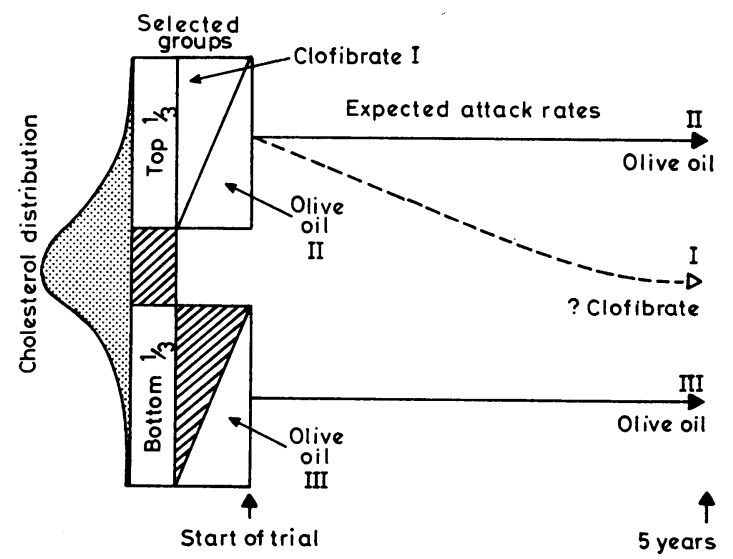

Fig. 1 Design of the trial (broken line represents hypothetical effect of clofibrate on serum cholesterol and IHD attack rates). 
ment. It also, in fact, served as a useful comparison with the other control group.

The study was designed to last 5 years for each subject admitted and it was assumed that (a) 70 per cent of the volunteers. would remain in the study for that length of time, and $(b)$ the untreated incidence of clinical episodes of coronary heart disease in healthy men aged 30 to 59 with moderately raised serum cholesterol levels would be 1 per cent per annum. The number of volunteers was to be large enough to give a 90 per cent chance $(\beta=10 \%)$ of detecting, in the clofibrate treated group, a reduction of one third in the incidence of heart attacks compared with the high cholesterol control group, at the 1 per cent level of significance (two-sided). To meet these requirements the study would have to admit at least 15000 subjects.

The figure of one-third reduction in incidence was chosen because available evidence in the early 1960's suggested that clofibrate might be expected to reduce raised serum cholesterol levels by about 15 per cent and that such a reduction might be associated with a fall in incidence of about 30 per cent. It was also felt that if a reduction of 30 per cent were achieved it would be a reasonable basis for prophylactic treatment, whereas with a smaller reduction the value of such intervention would be more problematical.

The men were recruited in ways which differed in the 3 centres (Heady, 1973) from lists of blood donors, electoral rolls, tuberculosis screening registers, and by advertising among the general public. Recruitment started in 1964 but was not complete until March 1972. After primary selection on the basis of serum cholesterol level, an explanation of the purpose of the study was made to the subject, and those who were willing to participate were medically examined before admission to the trial. The men with high serum cholesterol levels were then randomised to the clofibrate treated and the control group at each centre separately. After admission to the trial men were examined at 6 monthly intervals for 2 years, and thereafter at yearly intervals though they were still contacted by post, or otherwise, at 6-monthly intervals. A final follow-up took place a year after cessation of medication.

The trial was closed down from July 1975 onwards, treatment being withdrawn at the man's next scheduled visit after that date. The process took about one year, so that by the late summer of 1976, no more active treatment was being given.

EXCLUSIONS AND WITHDRAWALS

The criteria for rejection at admission on medical grounds are detailed in Appendix 1. They consisted mainly of evidence of previous myocardial infarc- tion; other types of heart disease, arterial hypertension as defined, diabetes mellitus requiring drug therapy, or other diseases with a poor prognosis were also reasons for exclusion. Criteria for withdrawal from the trial were similar (Appendix 1) but, of course, included adverse reactions. Because of different practice in the 3 centres, and for obvious ethical reasons, the attendant physicians were allowed latitude in withdrawing subjects from the trial, though this was of course done 'blind'. A history of exercise-induced chest pain was not a reason for withdrawal. At first, hypertension was a firm indication for withdrawal but later this was modified and concurrent antihypertensive therapy was permitted.

\section{FOLLOW-UP PROCEDURE}

Medical examination at follow-up was similar to that at entry. Questioning about side effects was general. Specific symptoms were not asked for by name, except indigestion, diarrhoea, and skin reactions, which were known side effects of clofibrate.

Men who gave a positive answer to the standard questionnaire on effort chest pain, and whose resting electrocardiogram was normal, were given a further electrocardiographic examination during and after exercise on a bicycle ergometer.

No systematic advice was given on diet, weight reduction, smoking, or exercise.

Failure to keep an appointment was investigated by the use of 'progress chasers' when necessary. Copies of death certificates were obtained.

All men who withdrew from the trial, or were withdrawn for any reason, medical or non-medical, were considered to be still in the trial for the purpose of calculating exposure-to-risk, up to the date of withdrawal (see Appendix 2). The criteria for classifying events such as death, or ischaemic heart disease, as occurring 'in the trial', or otherwise, are described below, under criteria for assessing the results of the trial.

\section{BIOCHEMICAL MONITORING}

Blood was taken for estimation of serum cholestero concentrations at each visit. In Edinburgh, from 1972 onwards, triglycerides were estimated by AutoAnalyzer (Kessler and Lederer, 1965). Urine was examined for sugar and albumin as a routine in Prague and Budapest but not in Edinburgh. Other laboratory tests were carried out as indicated by the history or examination.

\section{DRUG SUPPLIES}

Clofibrate for the trial was prepared at Imperial Chemical Industries in opaque white capsules 
containing $400 \mathrm{mg}$. The daily dose was $1.6 \mathrm{~g}$. The choice of $400 \mathrm{mg}$ antedated the availability of 500 $\mathrm{mg}$ capsules for clinical use. There is no evidence that $1.6 \mathrm{~g}$ is less effective than $2.0 \mathrm{~g}$. Control capsules were identical in appearance but, as said, contained $400 \mathrm{mg}$ olive oil. Each pack was labelled with the man's name and trial-number in the pharmacy at each centre.

\section{CONCURRENT MEDICATION}

There was no restriction on other drugs, but diabetic patients requiring drug treatment and patients receiving anticoagulants were withdrawn from the trial.

\section{DRUG ADHERENCE}

Adherence to treatment was assessed by arranging for the blood which was taken for serum cholesterol estimation to be tested also for the presence of clofibrate (chlorophenoxyisobutyric acid, CPIB). This was done by a semiquantitative method (Barrett and Thorp, 1968) in all the men in the clofibrate treated group at every visit and also in a random 10 per cent of the men in the 2 control groups. The purpose of including the control group was twofold: to make the laboratory assessment 'blind' and to assess the level of prescribing of clofibrate in the general population in each centre. 'Blindness' was arranged by compiling a single list of the trial numbers of all subjects on clofibrate and 10 per cent of the controls arranged in numerical order. The blood samples of the men on this list were routinely examined for the presence of clofibrate, the laboratory staff being aware that some men were not in the treated group but not which men.

\section{RECORDING OF DATA}

A standard record was completed on admission, and at each follow-up visit. Events occurring during the trial were notified on a separate form. (Copies of forms are available on request-Addendum A.) After completion at the trial centres, the forms were forwarded to the Medical Research Council's Social Medicine Unit in London, for scrutiny and transfer of the information to computer.

CRITERIA FOR ASSESSING THE RESULTS OF THE TRIAL (See Appendix 3)

(I) Ischaemic heart disease (IHD)

The following major end-points were defined:

(a) Fatal IHD (i) deaths known to have occurred less than 3 hours after onset of symptoms

(ii) deaths occurring more than 3 hours but less than 28 days after onset.

(b) Non-fatal myocardial infarction and acute coronary insufficiently surviving more than 28 days.

(Men who died more than 28 days after onset of symptoms were arbitrarily considered to have had a fresh attack. The death was, therefore, not included as a death in the first attack, or 'in the trial', since men with non-fatal infarctions were wihhdrawn from the trial. If the death occurred within 1 year of the attack it was included in the total of deaths within 1 year of leaving the trial.)

Additionally, the following minor IHD end-points were distinguished:

(a) Angina pectoris with abnormal electrocardiogram;

(b) Angina pectoris without abnormal electrocardiogram;

(c) Abnormal electrocardiogram without chest pain.

\section{(2) Deaths from all causes}

These were subdivided into deaths from IHD and other deaths. In tables of deaths from all causes, deaths occurring within 1 year of leaving the trial have been included.

Definitions of the terms used are given in Appendix 3 , as also are those of other events such as 'claudication' which were notified but were not reasons for withdrawal.

A panel of 2 physicians, not concerned with the day-to-day running of the trial, and situated at WHO headquarters in Geneva, reviewed all events that the participating physicians in the centres considered might be due to ischaemic heart disease, as defined.

Deaths or other events, such as IHD, were deemed to have occurred 'out of the trial' if they occurred after a visit at which the subject was excluded on medical grounds or had, himself, 'opted out', that is had stated his intention of not continuing to take the treatment. If, however, the last visit had been one at which neither of these things had happened, a death (or other event) was considered to have occurred 'in the trial' if it occurred within 9 months of the last visit, at the stage in the trial when visits should have occurred at 6monthly intervals, or within 18 months at the stage when visits should have occurred at yearly intervals. These periods were chosen to coincide with the definitions of a 'missed visit' or 'failure to attend', which, in turn, were related to the supply of pills which a subject would take away with him at an ordinary visit. Events which, after such visits, did not occur within these time limits were considered to have occurred 'out of the trial'. A special attempt was made to trace all deaths occurring within 1 year 
of leaving the trial, and for the most part, other outof-trial deaths have not been considered in the analysis.

\section{MONITORING OF RESULTS}

The policy was adopted of not reporting results to the investigators so as to avoid influencing their attitude to the trial. The statisticians and an epidemiologist chosen for this purpose alone had access to the results as they came in. The following rules were developed during the study for determining when the main results should be released to the principal investigators:

(a) If there were a significant result $(P<0 \cdot 10)$ against the treatment in terms of the main endpoints.

(b) If there were a significant result $(P<0 \cdot 10)$ against the treatment for any important side effect where useful discussion would be inhibited by lack of knowledge of the main results.

(c) If it became clear that the main result could not became significant $(P<0.01)$ in favour of the treatment.

(d) If there were a significant result $(P<0.01)$ in favour of the treatment in terms of the main endpoints.

A sequential scheme was used with a power of over 90 per cent to detect a difference of 33 per cent between treated and control at the appropriate levels of significance (Appendix 2).

\section{STANDARDISATION OF PROCEDURES}

(a) Blood pressure was taken in accordance with WHO recommendations (1962). (Observer variability was checked periodically within centres.)

(b) Skinfold thickness (triceps and subscapular) were measured according to the recommendations of Rose and Blackburn (1968).

(c) Electrocardiograms, at rest, were recorded on 12-lead electrocardiographs (unipolar chest leads). Exercise electrocardiograms were done under conditions which complied with the World Health Organization criteria (WHO, 1968). Classification of electrocardiogram was by Minnesota Code (Blackburn et al., 1960; Rose and Blackburn, 1968), and was carried out 'blind, that is in ignorance of the subject's treatment group. The case records of all infarctions or deaths attributed to ischaemic heart disease were checked by the panel at WHO, Geneva, mentioned earlier. In case of disagreement between the finding of the centre and that of the WHO panel, the electrocardiogram was reviewed at the annual meeting of the investigators and a committee decision was reached.

To maintain comparability between centres, sets of electrocardiograph recordings were circulated for coding at all centres with satisfactory results.

(d) Serum cholesterol: different methods of cholesterol estimation were used in each centre. The laboratories were subject to both internal and external quality control.

Internal quality control was mainly by the inclusion of a sample of an internal control pool of frozen lyophilised serum in each analytical day (or run). When pools were renewed there was a period of overlap between the new and old pools.

External quality control was by exchange of samples between centres and also by the participation of each centre, first in the programme in the WHOCDC International Lipid Standardization Laboratory in Atlanta, USA, and later in that of the European Regional WHO Lipid Reference Centre in Prague, which was itself one of the trial laboratories.

Procedures are available on request (Addendum B).

\section{STATISTICAL METHODS}

The details of the statistical methods used are in Appendix 2. This deals with age-standardisation, life-table calculations, the definitions and calculation of cholesterol change and mean in-trial cholesterol levels, and with multivariate analysis. A few points only need to be mentioned here.

Life table calculations were carried out by standard methods. Tests of statistical significance of differences in 'survivorship' use a method, similar to the 'log-rank' method (Mantel, 1966; Breslow, 1975), which compares the survivorship curves as a whole rather than at a single time interval after admission.

Statistical significance: in the tables attention is drawn to significant differences between Groups I and II only. Other significant differences are discussed in the text.

Age-standardisation is not necessary for comparing incidence and mortality rates in Groups I and II since the age-distributions in these 2 randomly allocated groups were almost identical. It is, however, necessary in comparing the rates in Group III with those in Groups I and II because the men in Group III, chosen on the basis of lower serum cholesterol levels, were on average slightly younger than those in Groups I and II.

Age-standardisation is also important in comparing other groups whose age-distributions cannot be assumed to be the same, for example those with high or low blood pressure, or smokers and nonsmokers. Standardisation was confined to the ages 40 to 59 because the number of events at ages 30 to 39 was small ( $6 \%$ of all incidents of IHD) and 
TABLE 1

Charactaristics :

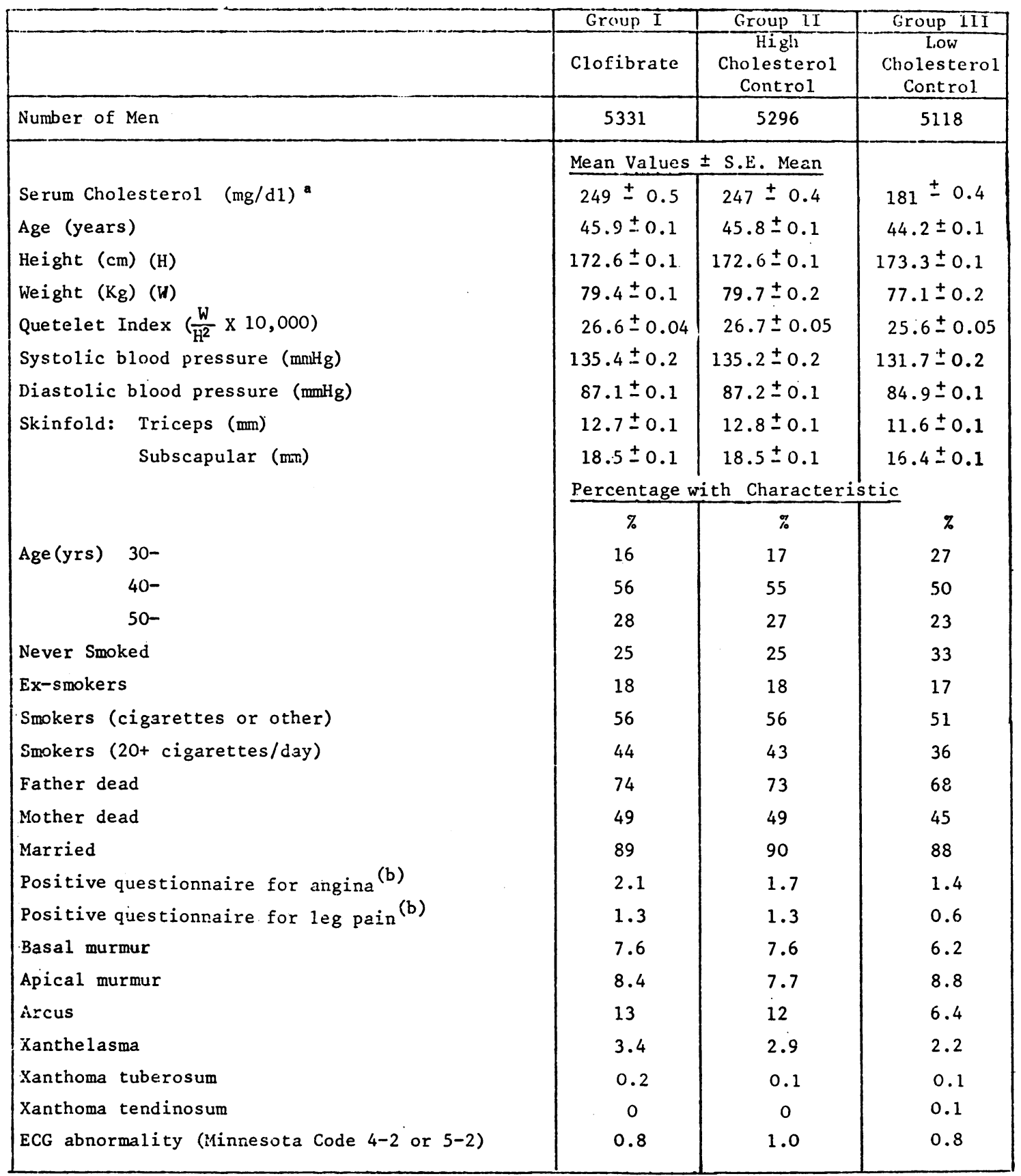

(a) Mean of pre-treatment serum cholesterol values corrected for Centre differences. See Appendix 2 .

(b) A modified version of the Loncion School of Hygiene Cardiovascular Questionnaire, Rose \& Blackburn 1968. (Addendum A). 
might produce spurious results, and, also, because there were virtually no men in Prague under the age of 40 . For the particular purpose of comparing rates between centres standardisation was restricted to the age-range 40 to 54 because there were also very few men aged 55 or over in Prague. Equal weightings were given to each 5-year age-group in the standardisation, for simplicity, and because, as it happened, in each centre, the number of men in each of the 4 age-groups, from 40 to 59 , in the general population was not very different.

\section{Results}

Results are presented in the main part of this report for the 3 centres combined, though attention is drawn to important differences between centres. The main results for IHD for the separate centres individually are shown in Appendix 4 and additional inter-centre differences are available in Addendum C.

\section{COMPARABILITY OF GROUPS}

Table 1 shows the characteristics recorded at entry to the trial, for all 3 centres combined, for each Group. There were no important differences between Groups I and II, the high serum cholesterol groups, in any of these characteristics; and this was true also within each centre. Group III, selected on the basis of lower serum cholesterol levels, did however show differences from the other 2 groups. On average, the men in this group were younger, lighter, taller, had lower blood pressures, and smoked less.

There was an important difference between centres in age-distribution of the subjects (Addendum D). In Prague virtually no subjects were recruited under the age of 40 , whereas one third of those in Edinburgh and one quarter of the Budapest men were under that age. Budapest, at 32 per cent, had the highest proportion of men over 50 compared with 21 per cent in Edinburgh, and 24 per cent in Prague. Only 57 men in Prague were aged 55 or more. For the trial as a whole, more than half of the subjects were aged between 40 and 50.

\section{MEN AND MAN-YEARS IN TRIAL}

Table 2 shows the numbers of men who entered, and completed, or failed to continue in the trial for various reasons. Some $300 \mathrm{had}$ in fact been in the trial for as many as $\mathbf{8}$ years when it closed. On the other hand, 227 late entrants did not have the opportunity to complete 5 years before it ended. Subtracting these from the total admitted, 69 per cent of those for whom it was possible remained in the trial for 5 years, slightly less than the 70 per cent allowed for in the planning stage. The percentage of men who left the study for any reason was 13 per cent in the first year, and about 5 per cent annually thereafter; the 3 centres behaved similarly.

An attempt was made to establish whether those who 'defaulted' or who were excluded for medical reasons, and those who were in the trial at the end of the study were alive or dead 1 year after leaving the trial. This information was available for 99 per cent of all the men in the trial.

The numbers of men admitted to the trial and the numbers of man-years they experienced in the trial for each centre and each 5-year group of age at admission are available on request (Addendum D).

\section{DRUG ADHERENCE}

\section{Group I}

In Budapest, 98 per cent of men who were in the trial for at least 5 years showed positive readings on all but 2 occasions and 94 per cent on all but 1 occasion. The corresponding figures for Prague were 94 and 85 per cent. For Edinburgh, during the first 4 years of the trial, the figure was 95 per cent on all but 1 occasion.

Average concentrations of clofibrate in the blood of those men with positive readings in the clofibrate treated group are shown in Appendix 5 (i).

\section{Groups II and III}

In Budapest, 1 per cent of men who were in the trial for at least 5 years showed positive readings on more than 1 occasion. In Prague, 19 per cent showed positive readings on more than 1 occasion and 5 per cent on more than 2 occasions. In Edinburgh, 4 per cent showed positive readings on more than 1 occasion. No explanation is available for the higher proportion of positive readings in Prague.

\section{Incidence of IHD and mortality from all causes}

Comparing the clofibrate-treated group with the high cholesterol control group the 3 main results of the study are:

(a) the overall incidence of major IHD was significantly lower in the clofibrate-treated group;

(b) this difference was confined to non-fatal myocardial infarction;

(c) total mortality from all causes was significantly higher in the clofibrate-treated group.

Details of these findings are given below, those relating to the incidence and mortality from IHD first, and the mortality from other causes later. 
TABLE 2

Numbers of Men at Different Stages

\begin{tabular}{|c|c|c|c|c|}
\hline \multicolumn{3}{|c|}{$\begin{array}{l}\text { Total Number of Men Screened } \\
\text { Number of Men invited to attend on basis of their } \\
\text { serum cholesterol level } \\
\text { Number Rejected for Medical Reasons } \\
\text { Number of Men who did not attend for Entry } \\
\text { Number of Men admitted to Trial }\end{array}$} & \multicolumn{2}{|c|}{$\begin{array}{l}52,519 \\
26,259(a) \\
725 \\
9,789 \\
15,745\end{array}$} \\
\hline & $\frac{\text { Group I }}{\text { Clofibrate }}$ & \begin{tabular}{|c|} 
Group II \\
High Cholesterol \\
Control \\
\end{tabular} & $\begin{array}{l}\text { Group III } \\
\text { Low Cholesterol } \\
\text { Control }\end{array}$ & $\begin{array}{c}\text { A11 } \\
\text { Groups }\end{array}$ \\
\hline $\begin{array}{l}\text { Admitted to Trial } \\
\text { Of these:- } \\
\text { Withdrawn after entry } \\
\text { for medical reasons } \\
\text { (including deaths and } \\
\text { myocardial infarction) } \\
\text { Failed to continue for } \\
\text { other reasons } \\
\text { In the Trial when it } \\
\text { ended }\end{array}$ & 5,331 & 5,296 & 5,118 & $\begin{array}{r}3,690 \\
10,495\end{array}$ \\
\hline $\begin{array}{l}\text { Number who completed } \\
5 \text { years }\end{array}$ & 3,586 & 3,608 & 3,509 & 10,703 \\
\hline
\end{tabular}

(a) Half those otherwise eligible were excluded because of the cholesterol levels found at the preliminary screening. (See text and Figure 1).

\section{INCIDENCE AND MORTALITY FROM}

MAJOR IHD

Table 3 shows the incidence of the first episodes of major IHD in each Group according to the age of the subject at entry to the trial, and distinguishes between fatal and non-fatal attacks. Data for deaths within 3 hours of onset of symptoms are given separately. Rates are standardised at ages 40 to 59 .

The overall incidence of major IHD (first clinical episodes) in the clofibrate-treated group (5.9 per thousand per annum) was 20 per cent lower than the incidence in the high cholesterol control group (7.4) $(P<0.05)$.

The mortality from IHD in first episodes, on the other hand, was virtually the same in the 2 groups
$(1 \cdot 3$ and 1.2$)$ and, hence, the difference between the 2 groups lies in non-fatal myocardial infarcts (4.6 and 6.2 per thousand) $(P<0.05)$.

The incidence of both fatal and non-fatal major IHD events was significantly less in Group III, the low cholesterol control, than in either of the 2 high cholesterol groups $(P<0.01$ for non-fatal and $<0.05$ for fatal, age-standardised).

Deaths known to have occurred less than 3 hours from the onset of symptoms were more common (23), though not significantly so, in Group I than in Group II (17). Again, the numbers in Group III were much smaller (8).

The same information (except for sudden deaths) is shown diagrammatically in Fig. 2 on a life-table 
TABLE 3

Incidence of Major Ischaemic Heart Disease (III)), Non-fatal and Fatal, by Age at Entry

Rates per 1000 per annum

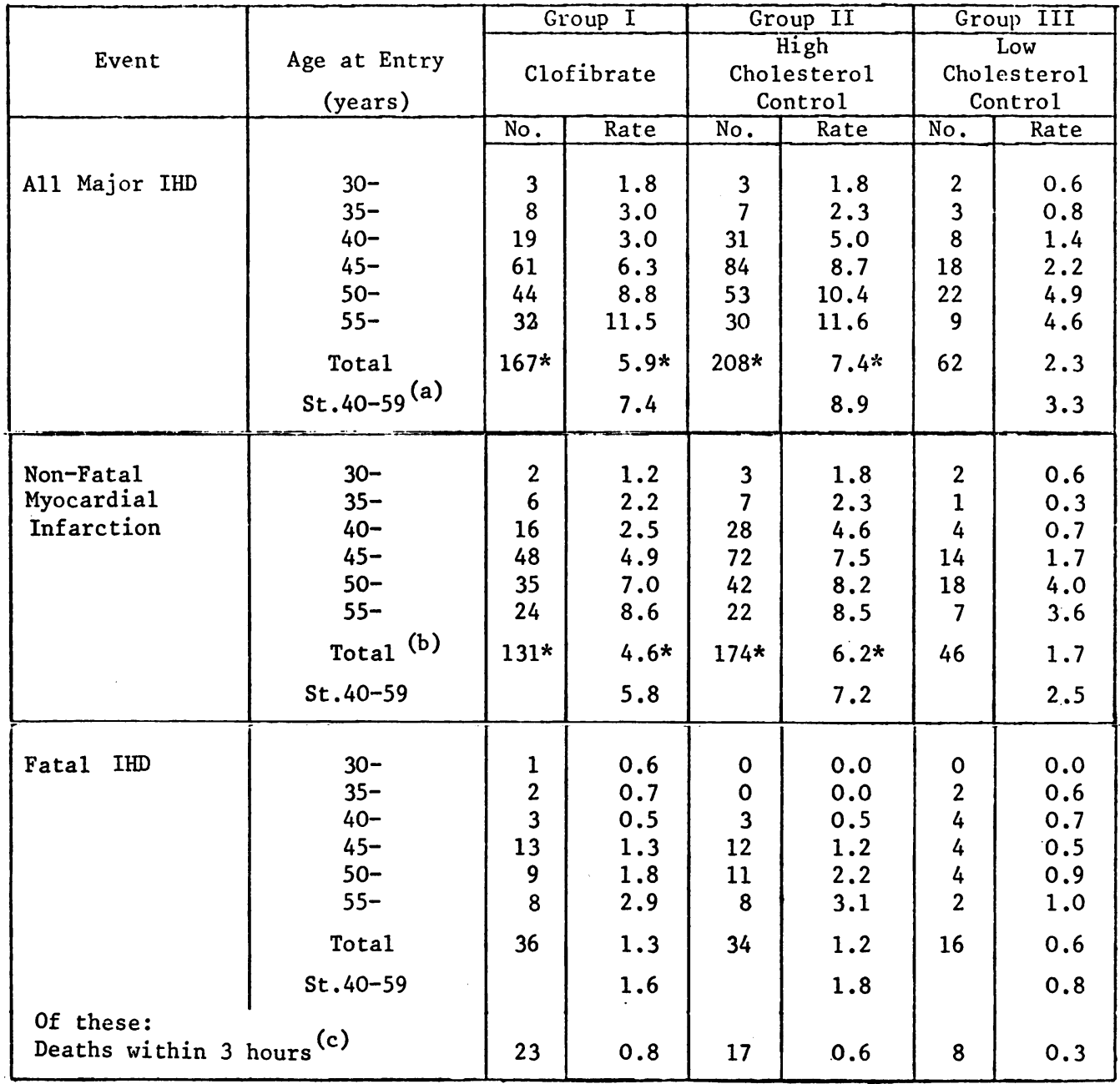

(a) Standardised rates for the four age-groups 40-44, 45-59, 50-54, 55-59, equal weights being given to each age-group.

(b) Includes 38 with Acute Coronary Insufficiency (Intermediate Coronary Syndrome), 18, 16 and 4 in Groups I, II and III respectively.

(c) The numbers of IHD deaths occurring from 3-12 hours were $4,6,3$, in the three groups respectively.

* Significant difference between Groups I and II $(P<.05)$. 

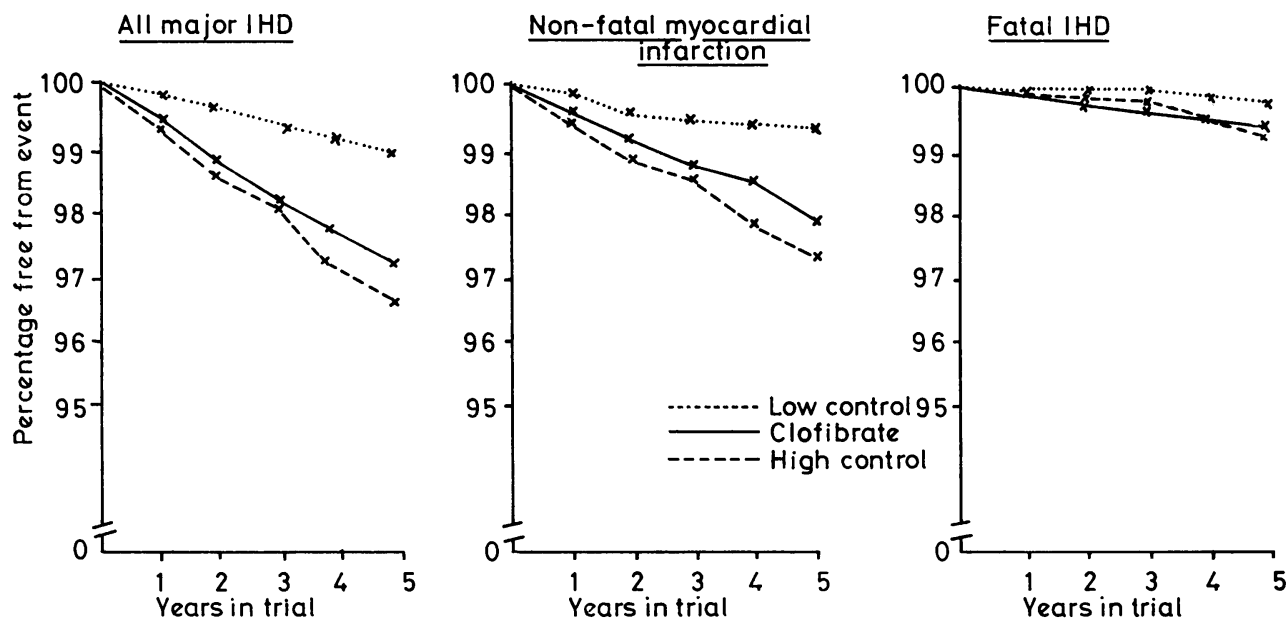

Fig. 2 Major ischaemic heart disease in the first 5 years (calculated on a life-table basis).

basis, that is showing the proportions free of IHD at various periods after entry to the trial. The significance tests based on this form of analysis, which take into account the shape of the whole curve, give similar results to those given above based on the comparison of overall rates, that is a significant $(P<0.05)$ reduction in non-fatal myocardial infarction in Group I compared with Group II. The diagram itself shows results up to 5 years only, because after that stage rates are based on very small numbers and diagrammatic representation would be misleading. It would be unwise to interpret the apparently greater divergence at 3 years of the curves for the clofibrate and high cholesterol groups as showing that 3 years of treatment has some critical importance. It is more likely to be a random fluctuation. Details of the life-table analysis and of the method used are shown in Appendix 2.

Figure 3 shows the standardised rate for each centre, by Group, for all major IHD, for fatal IHD, and for non-fatal myocardial infarction. For the reasons stated above, standardisation is at ages 40 to 54, not 40 to 59. At each centre the rates for all IHD, and for non-fatal myocardial infarction, were higher in Group II than in Group I, and the rates in both Groups were higher than those in Group III. There was no consistent pattern for fatal IHD in the centres, but the numbers of deaths were small.

The incidence of major IHD (taking all groups together) was significantly lower $(P<0.01)$ in Budapest than in either of the other 2 centres. Details of numbers and rates are shown in Appendix 4.

In order to test whether adherence to treatment had any important influence on the main result (that is whether, for instance, the difference between the clofibrate-treated group and the high cholesterol control group in the number of major IHD events might have been greater if the treatment had been more strictly observed in Group I than it was) the proportion of negative estimates of chlorophenoxyisobutyric acid (CPIB) in the blood was calculated for the men in Group I who had such an event and compared with the same proportion in all men in Group I. A further test was made, in Group I, of adherence to treatment at the last visit before an IHD event compared with visits at the same stage in the study for all men. The results are shown in Appendix 5 (ii) and (iii). There seems to be no

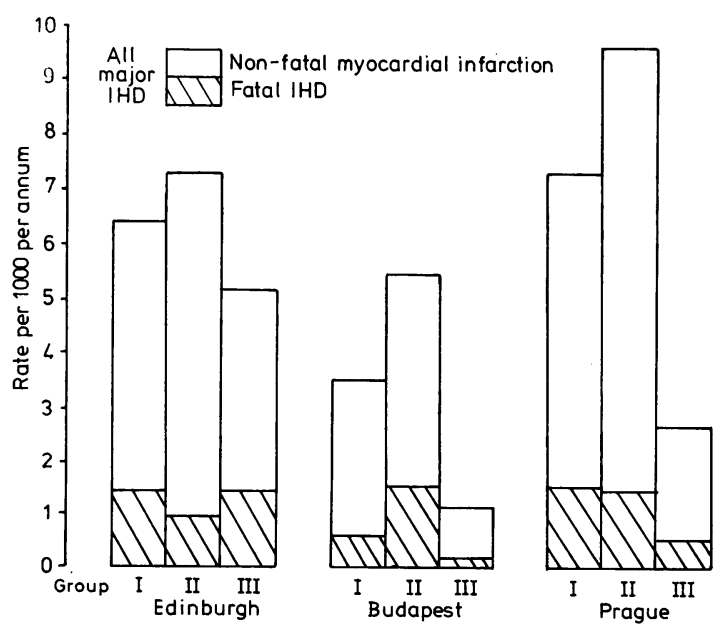

Fig. 3 Age-standardised incidence and mortality rates of major IHD, 40 to 54 years, per 1000 per annum by centre. 
TABLE 4

Incidence of Minor Ischaemic Heart Disease

Rates per 1000 per annum

\begin{tabular}{|c|c|c|c|c|c|c|c|c|c|}
\hline \multirow{3}{*}{$\begin{array}{l}\text { Condition }^{(a)} \\
\text { (newly arising in the trial) }\end{array}$} & \multirow{2}{*}{\multicolumn{3}{|c|}{$\begin{array}{l}\text { Group I } \\
\text { Clofibrate }\end{array}$}} & \multirow{2}{*}{\multicolumn{3}{|c|}{$\begin{array}{c}\text { Group II } \\
\text { High Cholesterol Control }\end{array}$}} & \multicolumn{3}{|c|}{ Group III } \\
\hline & & & & High & & Sontrol & Low & estero & ontrol \\
\hline & No. ${ }^{(b)}$ & Rate & $\begin{array}{l}\text { Age-St. } \\
\text { Rate }\end{array}$ & No. ${ }^{(b)}$ & Rate & $\begin{array}{c}\text { Age-St. } \\
\text { Rate }\end{array}$ & No. ${ }^{(b)}$ & Rate & $\begin{array}{l}\text { Age-St. } \\
\text { Rate }\end{array}$ \\
\hline $\begin{array}{l}\text { Angina Pectoris with } \\
\text { abnormal ECG }\end{array}$ & 60 & 2.1 & 2.6 & 48 & 1.7 & 2.4 & 31 & 1.1 & 1.4 \\
\hline $\begin{array}{l}\text { Angina Pectoris without (d) } \\
\text { abnormal ECG }\end{array}$ & 212 & 7.4 & 9.0 & 226 & 8.0 & 9.6 & 181 & 6.7 & 8.4 \\
\hline $\begin{array}{l}\text { Abnormal ECG without (c) } \\
\text { chest pain }\end{array}$ & 223 & 7.9 & 9.1 & 260 & 9.3 & 10.6 & 176 & 6.5 & 8.8 \\
\hline
\end{tabular}
(a) For definitions see Appendix 3.
(b) Numbers and crude rates relate to men aged 30-59. Age-standardised rates relate to men aged $40-59$.

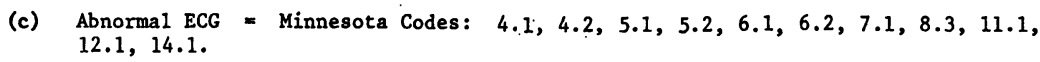
d) As defined by angina questionnaire. (Addendum A).

TABLE 5

Other Vascular Bvents and Diabetes: Incidence and Withdrawa1s

\begin{tabular}{|c|c|c|c|c|c|c|c|c|c|c|c|c|}
\hline \multirow{4}{*}{$\begin{array}{l}\text { Condition (a) } \\
\text { (newly arising in the trial) }\end{array}$} & \multicolumn{9}{|c|}{ INCIDENCE } & \multicolumn{3}{|c|}{ WITHDRANALS } \\
\hline & \multirow{2}{*}{\multicolumn{3}{|c|}{$\begin{array}{l}\text { Group I } \\
\text { Clofibrate }\end{array}$}} & \multicolumn{3}{|c|}{ Group II } & \multirow{2}{*}{\multicolumn{3}{|c|}{ Group III }} & \multirow{3}{*}{$\begin{array}{l}\text { I } \\
\text { Clof. } \\
\text { No. }\end{array}$} & \multirow{3}{*}{$\begin{array}{l}\text { II } \\
\text { H.C.C. } \\
\text { No. } \\
\end{array}$} & \multirow{3}{*}{$\frac{\text { III }}{\text { L.C.C. }}$} \\
\hline & & & & $\mathrm{High} \mathrm{Cho}$ & estero & 1 Control & & & & & & \\
\hline & No. ${ }^{(b)}$ & Rate & $\begin{array}{c}\text { Age } \\
\text { St.Rate }\end{array}$ & No. ${ }^{(b)}$ & Rate & \begin{tabular}{|c|} 
Age \\
St.Rate \\
\end{tabular} & No. ${ }^{(b)}$ & Rate & $\begin{array}{c}\text { Age } \\
\text { St.Rate }\end{array}$ & & & \\
\hline \multicolumn{13}{|l|}{ Vascular Conditions } \\
\hline Cardiac Arrhythmia (c) & 173 & 6.1 & 7.5 & 166 & 5.9 & 6.7 & 152 & 5.6 & 8.1 & 1 & 1 & 0 \\
\hline Hypertension (as defined) & 192* & $6.8 *$ & 7.5* & 242* & $8.6 *$ & $9.9 *$ & 146 & 5.4 & 6.3 & $63 * *$ & $96 * *$ & 60 \\
\hline Other Heart Disease ${ }^{(d)}$ & - & - & - & - & - & - & - & - & - & 9 & 9 & 11 \\
\hline $\begin{array}{l}\text { Non-fatal Cerebrovascular } \\
\text { disease }\end{array}$ & 18 & 0.6 & 0.9 & 13 & 0.5 & 0.8 & 14 & 0.5 & 1.0 & 5 & 1 & 2 \\
\hline Intermittent Claudication ${ }^{(e)}$ & 184 & 6.5 & 7.5 & 184 & 6.5 & 8.3 & 108 & 4.0 & 4.8 & 43 & $30^{(f)}$ & $16^{(f)}$ \\
\hline Venous Thrombosis \& Embolism ${ }^{(d)}$ & - & - & - & - & - & - & - & - & - & 7 & 2 & 1 \\
\hline $\begin{array}{c}\text { Diabetes (as defined in each } \\
\text { centre) }\end{array}$ & 129 & 4.6 & 5.1 & 102 & 3.6 & 4.0 & 67 & 2.5 & 3.4 & 47* & $26 *$ & 18 \\
\hline
\end{tabular}

(a) For definitions see Appendix 3.

(b) The numbers and rates relate to men aged 30-59. The age standardised rates relate to men aged $40-59$.

(c) Minnesota code 8-1, 8-3.

(d) Incidence figures are not available because these conditions were not notifiable.

(e) As defined by intermittent claudication questionnaire. (Addendum A).

(f) In Edinburgh 6 men in Group II and 3 men in Group III with confirmed peripheral artery disease were not withdrawn from the study. (See text.)

* Signif cant difference between Groups I and II $(P<0.05)$.

** " " Groups I and II $(P<0.01)$. 
consistent difference between the CPIB values of men who developed events compared with all men.

\section{INCIDENCE OF MINOR IHD}

Table 4 shows the number of minor IHD events in each group together with incidence rates, both crude, for all ages, 30 to 59, and standardised at ages 40 to 59. Minor IHD is classified as angina pectoris with and without abnormal electrocardiogram and as an electrocardiographic abnormality without chest pain, as defined earlier under 'criteria for assessing the results of the trial'. There was no significant difference between Groups I and II in angina pectoris with or without abnormal electrocardiogram, or in those with electrocardiographic abnormalities in the absence of chest pain. The major items of the Minnesota code (4-1, 5-1, 7-1, and 11-1) were analysed separately and together, and again no difference was found between Groups I and II.

\section{OTHER VASCULAR EVENTS AND DIABETES}

Table 5 shows the result for other vascular events and diabetes, and includes withdrawals from the trial, as well as incidence.

Apart from hypertension and diabetes there were no significant differences in these conditions between Groups I and II.

Hypertension is defined for the purposes of this trial as a diastolic pressure of $120 \mathrm{mmHg}$ or more on one occasion, between 110 and $119 \mathrm{mmHg}$ more than once, or once only if specific electrocardiographic abnormalities were present (Appendix 3). The incidence and rate of withdrawal in Group I was significantly lower than in Group II. The incidence in Group I was lower than Group II in each centre.

In spite of this, however, mean blood pressure for all subjects during the trial was not materially different in Groups I and II as shown in Table 6 (i). Thus, clofibrate appeared to show no appreciable blood pressure lowering effect overall.

Table 6 (ii) shows that mean blood pressure at the visit immediately before a major event was higher than the mean pressure in men, at the same stage in the trial, who did not have such an event. This was equally true for Groups I and II.

The incidence of hypertension in Group III was significantly lower than in Groups I or II (Table 5) and higher in Prague than in either of the other two centres (Addendum C).

Diabetes was notified more frequently in Group I than in Group II. Though this difference was not statistically significant the number of withdrawals for diabetes requiring drug treatment was significantly higher in Group I than in Group II. Diabetes was much more frequently notified in Prague than in the other centres and, indeed, accounted for more than half the number in the whole trial (Addendum C).

Peripheral artery disease was not a specified reason for withdrawal. Ischaemic leg pain, identified by

TABLE 6

Mean Blood Pressure (ming)

\begin{tabular}{|c|c|c|c|c|c|c|c|c|c|}
\hline \multirow[b]{2}{*}{ (i) } & \multirow[b]{2}{*}{ Al1 Men } & \multirow[b]{2}{*}{$\begin{array}{l}\text { Mean Systolic Blood Pressure } \\
\text { Mean Diastolic Blood Pressure }\end{array}$} & Group & $\begin{array}{c}\text { At } \\
\text { Entry }\end{array}$ & \multicolumn{5}{|c|}{ Years in Trial } \\
\hline & & & $\begin{array}{l}\text { I Clofibrate } \\
\text { II High Cholesterol Control } \\
\text { I Clofibrate } \\
\text { II High Cholesterol Control }\end{array}$ & $\begin{array}{r}135 \\
135 \\
87 \\
87\end{array}$ & $\begin{array}{r}132 \\
132 \\
84 \\
85\end{array}$ & $\begin{array}{l}131 \\
131\end{array}$ & $\begin{array}{l}133 \\
133 \\
84 \\
85\end{array}$ & $\begin{array}{r}133 \\
134 \\
83 \\
85\end{array}$ & $\begin{array}{l}134 \\
134\end{array}$ \\
\hline (ii) & $\begin{array}{l}\text { Men with } \\
\text { (value a } \\
\text { Men who }\end{array}$ & $\begin{array}{l}\text { major I.H.D. event } \\
\text { isit immediately preceding I.H. } \\
\text { Mean Systolic Blood Pressure } \\
\text { Mean Diastolic Blood Pressure } \\
\text { not have a major I.H.D. event } \\
\text { Mean Systolic Blood Pressure } \\
\text { Mean Diastolic Blood Pressure }\end{array}$ & $\begin{array}{l}\text { I Clofibrate } \\
\text { II High Cholesterol Control } \\
\text { I Clofibrate } \\
\text { II High Cholesterol Control } \\
\text { I Clofibrate } \\
\text { II High Cholesterol Control } \\
\text { I Clofibrate } \\
\text { II High Cholesterol Control }\end{array}$ & $\begin{array}{r}148 \\
144 \\
89 \\
88\end{array}$ & $\begin{array}{r}141 \\
142 \\
88 \\
88\end{array}$ & $\begin{array}{l}131 \\
131\end{array}$ & $\begin{array}{r}144 \\
143 \\
86 \\
90\end{array}$ & $\begin{array}{l}140 \\
136\end{array}$ & $\begin{array}{l}137 \\
149\end{array}$ \\
\hline
\end{tabular}


questionnaire (Addendum A), was notifiable to the controlling centre in London. In 1971 notifications in Group I had reached a number which was significantly higher than in Group II (though, as Table 5 shows, the numbers were finally exactly equal) and a special investigation was set up to assess the situation. All cases reported as having ischaemic leg pain were examined by a vascular specialist at each centre, who was unaware of group identity. Blood flow measurements were carried out on doubtful cases. 'Confirmed' cases of peripheral artery disease were withdrawn from the trial and these are the figures shown in Table 5. The difference between Groups I and II is not statistically significant. At Edinburgh the numbers confirmed were small and it was decided to withdraw from the trial only the 6 patients receiving clofibrate. (This was possible without disclosing to the physicians running the clinics the identity of the cases 'confirmed' in the 2 placebo groups.) In comparing Groups I and II in Table 5 this should be borne in mind.

Since 1971, the presence or absence of peripheral arterial pulses was notified to London. The numbers of men, in all centres, with at least one absent pulse

TABLE 7

Seruin Cholestcrol (mg/dil)

Mean Values during the Trial

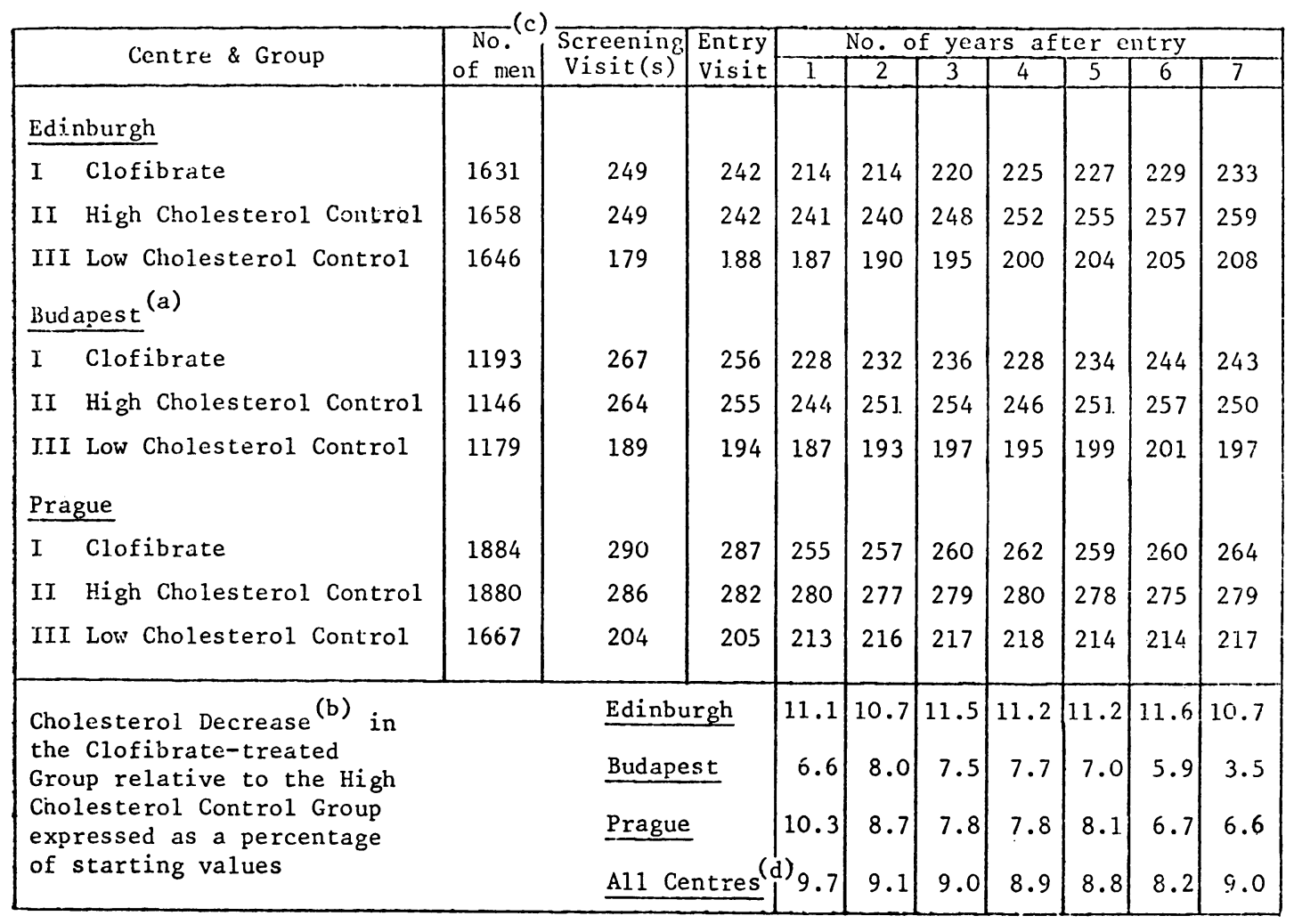

(a) Throughout this Report, Budapest cholesterol figures refer only to men admitted on the basis of the Watson method of cholesterol estimation. (Addendum $B$ ).

(b) Decrease is measured in each Group from the mean pre-treatment levels, i.e. the. levels at the Screening Visit(s) and at Entry Visit.

(c) Men who had cholesterol values at screening and entry visits.

(d) Adjusted for differences between Centres, see Appendix 2. 
on at least one occasion were: Group I: 257; Group II: 309; Group III: 196 and, with at least two on any occasion: 155,192 , and 114 respectively. The figures for Group III are significantly lower than for Groups I and II $(P<0.01)$, as might be expected. The differences between Groups I and II are also significant $(P<0.05)$.

\section{CHANGE IN SERUM CHOLESTEROL LEVELS DURING THE STUDY}

Table 7 shows the mean serum cholesterol levels at screening and at each trial visit for the men in each Group in each centre. The mean starting levels (both at screening and at first visit) are different in the 3 centres and, in particular, the values are somewhat higher in Prague. The greater part of this excess has been shown by tests of control samples (or by the reference system used) to be the result of the methods of cholesterol determination (Addendum B), so that the actual average cholesterol levels before treatment differed little, in fact, between the 3 centres.

There were considerable variations from visit to visit in the mean levels of cholesterol in all groups during the study, particularly in Edinburgh and Budapest. Whatever the reasons for these variations, in the clofibrate-treated group they were, of course, operative in addition to the effects of the drug. To allow for this, when assessing change from mean pretreatment level, at any stage during the trial, the change seen in the high cholesterol control group was deducted from the change seen in the clofibrate-treated group (Appendix 2). This adjusted figure for Group I, therefore, represents that part of the evident change which could, presumptively, be attributed to clofibrate.

The adjusted figures for change in Group I are shown in the lower section of Table 7 for each centre in each year after entry: they are expressed as a percentage of the mean pretreatment levels. The change remains fairly steady after the initial fall measured at the first follow-up visit (that is 6 months) in each centre. In Edinburgh a decrease of about 11 per cent, in Budapest of about 7 per cent, and in Prague of about 8 per cent was maintained; an adjusted figure for all centres is also presented which varies from 9.7 to 8.2 per cent. These figures fell short of the 15 per cent reduction in serum cholesterol envisaged at the outset of the trial.

\section{INCIDENCE OF IHD IN RELATION TO}

CHOLESTEROL CHANGE

The relation between incidence of IHD and change in serum cholesterol levels can be studied in 2 ways: by comparing the experience of Group I, where the mean serum cholesterol level was reduced by treat-

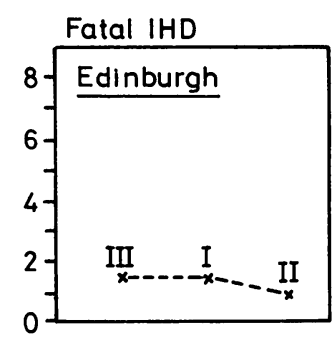

Non-fatal myocardial infarction
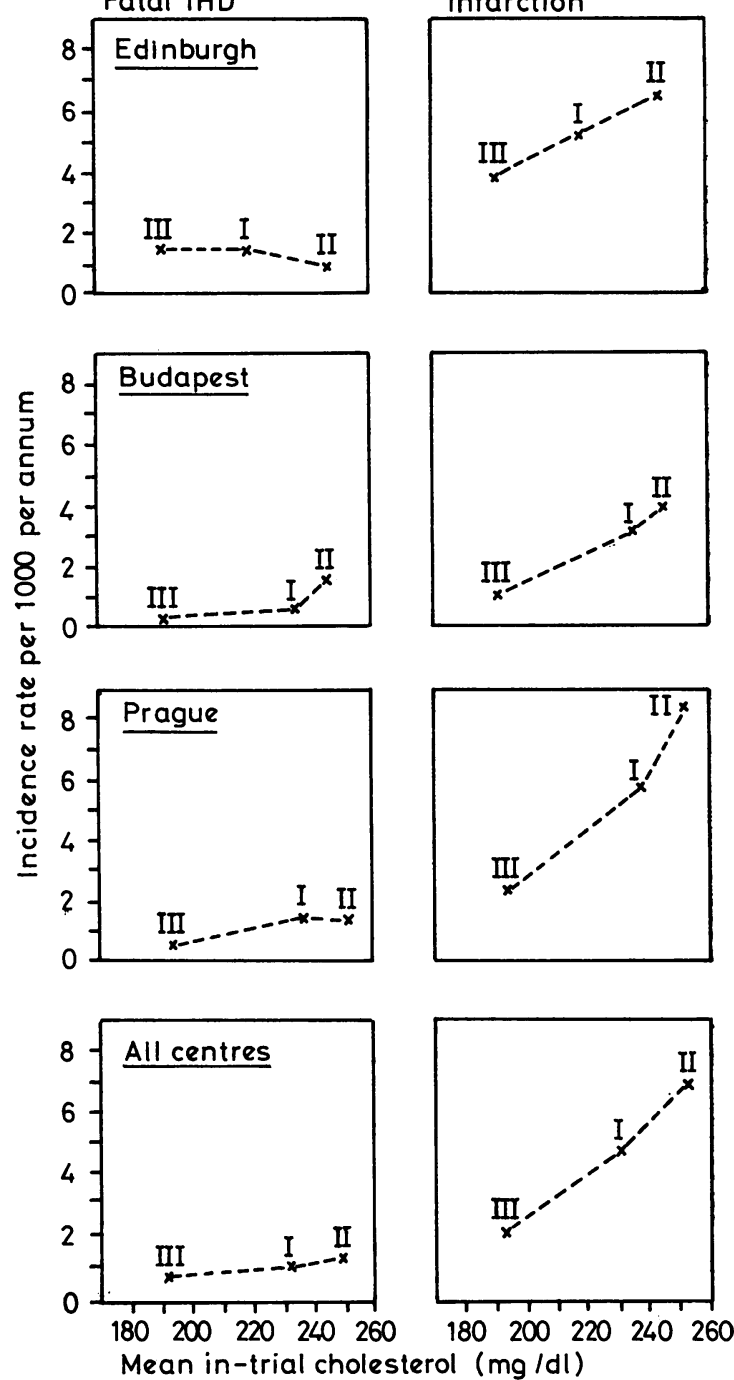

Fig. 4 Incidence of major ischaemic heart disease and mean in-trial cholesterol by centre and group. Agestandardised rates per 1000 per annum at ages 40-54.

ment, with that of the 2 control groups, and by relating the individual change in serum cholesterol levels to incidence.

Incidence related to group changes in cholesterol The first approach is illustrated in Fig. 4 where the 'mean in-trial cholesterol level' for each Group is related to the age-standardised incidence of IHD, at ages 40 to 54, in that Group. This was done for each centre, and separately for fatal and non-fatal IHD. (Again, this age-range was chosen because centre 
comparisons are involved.) The derivation of 'mean in-trial cholesterol level' is described in Appendix 2. It allows for variations from visit to visit in mean cholesterol levels, averages the levels over all visits, and takes account of differences between centres in mean levels. For non-fatal myocardial infarction the point for Group I in each centre lies somewhat below the straight line between the points for Groups II and III. The results are not inconsistent with the possibility of some fairly simple one-to-one relation. The results for fatal IHD are less consistent, possibly because of small numbers of events.

\section{Incidence related to individual changes in cholesterol}

For the second approach, individual cholesterol change is defined in an analogous way to group change, that is the change in an individual's pretreatment cholesterol levels is adjusted by subtracting from it the change in the mean level of cholesterol of all the men in Group II at the same centre and at the same visit. The mean change for an individual is then calculated as the mean of all changes for that individual from his second visit to his last visit: this can be expressed in absolute terms, or as a percentage of starting values. If a man did not have a second visit, that is he left the trial for any reason before then, it was not possible to calculate a change figure for him. This applies, in particular, to those men who had a heart attack in their first 6 months in the trial, and they are therefore excluded from this analysis.

Because men with the greatest reduction have, on average, the highest initial cholesterol levels and, therefore, are initially at higher risk of heart attack than the men with less reduction, it is necessary to study the relation between cholesterol change and the incidence of IHD within broadly similar levels of starting cholesterol.

In Table 8 the men in each of the 2 high cholesterol groups are classified simply (i) into those with a fall in mean cholesterol and those without, and (ii) into those whose initial pretreatment cholesterol was above or below the median of the distribution of pretreatment cholesterol levels. Since these men are all drawn from the highest third of the overall distribution of starting cholesterols, the figures refer to men in the two highest sixths of that distribution. The median was calculated separately in each centre because of the differences between centres in overall levels.

Table 8 is divided into three parts: $8(\mathrm{i}), 8(\mathrm{ii})$, 8(iii), dealing respectively with all major IHD, non-fatal myocardial infarction, and fatal IHD. In each cell there are 3 numbers: the number of events, the rate per thousand per annum (at all ages and unstandardised), and an 'expected' rate. This expected rate, also expressed per thousand per annum, is calculated from a multivariate analysis (see later) and takes into account the 5 factors which were measured at the start of the trial and were shown to have an independent effect on the subsequent incidence of major IHD-namely, age, initial cholesterol level, smoking, systolic blood pressure, and whether the man's father was alive at the start of the trial-and represents the rate of incidence which would be expected in a group of men in Group II whose ages, initial cholesterol levels, etc., were the same as those of the men who are actually included in the relevant cell of the table. Thus any difference between the observed rate and the expected rate in each cell represents, apart from sampling fluctuations, the effect of cholesterol change-that is a rise or fall in mean cholesterol during the trial whether due to clofibrate or not, and is better evidence than that of the crude rate which, of course, makes no allowance for the fact that the men in the different cells of the table almost certainly have different inherent risks because they are of different ages, have different initial cholesterol levels, etc.

The table shows, first, that, both for fatal and non-fatal infarction, the observed rates were higher in the men whose pretreatment cholesterol concentrations were above the median than in the men with values below the median, and the same is true for the expected rates.

Secondly, in terms of cholesterol change during the trial, the observed rates of major IHD for the men in Group I whose cholesterol fell during the trial were substantially below the expected rates whether their pretreatment cholesterols were low or high. Whereas, for the corresponding men in Group II, the difference between observed and expected was neither so clear nor so consistent. For men in both Groups whose cholesterol levels rose during the trial, on the other hand, the observed rates were higher than the expected. The pattern is similar but not quite so clear for non-fatal myocardial infarction alone, while for fatal IHD the picture is not clear.

Although the differences referred to above are not all individually statistically significant, they are consistent with the suggestion that most of the reduction of non-fatal myocardial infarction in the clofibrate treated Group is associated with reduction of cholesterol concentrations.

\section{Effect of other 'risk factors' on the incidence of major IHD}

Before proceeding to the multivariate analysis, Table 9 shows how incidence of major IHD is 
TABI.E 8

Incidence of Ischaemic Heart Disease

by Mean Pre-treatment Cholesterol and Mean Cholesterol. Change

Rates per 1000, per annum

(i) Incidence of Major IHD, Fatal and Non-fatal

\begin{tabular}{|c|c|c|c|c|c|}
\hline \multirow{3}{*}{\multicolumn{2}{|c|}{$\begin{array}{l}\text { Mean Pre-treatment } \\
\text { Cholesterol(a) }\end{array}$}} & \multirow{2}{*}{\multicolumn{2}{|c|}{$\begin{array}{c}\text { Group I } \\
\text { Clofibrate } \\
\end{array}$}} & \multicolumn{2}{|c|}{ Group II } \\
\hline & & & & \multicolumn{2}{|c|}{ High Cholesterol Control } \\
\hline & & $\begin{array}{c}\text { Fall in } \\
\text { Cholesterol }\end{array}$ & $\begin{array}{c}\text { Rise in } \\
\text { Cholesterol }\end{array}$ & $\begin{array}{c}\text { Fall in } \\
\text { Cholesterol }\end{array}$ & $\begin{array}{c}\text { Rise in } \\
\text { Cholesterol }\end{array}$ \\
\hline \multirow{3}{*}{$\begin{array}{l}\text { Below } \\
\text { Median }\end{array}$} & Observed Rate & 3.7 & 7.3 & 6.5 & 6.1 \\
\hline & Expected Rate ${ }^{(c)}$ & 6.2 & 6.7 & 6.4 & 5.9 \\
\hline & No. & 37 & 18 & 35 & 43 \\
\hline \multirow{3}{*}{$\begin{array}{l}\text { Above } \\
\text { Median }\end{array}$} & Olserved Rate & 6.4 & 12.6 & 7.6 & 11.2 \\
\hline & Expected Rate & 9.4 & 11.4 & 9.2 & 8.8 \\
\hline & No. & 73 & 14 & 61 & 47 \\
\hline
\end{tabular}

(ii)

Incidence of Non-fatal Myocardial Infarction

\begin{tabular}{|ll|r|r|r|r|}
\hline Below & Observed Rate & 2.7 & 6.1 & 6.1 & 5.1 \\
& Expected Rate & 5.3 & 5.8 & 5.5 & 5.1 \\
& No. & 27 & 15 & 33 & 36 \\
\hline Above & Observed Rate & 5.3 & 8.1 & 6.0 & 9.5 \\
Median & Expected Rate & 7.7 & 9.5 & 7.6 & 7.5 \\
& No. & 60 & 9 & 48 & 40 \\
\hline
\end{tabular}

(iii) Incidence of Fatal IHD

\begin{tabular}{|ll|r|r|r|r|}
\hline Below & Observed Rate & 1.0 & 1.2 & 0.4 & 1.0 \\
& Expected Rate & 0.9 & 0.9 & 0.9 & 0.8 \\
& No. & 10 & 3 & 2 & 7 \\
\hline Above & Observed Rate & 1.1 & 4.5 & 1.6 & 1.7 \\
Median & Expected Rate & 1.7 & 1.9 & 1.6 & 1.3 \\
& No. & 13 & 5 & 13 & 7 \\
\hline
\end{tabular}

(a) Corrected mean pre-treatment cholesterol (See Appendix 2).

(b) Median values were determined separately for each group and for each centre.

(c) See text.

The following table indicates the mean change in serum cholesterol for all men where a change could be calculated, together with the number of such men in each category

\begin{tabular}{|c|c|c|c|c|c|c|c|}
\hline \multirow{3}{*}{\multicolumn{2}{|c|}{\begin{tabular}{|c|} 
Mean \\
Pre-treatment \\
Cholesterol \\
\end{tabular}}} & \multirow{2}{*}{\multicolumn{3}{|c|}{ Group I }} & \multicolumn{3}{|c|}{ Group II } \\
\hline & & & & & \multirow{2}{*}{\multicolumn{3}{|c|}{$\begin{array}{l}\text { High Cholesterol Control } \\
\begin{array}{|l|c|c|}\text { Fall } & \text { Rise } & \text { Total } \\
\end{array}\end{array}$}} \\
\hline & & Fal1 & Rise & Total & & & \\
\hline \multirow{2}{*}{$\begin{array}{l}\text { Below } \\
\text { Median }\end{array}$} & Mean change \% & -10.2 & 6.2 & -6.7 & -6.2 & 7.4 & 1.5 \\
\hline & No. of men & 1739 & 479 & 2218 & 976 & 1281 & 2257 \\
\hline \multirow{2}{*}{$\begin{array}{l}\text { Above } \\
\text { Median }\end{array}$} & Mean change $\%$ & -13.6 & 5.7 & -11.6 & -7.7 & 5.5 & -3.0 \\
\hline & No. of men & 2027 & 231 & 2258 & 1427 & 779 & 2206 \\
\hline
\end{tabular}


TABLE 9

Incidence of Major Ischaemic Heart Disease by Factors Present at Entry A11 Centres, Age-standardised Rates per 1000 per annum at ages 40-59 (Rates in brackets are based on fewer than 10 events)

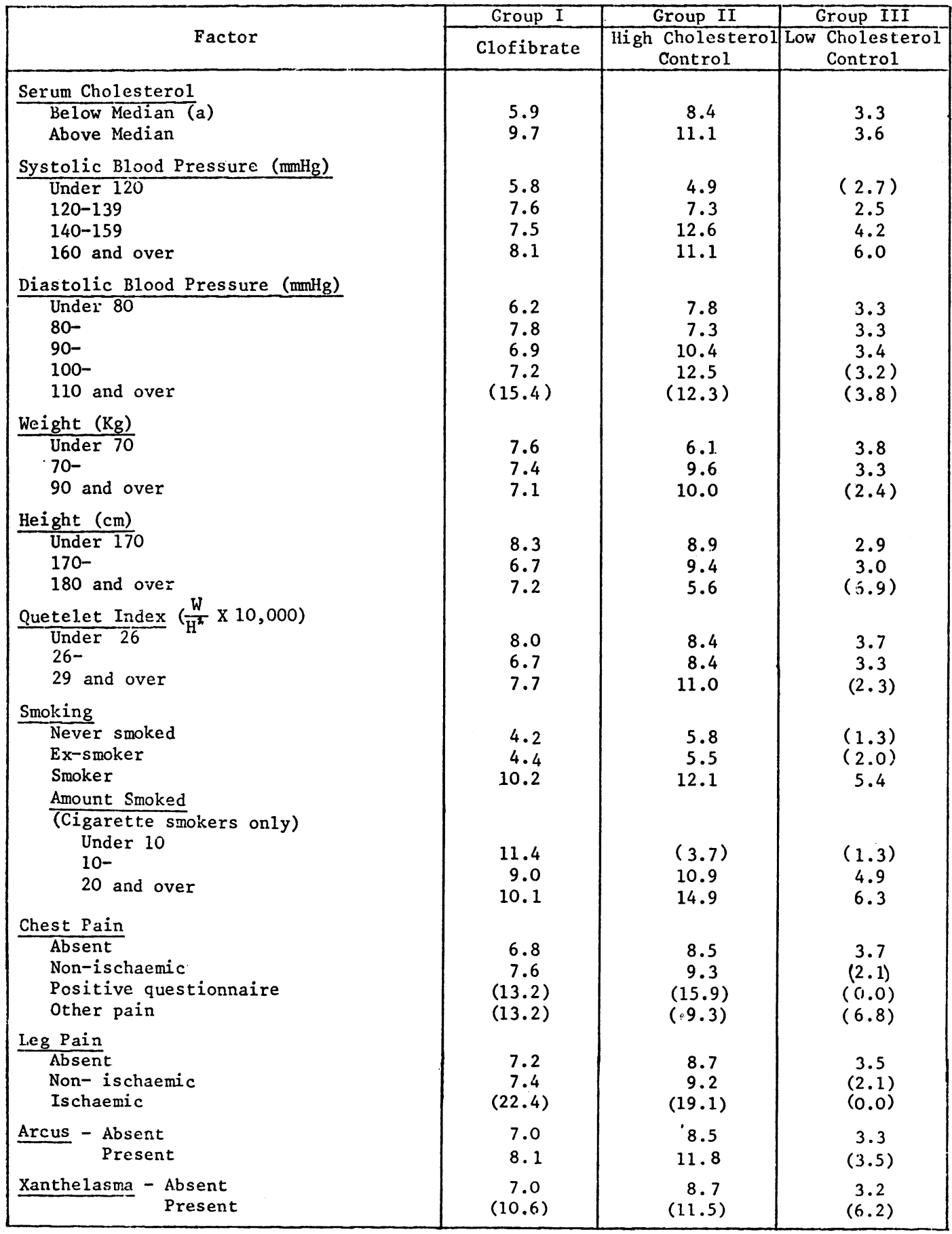

(a) Median values were determined separately for the high cholesterol groups and low cholesterol group within each centre. 
related to factors generally recognised as prognostically important in ischaemic heart disease. The rates shown are age-standardised and are surprisingly consistent with those expected from the results of other large population studies. In nearly every category, the incidence rises as the severity of the risk factor increases, and this applies to all 3 Groups, though at different levels. The exceptions are mostly associated with small numbers of events, but blood pressure as a risk factor deserves special mention. Compared with Group II, blood pressure in Group I had much less influence on the incidence of heart attacks.

MULTIVARIATE ANALYSIS

The data shown in Table 9, though striking in their regularity, take no account of the association of one factor with another and hence give no indication of the independent contribution of the various factors to prediction of outcome. For instance, the interesting relation between blood pressure and incidence of IHD might be due, partly or wholly, to a relation between blood pressure and age, smoking, or parental history. The appropriate statistical technique for taking account of these interrelations and producing a statement of the most important independent predictors of future IHD is some form of multivariate analysis. This has been carried out, using the multiple logistic function, as used, for instance, by Keys et al. (1972). Details of methods and results are given in Appendix 2.

In this analysis, carried out on men in Group II, in all centres, and excluding the clofibrate treated group for greater comparability with other published studies, the 5 variables which gave independently significant prediction of future IHD (fatal and non-fatal) were age, initial cholesterol, smoking, blood pressure, and whether the subject's father was alive at the start of the trial. Systolic blood pressure was a slightly more significant predictor than diastolic.

To give some idea of the magnitude of these effects (as distinct from their statistical significance) the following table shows the factors by which the risk of future IHD is increased for the indicated change in the variable concerned.

\begin{tabular}{|c|c|c|}
\hline Variable & Change & $\begin{array}{l}\text { IHD risks } \\
\text { multiplied by }\end{array}$ \\
\hline $\begin{array}{l}\text { Age } \\
\text { Smoking }\end{array}$ & $\begin{array}{l}+10 \text { years } \\
\text { present smoker of } \\
\text { anything } v \text {. never or } \\
\text { ex-smoker }\end{array}$ & $\begin{array}{l}1.9 \\
2.4\end{array}$ \\
\hline $\begin{array}{l}\text { Systolic blood pressure } \\
\text { Initial serum cholesterol } \\
\text { Father dead at start of trial }\end{array}$ & $\begin{array}{l}+20 \mathrm{mmHg} \\
+20 \mathrm{mg} / \mathrm{dl} \\
\text { dead v. alive }\end{array}$ & $\begin{array}{l}1 \cdot 3 \\
1 \cdot 2 \\
1 \cdot 6\end{array}$ \\
\hline
\end{tabular}

The 5 factors which, in the present analysis, give independently significant prediction are very similar to those shown in other prospective studies such as the Framingham Study, already mentioned, the 'Seven Country Study' (Keys et al., 1972), or the study by Medalie et al. (1973) in Israel. The regression coefficients concerned are compared in Appendix 2. The coefficients for initial cholesterol are all very similar in these studies and, substituting the average reduction of $9 \%$ in cholesterol observed in this study in any of the equations results in a predicted reduction in the incidence of IHD of about 20 per cent, which was the reduction observed in the present study.

Directly to study the effects of treatment, on the other hand, the analysis was carried out on the men in Groups I and II, the treated and untreated high cholesterol groups.

The same 5 variables were included together with a sixth, treatment by clofibrate, that is membership of Group I or Group II. From this analysis treatment emerged as significant $(P<0.05)$ and the effect was to reduce the incidence by 27 per cent. This figure is higher than the 20 per cent difference in incidence of major IHD reported above because of an accumulation of small differences in entry characteristics between the men in Groups I and II.

Cholesterol change, as previously defined, was next introduced as a variable (thereby automatically excluding all those who did not have a visit after the first, in whom, of course, no change could be measured). This was done, first, without including treatment and, secondly, including both treatment and cholesterol change. When cholesterol change but not treatment was included in the analysis, cholesterol change was significant and a reduction of 10 per cent in cholesterol (about 20 to $25 \mathrm{mg} / 100$ $\mathrm{ml}$ ) was associated with a reduction of 22 per cent in the risk. When both cholesterol change and treatment were included the significance of cholesterol change was slightly reduced but the effect of treatment was halved, suggesting that cholesterol change is associated with most (but not all) of the change in incidence resulting from treatment, that is that treatment may have some additional effect beyond that of cholesterol reduction. The excess effect is not itself significant.

OPTIMAL EFFECTS OF CLOFIBRATE ON MAJOR IHD EVENTS

Two approaches were used to find out whether there were any groups of subjects in whom clofibrate treatment was noticeably more, or less, effective than average in influencing major IHD events (fatal and non-fatal myocardial infarction).

The first, for which the results are set out in 
TABLE 10

\section{Differential. Effect of Clofibrate}

(a) By quartile of risk score

Major IHD events. Rates per 1000 per annum

\begin{tabular}{|c|c|c|c|c|c|c|}
\hline \multirow{3}{*}{$\begin{array}{c}\text { Quartile of risk } \\
\text { score }\end{array}$} & \multicolumn{2}{|c|}{ Group I } & \multicolumn{2}{|c|}{ Group II } & \multirow{3}{*}{$\begin{array}{l}\text { Ratio } \\
\text { of } \\
\text { Rates } \\
\text { (I/II) }\end{array}$} & \multirow{3}{*}{$\begin{array}{c}\text { Difference } \\
\text { between } \\
\text { Rates } \\
\text { (II-I) }\end{array}$} \\
\hline & \multicolumn{2}{|c|}{ Clofibrate } & \multicolumn{2}{|c|}{$\begin{array}{l}\text { High Cholesterol } \\
\text { Control }\end{array}$} & & \\
\hline & No. & Rate & No. & Rate & & \\
\hline 1 (lowest risk) & 7 & 1.11 & 16 & 2.51 & 0.44 & 1.40 \\
\hline 2 & 29 & 4.70 & 33 & 5.18 & 0.91 & 0.48 \\
\hline 3 & 41 & 6.58 & 59 & 9.47 & 0.69 & 2.89 \\
\hline 4 (highest risk) & 78 & 12.56 & 93 & 16.28 & 0.77 & 3.72 \\
\hline
\end{tabular}

Table 10(a), divided the men in the 2 high cholesterol Groups into quartiles of 'risk scores'. That is to say, a risk score was calculated for each man, based on the multiple logistic equation derived from Group II, and using the values of the 5 risk factors for that man at entry to the trial. This represented an assessment of his intrinsic risk of having a major IHD event. All the men in both Groups were ranked by this score and divided into 4 equal-sized quartiles of risk. For each such quartile, the number of major IHD events and the total number of manyears in the trial were determined to calculate a rate for each Group. The rates in the 2 Groups were then compared in each quartile. The difference varied from 0.48 per thousand per annum to 3.72 , the highest differences being in the 2 quartiles of highest risk. The greatest proportionate change in the rates is in the lowest quartile of risk, whereas the greatest absolute difference in rates is in the highest quartile. From the point of view of achieving the greatest reduction in the number of cases of ischaemic heart disease, the difference is the more relevant index, and it suggests that the greatest benefit would derive from a policy of treating those at highest risk.

The second approach was to evaluate the effects of clofibrate treatment in subjects who had low and high values of the 5 main risk factors (age, smoking, cholesterol, systolic blood pressure, and father alive or dead). For each risk factor, the men in Group I were divided into those with low and high values and the number of events observed are shown in the first line of Table 10(b). In the second line, the 'calculated' number of events is shown. This calcu-

TABLE 10 (b)

Major IHD events in Group I by risk factors et entry to Trial

\begin{tabular}{|c|c|c|c|c|c|c|c|c|c|c|c|c|}
\hline & \multicolumn{2}{|c|}{ Age } & \multicolumn{2}{|c|}{ Smoking } & \multicolumn{2}{|c|}{ Father } & \multicolumn{2}{|c|}{ Systolic BP } & \multicolumn{2}{|c|}{ Cholesterol } & \multirow{2}{*}{$\begin{array}{l}\text { Greatest } \\
\text { Effect }\end{array}$} & \multirow{2}{*}{ Remaincer } \\
\hline & $<45$ & 245 & $0+E x$ & + & Alive & Dead & $<135$ & 3135 & Smedian & >median & & \\
\hline Observed no. of events & 30 & 125 & 43 & 112 & 14 & 141 & 77 & 78 & 58 & 97 & 45 & 110 \\
\hline Calculated no. of events & 52 & 158 & 56 & 155 & 27 & 184 & 90 & 119 & 82 & 127 & 68 & 143 \\
\hline Observed rate/1000 p.a. (o) & 2.88 & 8.63 & 3.80 & 8.24 & 2.25 & 7.55 & 5.58 & 7.02 & 4.68 & 7.76 & 9.46 & 5.46 \\
\hline Calculated rate/ 1000 p.a. (c) & 5.02 & 10.93 & 4.91 & 11.42 & 4.36 & 9.84 & 6.55 & 10.71 & 6.60 & 10.13 & 14.30 & 7.10 \\
\hline$R=$ ratio of rates $(o / c)$ & 0.57 & 0.79 & 0.77 & 0.72 & 0.52 & 0.77 & 0.85 & 0.66 & 0.71 & 0.77 & 0.66 & 0.77 \\
\hline $\begin{array}{c}D=\text { difference between rates } \\
(c-0)\end{array}$ & 2.14 & 2.30 & 1.11 & 3.18 & 2.11 & 2.29 & 0.97 & 3.69 & 1.92 & 2.37 & 4.84 & 1.64 \\
\hline
\end{tabular}


lated number, based on the multiple logistic function, is the number of events which would have occurred in the Group I men had they not been given clofibrate. The difference between observed and calculated numbers thus represents the effect of clofibrate treatment, making allowance for all the risk factors used in the logistic analysis. From the observed and calculated numbers, rates were derived and the ratios and differences of these rates are shown in the last two lines. Thus, for instance, in younger men aged under 45 years, the ratio of the rate in the clofibrate-treated group to the rate in similar men in Group II is 0.57 compared with 0.79 in the older men, suggesting a greater benefit of treatment in the younger men independently of other risk factors. On the other hand, the absolute differences due to treatment $(2 \cdot 14 / 2 \cdot 30)$ do not differ appreciably between the younger and older groups. Similar contrasts between conclusions drawn from the ratio and the difference due to clofibrate treatment apply to parental history (ratios 0.52/0.77; differences $2.11 / 2.29$ ) and to cholesterol $(0.71 / 0.77 ; 1.92 / 2.37)$. For smoking, however, whether the ratios $(0.77 / 0.72)$ or the difference $(1 \cdot 11 / 3 \cdot 18)$ are taken as the best measure of the benefit of treatment, the result is similar, that is those at higher risk derive more benefit. This is even more so for systolic blood pressure (ratios $0.85 / 0.66$; differences $0.97 / 3.69$ ). These findings taken together with the results shown in Table 8 , suggest that the men likely to benefit most from clofibrate treatment would be those with systolic blood pressure over $135 \mathrm{mmHg}$, who smoked, and who showed a reduction of cholesterol on treatment. This subgroup, comprising men of mean age 46.5 and mean cholesterol of $258 \mathrm{mg} / 100 \mathrm{ml}$, are described in Table $10(\mathrm{~b})$ as those with 'greatest effect'. They are compared with the 'remainder', that is all other men in Group I. The ratios of major IHD rates in 'greatest effect' and 'remainder' subgroups were 0.66/0.77 and the differences 4.84/1.64. There is a 34 per cent reduction of events in the 'greatest effect' subgroup, compared with 23 per cent in the 'remainder'. These reductions in incidence are associated with mean cholesterol changes of 12 and 8 per cent, respectively. The 872 men in the 'greatest effect' subgroup represent 18.4 per cent of Group I, which in turn was selected from the upper third of the population. Thus this subgroup represents, at most, 6 per cent of men in the age range concerned.

TABLE 11

Serum Triglycerides (mg/d1)

Last in-trial reading for each man. Edinburgh only.

\begin{tabular}{|c|c|c|c|c|c|}
\hline & & & \multicolumn{3}{|c|}{ Years in Trial } \\
\hline & & & 5 & 6 & 7 \\
\hline Group I & Clofibrate & $\begin{array}{l}\text { Mean TG } \\
\text { No. of men }\end{array}$ & $\frac{161}{178}$ & $\begin{array}{l}158 \\
294\end{array}$ & $\frac{162}{592}$ \\
\hline Group II & $\begin{array}{l}\text { High } \\
\text { Cholesterol } \\
\text { Control }\end{array}$ & $\begin{array}{l}\text { Mean TG } \\
\text { No. of men }\end{array}$ & $\frac{205}{1.84}$ & $\frac{211}{276}$ & $\frac{209}{601}$ \\
\hline Group III & $\begin{array}{l}\text { Low } \\
\text { Cholesterol } \\
\text { Control }\end{array}$ & $\begin{array}{l}\text { Mean TG } \\
\text { No. of Men }\end{array}$ & $\frac{160}{181}$ & $\frac{163}{248}$ & $\frac{174}{658}$ \\
\hline
\end{tabular}


CHANGE IN SERUM TRIGLYCERIDES

DURING THE STUDY

As mentioned earlier under biochemical monitoring, serum triglycerides were measured in one centre only (Edinburgh) and then only from 1972. Since no baseline analysis was made, it is not possible to produce serial measures of individual change of triglyceride concentrations. Nevertheless, Table 11 shows that the concentrations after 5,6 , and 7 years of treatment with clofibrate were much lower than in the untreated high cholesterol group, and even slightly lower than in the low cholesterol control group.

\section{Deaths from"causes other than ischaemic heart disease}

In the analysis of many conditions other than ischaemic heart disease there are good reasons for including deaths that occur after leaving the trial with those that occur in the trial. Deaths from cancer form an obvious example. The centres

TABLE 12

Deaths in the Trial and Within 1 year of Leaving it Main Cause Groups. Numbers of Deaths \& Rates at Ages 30-59, and Age-standardised Rates per 1000 per annum at ages 40-59

\begin{tabular}{|c|c|c|c|c|c|c|c|c|c|}
\hline \multirow{4}{*}{ Cause of Death } & \multicolumn{3}{|c|}{ Group I } & \multicolumn{3}{|c|}{ Group II } & \multicolumn{3}{|c|}{ Group III } \\
\hline & \multicolumn{3}{|c|}{ Clofibrate } & \multicolumn{3}{|c|}{$\begin{array}{l}\text { High Cholesterol } \\
\text { Control }\end{array}$} & \multicolumn{3}{|c|}{$\begin{array}{l}\text { Low Cholesterol } \\
\text { Control }\end{array}$} \\
\hline & No. & Rate & \multirow{2}{*}{$\begin{array}{c}\text { St. } \\
\text { Rate } \\
40-59 \\
\end{array}$} & No. & Rate & \multirow{2}{*}{\begin{tabular}{|c|} 
St. \\
Rate \\
$40-59$ \\
\end{tabular}} & No. & Rate & \multirow{2}{*}{$\begin{array}{c}\text { St. } \\
\text { Rate } \\
40-59\end{array}$} \\
\hline & (A1.1 & (ges) & & $(A 11$ & Ages ) & & (A11 & Ages) & \\
\hline Ischaemic Heart Disease & 54 & 1.6 & 2.1 & 48 & 1.4 & 2.1 & 20 & 0.6 & 0.8 \\
\hline Other Vascular & 14 & 0.4 & 0.5 & 14 & 0.4 & 0.6 & 9 & 0.3 & 0.5 \\
\hline Neoplasm: malignant & 58 & 1.7 & 2.2 & 42 & 1.3 & 1.7 & 41 & 1.3 & 2.5 \\
\hline Neoplasm: benign & 3 & - & - & - & - & - & 1 & - & - \\
\hline Other Medical Causes & $16 *$ & $0.5 *$ & $0.8 *$ & $5 *$ & $0.2 *$ & $0.2 *$ & 7 & 0.2 & 0.4 \\
\hline Accidents and Violence & 17 & 0.5 & 0.6 & 18 & 0.5 & 0.6 & 15 & 0.5 & 0.6 \\
\hline $\begin{array}{l}\text { A11 causes other than IHD } \\
\text { A11 causes other than IHD, } \\
\text { Vascular and Accidents \& } \\
\text { Violence }\end{array}$ & $108 *$ & $2.3 *$ & $3.1 *$ & $47 * *$ & $1.4 * *$ & $1.9 *$ & 73 & 1.5 & 3.9 \\
\hline TOTAL ALL CAUSES & $162 *$ & $4.9 *$ & 6.2 & $127 *$ & $3.8 *$ & 5.2 & 93 & 2.9 & 4.7 \\
\hline
\end{tabular}

* Significant difference between Groups I and II $(P<0.05)$. 
differed, for valid local reasons, in their policies for excluding men from the study who developed malignant disease. On the other hand, it was not possible to be sure that all deaths occurring out of the trial were included. As mentioned earlier, a thorough search was made for all deaths occurring within one year of leaving the trial and, almost certainly, all but a few of these have been found. The figures in the report include all such deaths notified to the statistical centre up to the end of 1977 . In this section, therefore, dealing with deaths from all causes, Table 12 shows the number of deaths and the unstandardised and age-standardised death rates for the principal causes of deaths occurring in the trial' and within 1 year of leaving it. Table 14 shows the numbers of deaths in more detailed categories of causes, and also distinguishes between deaths in the trial and those occurring within 1 year of leaving it. Such information as is available about deaths occurring out of the trial but more than 1 year after leaving it is available on request (Addendum E).

The total number of deaths was significantly greater in Group I (162) than in Group II (127, $P<0.05)$, and the life-table analysis also shows a significant $(P<0.05)$ excess in Group I. There was a slight excess of deaths from ischaemic heart disease in Group I but nearly all the difference between Groups I and II lies in the deaths from causes other than IHD. Here again the differences in total numbers (108 and 79) and in crude rates (3.2 and 2.4) are significant $(P<0.05)$ and the life-table analysis gives a similar result $(P<0.05$, Fig. 5).

In terms of the individual cause groups other than IHD, shown in Table 12, the numbers of deaths from 'other vascular' conditions and from 'accidents and violence' are almost exactly the same in both groups, so that virtually the whole difference lies in deaths from cancer and from 'other medical causes', which are shown in detail in Table 14. However, when considering deaths from conditions not usually considered to be related to serum cholesterol level (which applies to the deaths in these 2 categories), it is appropriate to compare the mortality in Group I with that in Group III (the low cholesterol control group) as well as Group II, provided that in so doing allowance is made for the younger age at entry in Group III. (There are other differences between Group III and the other groups, but age is probably the most important. Appendix 2, multivariate table, Nos. 10, 11, and 12.) In Table 12 the age difference is taken into account by standardisation, and the effect of this adjustment is, of course, to increase the death rates in Group III compared with those in Groups I and II.

A comparison of the age-standardised rates in Groups I, II, and III for all causes other than IHD $(4 \cdot 1,3 \cdot 1,3 \cdot 9)$ suggests that part of the difference between Groups I and II is partly or largely the result of a low mortality in Group II rather than a high mortality in Group I. For cancer the corresponding rates are $2.2,1.7$ and 2.5 respectively, with a stronger indication of the same point.

Because of its importance, a detailed follow-up of all in- and ex-trial morbidity and mortality due to cancer was carried out. Table 13 shows that there was little difference between Groups I and II (66 cases against 61) in ex-trial deaths and cases still surviving. The main difference between these Groups thus lies in the in-trial mortality. Comparing all 3 Groups, the standardised rates for all malignant neoplasms are $3 \cdot 6,2 \cdot 8$, and $3 \cdot 4$, and for mortality,
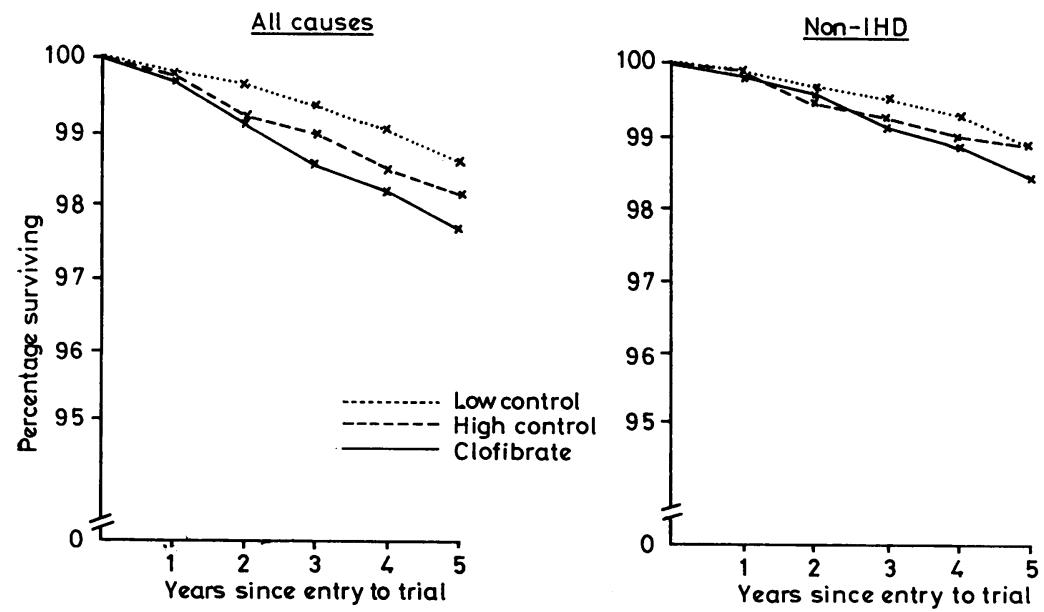

Fig. 5 Total mortality. Intrial and within 1 year of leaving. Life-table basis. 
TABLE 13

Malignant Neoplasms

\begin{tabular}{|c|c|c|c|}
\hline & Group I & Group II & Group III \\
\hline & Clofibrate & $\begin{array}{c}\text { High Cholesterol } \\
\text { Control }\end{array}$ & $\begin{array}{l}\text { Low Cholesterol } \\
\text { Control }\end{array}$ \\
\hline Deaths: & & & \\
\hline In-trial & 40 & 24 & 30 \\
\hline Ex-trial: within 1 year & 18 & 18 & 11 \\
\hline after 1 year & 20 & 13 & 11 \\
\hline Still living at 31.12 .76 & 28 & 30 & 24 \\
\hline Total known cases & 106 & 85 & 76 \\
\hline $\begin{array}{l}\text { Standardised Rate } \\
\text { (all malignant neoplasms) } \\
40-59 \text { per } 1000 \text { per annum }\end{array}$ & 3.6 & 2.8 & 3.4 \\
\hline $\begin{array}{l}\text { Standardised Death Rate } \\
40-59 \text { per } 1000 \text { per annum } \\
\text { (in-trial \& within } 1 \text { year) }\end{array}$ & 2.2 & 1.7 & 2.5 \\
\hline
\end{tabular}

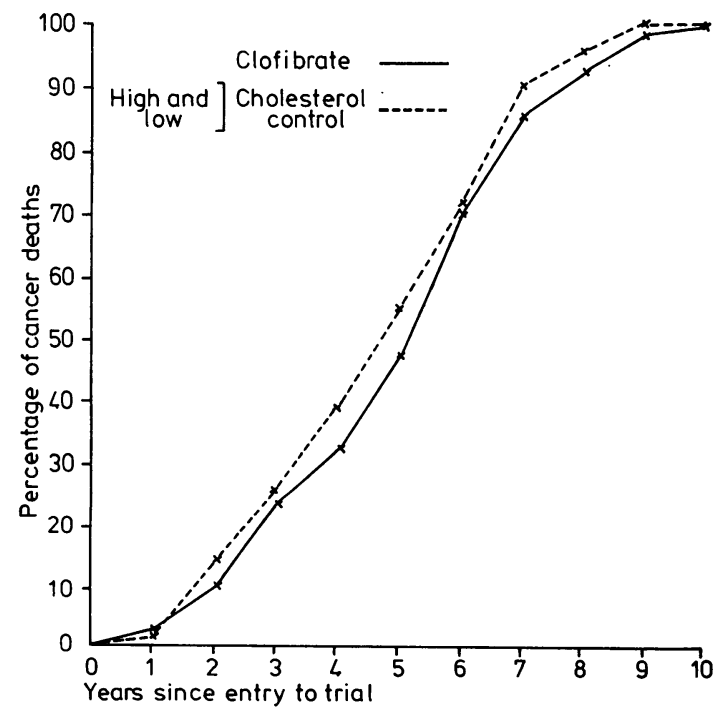

Fig. 6 Cumulative cancer mortality by years in trial. Total cancer deaths in and out of trial.
$2 \cdot 2,1 \cdot 7$, and $2 \cdot 5$, respectively. Fig. 6 compares the cumulative percentage of cancer deaths occurring in Group I with those occurring in Groups II and III at different times after entry. The curves are almost identical.

The remaining deaths which show a difference between Groups I and II are those resulting from 'other medical causes', and again the difference is confined almost entirely to the in-trial deaths (16 and 5 , overall, 15 and 3 in-trial). Though the numbers are much smaller, these differences are significant. There is, however, once again, the suggestion, when age-standardised rates for all deaths in the trial and within one year of leaving it in all three groups are compared $(0 \cdot 8,0 \cdot 2$, and $0 \cdot 4)$ that Group II may have a fortuitously low rate. Deaths from disease of the liver and gall bladder appear among the detailed causes of the excess in this group, and there is an excess in Group I of deaths from cancer of these sites and of the intestines. These issues are taken up in the discussion and Table 17.

Because of the suggestion in the report of the 
TABLF 14

Deaths in the Trial and Within 1 year of Leaving it ${ }^{(a)}$ Detailed Causes, distinguishing deaths in the Trial from those out of the Trial

Numbers of deaths at ages 30-59

\begin{tabular}{|c|c|c|c|c|c|c|c|c|c|}
\hline \multirow[b]{3}{*}{ Cause of Death } & \multirow{2}{*}{\multicolumn{3}{|c|}{$\frac{\text { Group I }}{\text { Clofibrate }}$}} & \multirow{2}{*}{\multicolumn{3}{|c|}{$\frac{\text { Group II }}{\text { High Cholesterol }}$}} & \multicolumn{3}{|c|}{ Group III } \\
\hline & & & & & & & \multicolumn{3}{|c|}{$\begin{array}{l}\text { Low Cholesterol } \\
\text { Control }\end{array}$} \\
\hline & $\mid \begin{array}{c}\text { In- } \\
\text { Trial }\end{array}$ & $\begin{array}{c}\text { Out of } \\
\text { Trial } \\
\text { within } \\
1 \text { year }\end{array}$ & Tota1 & $\begin{array}{c}\text { In- } \\
\text { Trial }\end{array}$ & \begin{tabular}{|c|} 
Out of \\
Trial \\
within \\
1 year \\
\end{tabular} & Total & $\begin{array}{l}\text { In- } \\
\text { rial }\end{array}$ & $\begin{array}{c}\text { Out of } \\
\text { Trial } \\
\text { within } \\
1 \text { year }\end{array}$ & Total \\
\hline Ischaemic heart Disease & & & & & & & & & \\
\hline Within 3 hours & 23 & 9 & 32 & 17 & 8 & 25 & 8 & 2 & 10 \\
\hline More than 3 hours & 13 & 9 & 22 & 17 & 6 & 23 & 8 & 2 & 10 \\
\hline Total & 36 & 18 & 54 & 34 & 14 & 48 & 16 & 4 & 20 \\
\hline $\begin{array}{l}\text { 0ther diseases of the } \\
\text { Circulatory System } \\
\text { Cerebrovascular disease } \\
\text { Thrombophlebitis } \\
\text { Chronic pulmonary heart disease } \\
\text { Other diseases of circulatory } \\
\text { systen }\end{array}$ & $\begin{array}{l}8 \\
4 \\
1 \\
-\end{array}$ & $\begin{array}{l}1 \\
- \\
-\end{array}$ & $\begin{array}{l}9 \\
4 \\
1 \\
-\end{array}$ & $\begin{array}{l}7 \\
3 \\
- \\
-\end{array}$ & $\begin{array}{l}3 \\
1 \\
- \\
-\end{array}$ & $\begin{array}{r}10 \\
4 \\
- \\
-\end{array}$ & $\begin{array}{l}3 \\
- \\
-\end{array}$ & $\begin{array}{l}2 \\
\overline{2} \\
1\end{array}$ & $\begin{array}{l}5 \\
- \\
3 \\
1\end{array}$ \\
\hline Total & 13 & 1 & 14 & 10 & 4 & 14 & 4 & 5 & 9 \\
\hline $\begin{array}{l}\text { Malignant Néoplasms } \\
\text { Oesophaguis, stomach } \\
\text { Small intestine, colon, rectum } \\
\text { Liver, gall bladder, pancreas } \\
\text { Larynx, bronchus and lung } \\
\text { Skin } \\
\text { Brain } \\
\text { Haematopoietic tissue } \\
\text { Other, or not known } \\
\text { Total }\end{array}$ & $\begin{array}{r}6 \\
6 \\
6 \\
13 \\
2 \\
4 \\
2 \\
1 \\
40 \\
\end{array}$ & $\begin{array}{r}3 \\
5 \\
1 \\
4 \\
- \\
1 \\
- \\
4 \\
18 \\
\end{array}$ & $\begin{array}{r}9 \\
11 \\
7 \\
17 \\
2 \\
5 \\
2 \\
5 \\
58 \\
\end{array}$ & $\begin{array}{r}4 \\
3 \\
3 \\
7 \\
2 \\
2 \\
1 \\
2 \\
24 \\
\end{array}$ & $\begin{array}{r}1 \\
3 \\
2 \\
4 \\
- \\
3 \\
2 \\
3 \\
18\end{array}$ & $\begin{array}{r}5 \\
6 \\
5 \\
11 \\
2 \\
5 \\
3 \\
5 \\
42\end{array}$ & $\begin{array}{r}6 \\
3 \\
5 \\
10 \\
2 \\
1 \\
1 \\
2 \\
30\end{array}$ & $\begin{array}{r}2 \\
2 \\
- \\
4 \\
1 \\
1 \\
-1 \\
11\end{array}$ & $\begin{array}{r}8 \\
5 \\
5 \\
14 \\
3 \\
2 \\
1 \\
3 \\
41\end{array}$ \\
\hline Benign Neoplasms & 3 & - & 3 & - & - & - & 1 & - & 1 \\
\hline Other Medical Causes & & & & & & & & & \\
\hline Pulmonary Tuberculosis & 1 & - & 1 & 1 & - & 1 & - & - & - \\
\hline $\begin{array}{l}\text { Diseases of the Central } \\
\text { Nervous Sysrem }\end{array}$ & - & - & - & - & 1 & 1 & - & - & - \\
\hline Diseases of the Respiratory System & & & & & & & & & \\
\hline Influenza & 1 & - & 1 & - & - & - & - & - & - \\
\hline Bronchopneumonia & 1 & $\overline{-}$ & 1 & $\overline{1}$ & $\overline{-}$ & $\overline{1}$ & 2 & $\overline{-}$ & $\begin{array}{l}2 \\
-\end{array}$ \\
\hline Peptic Ulcer & 2 & - & 2 & 1 & - & 1 & 2 & - & 2 \\
\hline Liver \& Gall Bladder Diseases & & & & & & & & & \\
\hline Acute Hepatitis & 1 & - & 1 & - & - & - & - & - & - \\
\hline Liver cirrhosis & $\overline{3}$ & - & $\overline{3}$ & - & $\overline{-}$ & - & 1 & $\overline{-}$ & 1 \\
\hline Cnolecystectomy (see, rable l6) & 3 & - & 3 & - & - & - & 1 & - & 1 \\
\hline Pancreatitis & 2 & 1 & 3 & - & - & - & - & - & - \\
\hline $\begin{array}{l}\text { Diseases of the Genito-urinary } \\
\text { System }\end{array}$ & & & & & & & & & \\
\hline $\begin{array}{l}\text { Chronic pyelonephritis } \\
\text { Calculus of kidney }\end{array}$ & $\begin{array}{l}1 \\
1\end{array}$ & $\overline{-}$ & $\begin{array}{l}1 \\
1\end{array}$ & $\overline{-}$ & $\overline{-}$ & $\overline{-}$ & $\overline{-}$ & $\overline{-}$ & - \\
\hline Hyperplasia of Prostate & 1 & - & 1. & - & - & - & 1 & - & 1. \\
\hline Chronic Osteomyelitis & - & - & - & - & 1 & 1 & - & - & - \\
\hline Total & 15 & 1 & $16 *$ & 3 & 2 & $5 *$ & 7 & - & 7 \\
\hline Accidents \& Violence & & & & & & & & & \\
\hline $\begin{array}{l}\text { Injuries, homicide, accidents } \\
\text { Suicide }\end{array}$ & $\begin{array}{r}13 \\
4 \\
\end{array}$ & - & $\begin{array}{r}13 \\
4 \\
\end{array}$ & $\begin{array}{r}13 \\
2 \\
\end{array}$ & $\begin{array}{l}1 \\
2 \\
\end{array}$ & $\begin{array}{r}14 \\
4 \\
\end{array}$ & $\begin{array}{r}11 \\
3 \\
\end{array}$ & 1 & $\begin{array}{r}12 \\
3\end{array}$ \\
\hline Total & 17 & - & 17 & 15 & 3 & 18 & 14 & 1 & 15 \\
\hline TOTAI all Causes other than IHD & 88 & 20 & $108 *$ & 52 & 27 & $79 *$ & 56 & 17 & 73 \\
\hline TOTAL ALL CAUSES & 124 & 38 & $162 *$ & 86 & 41 & $127 * 1$ & 72 & 21 & 93 \\
\hline
\end{tabular}

(a) Deaths occurring more than one year after leaving the Trial, so far as they are known, are shown in Addendurn $E$.

* Significant difference between Groups I and II (P $<0.05)$. 
TABLE 15

Withdrawa1s for Medica1 Reasons other than Major Ischaemic lleart Disease

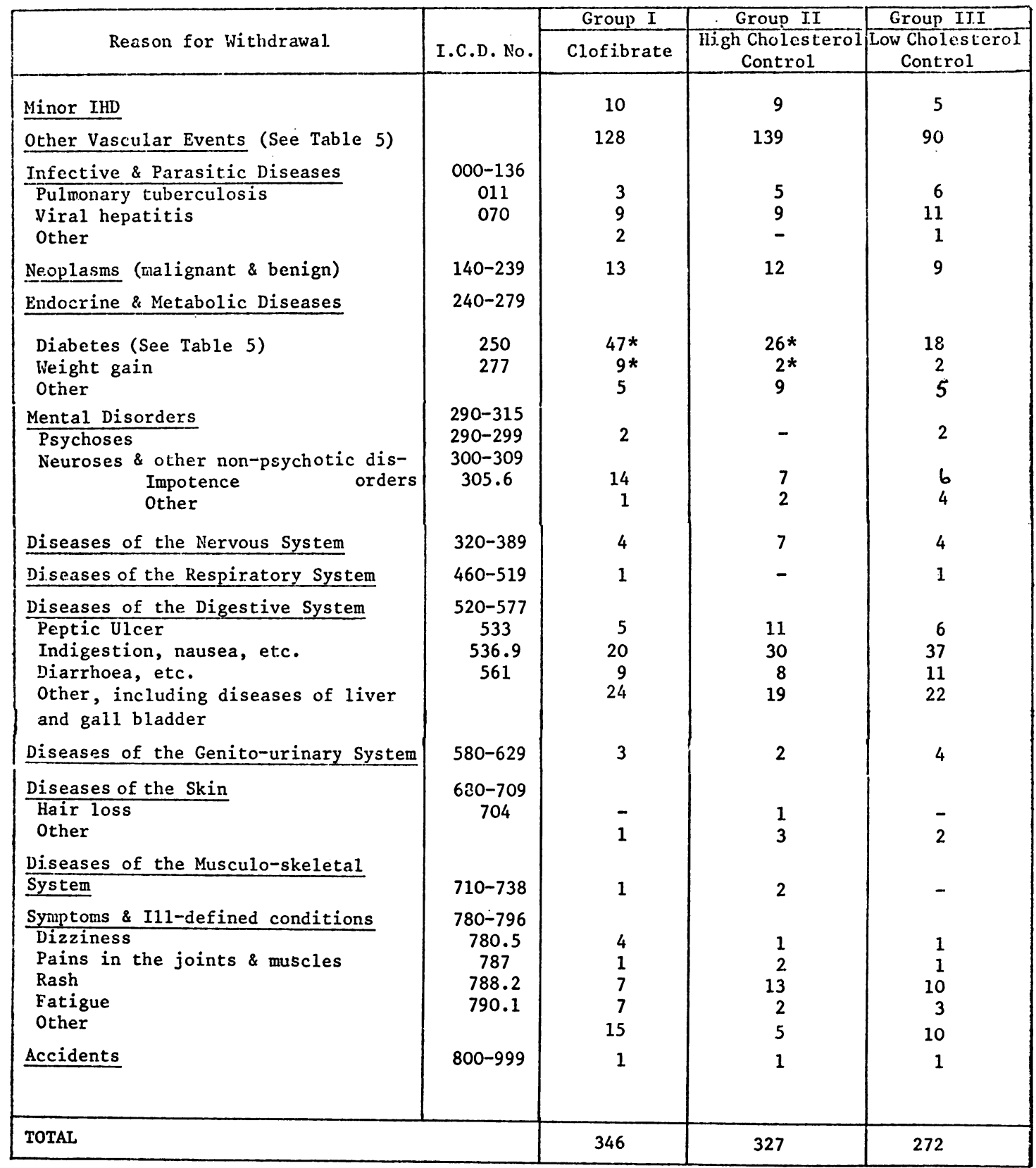

* Significant difference between Groups I and II $(P<0.05)$. 
TABLE 16

Cholecystectomies for Gallstones

\begin{tabular}{|c|c|c|c|}
\hline & Group I & Group II & Group III \\
\hline & Clofibrate & $\begin{array}{c}\text { High Cholesterol } \\
\text { Control }\end{array}$ & $\begin{array}{l}\text { Low Cholesterol } \\
\text { Concrol }\end{array}$ \\
\hline \multicolumn{4}{|l|}{ (i) Numbers and Rates } \\
\hline $\begin{array}{l}\text { No. of men admitted to } \\
\text { trial:- } \\
\text { No. of cholecystectomies } \\
\text { for gallstones in:- }\end{array}$ & 5331 & 5296 & 5118 \\
\hline Edinburgh & 22 & 4 & 10 \\
\hline Budapest & 18 & 11 & 9 \\
\hline Prague & 19 & 9 & 6 \\
\hline \multirow{2}{*}{$\begin{array}{l}\text { All Centres: No. (a) } \\
\text { Rate } \\
\text { Age-stand. rate (b) }\end{array}$} & $59 * * *$ & $24 \% * \%$ & 25 \\
\hline & $\begin{array}{l}2.1 * * * \\
2.0\end{array}$ & $\begin{array}{l}0.9 * * \star \\
1.2\end{array}$ & $\begin{array}{l}0.9 \\
1.6\end{array}$ \\
\hline \multicolumn{4}{|l|}{$\frac{\text { (ii) Numbers in relation to }}{\text { Time in Trial }}$} \\
\hline \multirow{6}{*}{$\begin{array}{l}<2 \\
2- \\
4- \\
6 \text { \& over } \\
\text { Not known }\end{array}$} & 11 & 2 & 5 \\
\hline & 17 & 7 & 6 \\
\hline & 18 & 11 & 10 \\
\hline & 12 & 4 & 4 \\
\hline & 1 & - & - \\
\hline & 59 & 24 & 25 \\
\hline
\end{tabular}

(a) Includes 4 deaths (see Table 14).

(b) Age-standardized 40-59.

*** Significant difference between Groups I and II $(P<0.001)$.

American Coronary Drug Project Research Group (1975) that clofibrate may have led to thromboembolic complications, a special examination of the death-record forms in the present study was carried out, under 'blind' conditions, to study whether deaths occurring after surgery, for example, might have been more commonly associated with thrombotic or embolic phenomena in Group I. The numbers for Groups I and II were not significantly different ( $6 v 3)$.
The differences in total mortality between Groups I and II were most obvious in Budapest and least in Edinburgh (Appendix 4) and this was most noticeable in death from causes other than IHD. As with deaths in the trial as a whole, however, the agestandardised mortality in Group III exceeded that in Group II.

WITHDRAWALS FOR MEDICAL REASONS

Table 15 shows the variety of conditions, some of 
TABLE 17

Regional Pathology

Numbers of deaths in the trial and within 1 year of leaving it, at ages 30-59

\begin{tabular}{|c|c|c|c|c|c|c|c|c|c|}
\hline \multirow[t]{2}{*}{ Site of Pathology } & \multicolumn{3}{|c|}{$\begin{array}{l}\text { Deaths from } \\
\text { "Other Medical } \\
\text { Causes"(a) }\end{array}$} & \multicolumn{3}{|c|}{$\begin{array}{l}\text { Deaths from } \\
\text { Malignant } \\
\text { Neuplasms }\end{array}$} & \multicolumn{3}{|c|}{$\begin{array}{l}\text { A1l Deaths at } \\
\text { these sites }\end{array}$} \\
\hline & I & II & III & I & II & III & $I$ & II & III \\
\hline Liver & 1 & 0 & 1 & 3 & 1 & 1 & 4 & 1 & 2 \\
\hline Galj bladder & 3 & 0 & 1 & 1 & 0 & 0 & 4 & 0 & 1 \\
\hline Smal1 intestine & 0 & 0 & 0 & 1 & 0 & 0 & 1 & 0 & 0 \\
\hline Colon & 0 & 0 & 0 & 6 & 5 & 3 & 6 & 5 & 3 \\
\hline Rectum & 0 & 0 & 0 & 4 & 1 & 2 & 4 & 1 & 2 \\
\hline Tota1 & 4 & 0 & 2 & 15 & 7 & 6 & $19 *$ & $7 *$ & 8 \\
\hline Rates per 1000 per annum & - & - & - & - & - & - & $0.57 *$ & $0.21^{*}$ & 0.25 \\
\hline $\begin{array}{l}\text { Age-standardised rates } \\
(40-59)\end{array}$ & - & - & - & - & - & - & $0.75 * *$ & $0.17 *$ & 0.65 \\
\hline
\end{tabular}

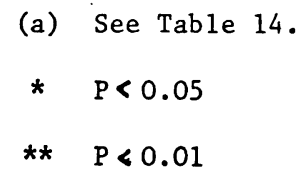

which were suspected of being adverse reactions, which caused withdrawal from the trial. Cholelithiasis was not known as an adverse effect of clofibrate until half-way through the trial and was not listed as such. A preliminary report on the incidence of cholecystectomy for gall stones occurring in the trial has already been published (Cooper et al., 1975). Table 16 (i) shows the final position, confirming beyond doubt the previous reports. Four of these men died in the perioperative period from sepsis or other complications, 3 in Group $I$ and 1 in Group III.

'Indigestion', 'diarrhoea', and 'skin reactions' were specifically recorded at follow-up visits because they are well recognised side-effects of clofibrate. Table 15 shows that none of these three caused withdrawal from the trial more frequently from
Group I than from the other groups. Weight gain, hair loss, muscle cramps, and cardiac arrhythmia are also listed because they have been questioned as possible adverse effects of clofibrate. Only weight gain accounts for a significant difference $(P<0.05)$ between Groups I and II, but the numbers are very small $(9 \vee 2)$.

The category 'other' includes a variety of complaints such as thirst, insomnia, vertigo, headache, and intolerance to alcohol. The numbers were too small to allow for statistical appraisal of individual conditions.

The centres differed considerably in the number of subjects withdrawn for medical reasons (Addendum C). Numbers were greater in Prague than in either of the other two centres; the conditions where this excess was most noticeable were diabetes, 
hypertension, 'other digestive' conditions, and infective hepatitis.

CONDITIONS NOT NECESSARILY CAUSING

WITHDRAWAL FROM THE TRIAL

Such conditions, recorded as possible side-effects of treatment, are shown in Appendix 6.

Approximately 13 per cent of men reported one of the conditions listed on at least one occasion (distribution between Groups was 15, 12, and 12 per cent $(P<0.01))$. Specific conditions are mentioned in the discussion. There were, however, substantial intercentre differences.

Various bizarre effects were attributed to the trial capsules, there being no significant difference in incidence between groups. Interestingly, increased sweating was reported as being more common in Group I than in Group II, but only at Edinburgh, where the difference in incidence was statistically significant (24 v 7, P < 0.01). No cases had to be withdrawn from the trial because of this symptom.

\section{Discussion}

\section{PRINCIPAL FINDINGS}

The trial has shown that healthy men, aged 30 to 59, with moderately raised serum cholesterol levels who were treated with the cholesterol-lowering drug clofibrate had significantly fewer major IHD events than comparable controls $(\mathbf{P}<0.05)$. This reduction was confined to non-fatal myocardial infarcts $(P<0.05)$. The incidence of fatal first IHD events, whether within or after 3 hours of onset of symptoms, did not differ significantly in the two groups. There were in the trial and within 1 year of leaving it significantly more deaths from all causes in those treated with clofibrate compared with the control groups (162, 127, and 93). This excess occurred mainly in the deaths from causes which were not due to IHD, other vascular disease, or accidents (77, 47, and 49 deaths).

Reviewing the assumptions made in planning this trial, the actual fall in serum cholesterol was less than the initial forecast of 15 per cent; the incidence of IHD at ages 30 to 59 in the high cholesterol control group was 0.74 per cent compared with a predicted 1 per cent; the reduction in incidence of IHD achieved in the treated group was 20 per cent compared with 30 per cent on which the original calculations were based. This was significant at the 5 and not the 1 per cent level. The total number of men recruited, however, was 15745 compared with 15000 and the number of man-years experienced 83534 against the postulated 75000 . The period of study was, of course, not 5 years for each individual though the average length of time in the study was
5.3 years: some were in the trial for 8 years and a few for only 4. The actual percentage of men lost to the trial for all reasons in the first 5 years was 31 per cent compared with the assumed 30 per cent.

\section{ISCHAEMIC HEART DISEASE}

\section{(a) Mortality}

The failure of clofibrate to reduce the incidence of fatal heart attacks is disappointing. The prevention of non-fatal infarction, however, might be expected to result in improved long-term mortality, since men with a history of myocardial infarction have a worse prognosis than those without such a history. Mortality from IHD, particularly early death, was not reduced in other primary prevention trials using a diet rich in polyunsaturated fats (Dayton et al., 1969; Miettinen et al., 1972); and the AlbanyFramingham study has shown that the incidence of sudden death bears no relation to prior serum cholesterol levels (Kannel et al., 1975). The mechanisms responsible for such deaths are probably less directly related to serum cholesterol change and the amount of coronary atheroma than those leading to non-fatal myocardial infarction. Deaths within 3 hours of the onset of symptoms are mostly the result of primary ventricular arrhythmias, probably resulting from acute myocardial ischaemia. Deaths more than 3 hours and less than 28 days after onset of symptoms are mostly related to the extent of the infarct itself and are the result of secondary arrhythmias, cardiogenic shock, heart failure, and rupture of the ventricle.

\section{(b) Non-fatal myocardial infarcts}

The results reported relate only to events occurring during the trial, when the men were taking the capsules. No systematic attempt was made to ascertain non-fatal myocardial infarcts after the end of treatment. Available data were examined, however, to identify any 'rebound' effect after withdrawal of clofibrate and there was no difference between Groups I and II in the incidence of total IHD after 3 months, 6 months, or 1 year.

Most of the difference in incidence of non-fatal myocardial infarction between Groups I and II appears to be related to cholesterol reduction. The effect of reducing cholesterol with clofibrate was to lower the incidence whatever the initial concentration and this is well illustrated by comparing Groups I and II in Table 8. Men with high initial serum cholesterol concentrations had a worse prognosis in both Groups, whatever changes occurred during the trial period. The highest incidence rates for all IHD in the high cholesterol control group occurred in those with initial concentrations above 
the median, that is in the upper sixth of the total cholesterol distribution for the populations studied. Cholesterol 'non-responders' comprised a substantial minority (about a sixth) of Group I, and the higher incidence rates of IHD events in these partly dilutes the results for the Group as a whole. Under conditions of ordinary medical practice such patients would be considered as 'failures', and an unsatisfactory regimen would be replaced with a potentially better one.

The extent to which concurrent reduction of elevated serum triglycerides could have contributed to the reduction in non-fatal IHD cannot be assessed from our data.

(c) Optimal effects of clofibrate on major IHD events An attempt was made to identify those most likely to benefit from clofibrate treatment. In this trial, they were men who had a reduction of serum cholesterol on treatment and had a systolic blood pressure of over $135 \mathrm{mmHg}$ and who smoked. This subgroup, comprising men with a mean age of 46.5 years and a mean initial serum cholesterol of $258 \mathrm{mg} / 100 \mathrm{ml}$ had a 34 per cent reduction in major IHD events compared with a 23 per cent reduction in the remainder in Group I. These reductions in incidence were associated with mean serum cholesterol changes of 12 per cent and 8 per cent, respectively. This subgroup represents, at most, 6 per cent of the men in the age range concerned.

\section{(d) Angina and myocardial ischaemia}

The incidences of angina pectoris occurring during the trial, whether with or without supporting electrocardiographic evidence, and of electrocardiographic signs of myocardial ischaemia in the absence of chest pain, were similar in Groups I and II. A decreased rate of development of the earliest symptoms of IHD might have been expected if clofibrate slowed the pace of narrowing in the coronary arteries. This was suggested in the results of the Scottish and Newcastle trials of clofibrate in patients with angina (Dewar and Oliver, 1971). But neither was specifically designed to test the possibility and a new trial was proposed. Results of the current study do not help to answer this question.

MORTALITY FROM ALL CAUSES

There were 162 deaths in the clofibrate-treated group during and in the first year after the trial compared wi:h 127 in the high cholesterol control group and 93 in Group III (Table 12). The excess of 35 deaths between Groups I and II is significant $(P<0.05) ; 6$ of the 35 were due to IHD and 29 to causes not usually associated with serum cholesterol concentrations or changes. The difference in overall crude rates was also significant $(P<0.05)$. The design of the trial provided a second control group (Group III) which, though chosen on the basis of relatively low initial cholesterol levels, should also be used for such comparison provided that correction is made for the fact that men in this group were slightly younger than those in Groups I and II. Agestandardised rates have been used for comparison for this purpose, since the multiple logistic analysis shows that correcting for other factors as well as age adds very little. There was no significant difference in age-standardised mortality from all causes between any of the Groups.

Numbers of deaths due to other vascular causes and from accidents and violence were similar in Groups I and II. The greater part of the excess in Group I was distributed over a wide range of medical conditions classified in Table 12 under 'malignant neoplasms' and 'other medical causes' and detailed further in Table 14. These two main categories, taken together, show an excess in Group I over Group II $(77 v 47 ; \mathrm{P}<0.01)$, and the crude rates were also significantly in excess $(P<$ $0.01)$. Though there was a significant difference in age-standardised rates $(3.1$ and $1.9 ; P<0.05)$ between Groups I and II, there was virtually none between Groups I and III (3.1 and 2.9), suggesting that the rates in Group II may be spuriously low.

\section{(a) Malignant neoplasms}

The excess in Group I over Group II of deaths due to cancer occurred mostly during the trial $(40 v 24)$, and not in ex-trial deaths either within or after 1 year $(38 v 31)$ or in those with diagnosed cancer still alive at the end of the trial (28v30). While neither the numbers nor the crude rates are significantly in excess, this might suggest that, while not being carcinogenic, clofibrate could have accelerated pre-existing cancer and have led to earlier death. But the cumulative percentages of cancer deaths occurring in Group I compared with Group II at different times after entry are almost identical (Fig. 6) and what difference there is suggests a later, rather than an earlier, mortality due to cancer in Group I. The age-standardised death rates in the three groups were $2 \cdot 2,1 \cdot 7$, and $2 \cdot 5$. The corresponding age-standardised rates for deaths from malignant neoplasms calculated from the official mortality statistics for men of the same age in the Edinburgh area, Budapest, and Prague are as follows: $2 \cdot 2$ (East Central and South Scotland, 1969-73), 2.6 Budapest (1972-74), $2 \cdot 8$ Prague (1968-73). These figures are surprisingly close to the rates observed in trial subjects in Groups I and III.

Thus the data for all cancer do not give rise to special concern. 
(b) 'Other medical causes'

There was a significant excess in deaths and crude death rates from 'other medical causes' in the clofibrate-treated group compared with the high cholesterol control group (16 and 5; 0.5 and 0.2 ; $P<0.05)$. This excess was most evident in Budapest and virtually absent in Edinburgh (Appendix 4). The age-standardised death rate in the clofibrate-treated group was significantly higher than in the high cholesterol control group but not significantly greater than in the low cholesterol control group.

Though the numbers are small, these results have caused much concern and particular care has been given to accurate assessment of necropsy reports, which were interpreted without knowledge of treatment groups by 2 observers. Of the 28 patients dying from 'other medical causes', 25 had necropsies performed.

\section{Regional pathology}

There were more deaths from diseases of the liver, gall bladder, and intestines, including malignant neoplasms of these sites, in the clofibrate-treated group than in the high cholesterol control group. Taken together with the significant excess in the treated group compared with both control groups of cholecystectomies for gall stones, there was therefore a possibility that clofibrate might be producing pathology in this area. The relevant mortality data are collected in Table 17. The difference in numbers of deaths between Groups I and II (19v7) is significant $(P<0.05)$ as also is the difference between age-standardised rates $(P<0.01)$. On the other hand, the similarity of the age-standardised rates in Groups I and III gives some reassurance, suggesting that the low rate in Group II may have been fortuitous. The numbers concerned are small. This shows up in the contrast between the crude and age-standardised rates for Group III. The proportions of all deaths not due to IHD but due to pathology of the liver, gall bladder, and intestines were $19 / 108=18$ per cent in Group I, 7/79 = 9 per cent in Group II, and 8/73 = 11 per cent in Group III. On entry, men who subsequently died from the causes shown in Table 17 were, on average, a few years older, slightly heavier, and more likely to have fathers who have died than the rest of the men in the same treatment group.

Although the statistical impropriety of retrospectively selecting a particular subgroup for analysis is fully recognised, investigators have to draw attention to any unexpected biological finding which might relate to the conclusions as a whole. A plausible biological hypothesis can be stated in support of the subgrouping shown in Table 17, and no other subgrouping of data or of major endpoints (other than IHD) has shown significant differences between the clofibrate-treated and high cholesterol control groups. The hypothesis is that clofibrate, through mobilisation of cholesterol from tissue pools (including arteries) resulting in excretion of cholesterol and related sterols, could contribute to liver, biliary, and intestinal pathology.

The mechanisms through which clofibrate might do this are not understood. It has been shown that after 3 years of daily administration of the drug, there is continued increase in excretion of cholesterol into the bile. There is also enhanced excretion of endogenous neutral sterols and this exceeds a decrease in acid sterol excretion (Grundy et al., 1972). No study has been reported of the relation of increased neutral sterol excretion to large bowel pathology, though raised faecal acid sterol concentrations have been implicated in the pathogenesis of cancer of the colon (Hill et al., 1975). Other possibilities are that clofibrate has some effect in altering intestinal bacterial flora; or that directly or indirectly it causes aromatisation of certain bile acids (Hill, 1977), leading to tissue damage. Another potent hypolipidaemic drug, nicotinic acid, also increases neutral sterol excretion (Einarsson et al., 1977).

In the Los Angeles Veterans Administration Study (Dayton et al., 1969), there were more deaths from non-atherosclerotic causes in the group receiving a polyunsaturated fat diet than in an untreated control group. In particular, there were more deaths caused by malignant disease in the treated compared with the control group (31 v 17), but further analysis of the results of this and other dietary studies disclosed no significant excess incidence of cancer in the experimental groups (Ederer et al., 1971). S. Dayton (1978, personal communication) has recently reanalysed his data and there was no evidence of excess pathology, including cancer, specifically in the liver, biliary, and intestinal systems in the diet group compared with controls. In the Helsinki Mental Hospital Study of the primary prevention of IHD (Miettinen et al., 1972) there was also a nonsignificant excess in total mortality among the experimental group taking a polyunsaturated fat diet. Age-adjusted death rates/1000 person-years for malignant neoplasms (5.02 diet $v 3.96$ control) and 'other diseases' (15.45 diet $v 13.03$ control) were both greater in men receiving the cholesterollowering diet. No data are available concerning regional pathology.

\section{MORBIDITY}

Cholecystectomies

The figures for cholecystectomy operations for gall 
stones shown in Table 16 confirm our own (Cooper et al., 1975) and other (Coronary Drug Project, 1975) reports that gall stone formation is an adverse effect of clofibrate therapy. Interestingly, the difference in incidence of cholecystectomy between Groups I and II appears to be greater, though not significantly, in the first 4 years of clofibrate treatment than later and does not increase with time. (Table 16 (ii)).

No attempt was made in the trial to determine the prevalence of gall stones, but clofibrate is known to decrease bile solubility leading to greater lithogenicity (Pertsemlidis et al., 1974). Diets with a high polyunsaturated/saturated fat ratio have also been reported to increase the incidence of gall stones (Sturdevant et al., 1973). Nicotinic acid also increases cholesterol saturation of bile and may increase the risk of gall stone formation (Leijd et al., 1978). Perhaps any procedure that promotes cholesterol excretion can lead to gall stone formation.

\section{Hypertension}

There were significantly fewer notifications $(P<$ $0.05)$ and withdrawals $(P<0.01)$ because of hypertension in Group I compared with Group II (Table 5). The explanation of this is not clear, though clofibrate may have prevented the development of hypertension in some patients. Support for this suggestion comes from the relatively weak relation in Group I between systolic or diastolic blood pressure at entry to the trial and the incidence of IHD. This might be expected if the beneficial effects of clofibrate were stronger than the adverse effects of developing hypertension as shown by the expected relation between blood pressure and prognosis in Group II. However, clofibrate did not appreciably lower blood pressure in Group I as a whole.

\section{Intermittent claudication}

There was no significant difference in the reported incidence of intermittent claudication. A clinical study, conducted without knowledge of treatment groups, confirmed that there was no difference between the groups in signs of peripheral arterial disease.

\section{Cardiac arrhythmias}

The incidence of cardiac arrhythmias was not significantly different in Groups I and II. Electrocardiograms, however, were recorded only from the time taken to complete a 12-lead record and not for longer periods for rhythm detection.

Cerebrovascular events

There was no significant difference in fatal or non- fatal cerebrovascular events between Groups I and II. The combined figures for the 3 Groups were 27, 23, 19.

\section{Thromboembolic events}

The slight excess in Group I compared with Group II of cases of non-fatal thromboembolism causing withdrawal from the trial $(7 v 2)$ was not reflected in an excess in fatal thromboembolism (4 and 4).

\section{Diabetes mellitus}

The apparent excess in Group I compared with Group II in 'diabetes mellitus requiring drug treatment' requires comment. Glucuronic acid, which can result from clofibrate glucuronide, can cause false positive urine tests but would not affect glucose tolerance tests. A special investigation during the terminal stages of the trial was carried out in Prague, which accounted for more than half of the cases. All men showing glycosuria in Prague had been referred to a department of diabetes for glucose tolerance tests and a decision regarding treatment, and possibly this accounted for part of the higher number of cases there. On final review a few cases were not confirmed. However, withdrawals at Budapest were also more numerous in Group I than Group II, though not significantly so.

These findings are puzzling in view of the number of published reports indicating that clofibrate has a beneficial effect on glucose tolerance and probably on insulin sensitivity (Barnett et al., 1977; Enger et al., 1977; Lithell et al., 1977). The latter two studies involved men with clinically latent diabetes discovered during a health screening programme and are, therefore, perhaps comparable with our own. The long-term effects of clofibrate treatment on diabetes in 50 hyperlipidaemic patients followed for 6 to 8 years were favourable (Berkowitz, 1971).

Withdrwals and reported side effects

Significantly more of the few men who were withdrawn from the trial for weight gain were in Group I than in Group II (Table 15), and significantly more men in Group I reported weight gain (Appendix 6). In fact, however, differences between mean weights during the trial for all men in the 2 groups were trivial. Impotence was also reported significantly more often by men in Group I than in Group II but no attempt has been made to establish its real incidence. Diabetes has been discussed above. Gastrointestinal symptoms and diarrhoea were also. reported significantly more commonly in Group I but were transient or quickly reversed on stopping medication.

TRIGLYCERIDES AND LIPOPROTEINS

The absence of analyses of serum triglycerides or of 
lipoprotein fractions at the start of the trial requires comment. This trial was initiated in the 3 centres between 1965 and 1968 and methods for serum triglyceride and lipoprotein analysis were still being devcloped at that time; automated systems for estimation of plasma lipids were not available to the centres at the start of the trial. The clinical importance of specific lipoprotein types was first described after the start of the trial (Frederickson et al., 1967) and internationally standardised by the World Health Organisation only in 1970. It is one of the fallibilities of long-term trials that methodology can improve to such an extent that the original design appears inadequate.

As mentioned earlier, serum triglycerides were measured in one centre only and the results confirm the well-known observation that clofibrate reduces serum triglycerides even more than serum cholesterol. It is particularly interesting that the concentrations in the treated group approximate to those in the low cholesterol control group. In view of the suggested importance of raised serum triglycerides as a risk factor for IHD (Brown et al., 1965; Carlson and Böttiger, 1972), their obvious reduction by clofibrate may also have contributed to the reduction of non-fatal IHD events.

\section{CHARACTERISTICS OF CONTROL GROUPS}

A low and a high cholesterol control group were included in the trial to provide additional means of appraising the response of the treatment group. For example, the importance to the community of changes in IHD incidence would be enhanced if the difference between treated and control high-risk groups was such that the incidence in the treated group approximated that of a low-risk control group. The inclusion of putatively high and low risk control groups also provides actual evidence for the community under study that the groups chosen do have a spectrum of risk.

The incidence of IHD in the high cholesterol control group was less than predicted. A degree of 'placebo response' is to be expected but this might not affect high and low risk groups equally. Attention to their health by attendance at clinics, blood tests, and the daily swallowing of capsules is likely to lead to 'correction' of more adverse habits in the group with the most adverse habits. Thus, the high cholesterol control group might be likely to alter the diet, stop their higher cigarette smoking, and increase physical activity more than the low cholesterol control group. Such changes could militate against being able to show highly significant differences compared with a treated high-risk group. Though we suspect that the rates in Group II for some major end-points not related to IHD and vascular events may be unrepresentatively low, this cannot be proved because the actual rates for these end-points are not known specifically for high cholesterol populations.

The men in Group III-as well as having lower serum cholesterol levels-were younger, lighter in weight, had lower blood pressure, and smoked less. As expected, their risk of IHD was relatively low. To some extent, the mortality figures for IHD for this group are reassuring when assessing the meaning of the differences between Groups I and II, and the age-standardised rates for deaths from causes other than IHD are more closely related in all categories to those for Group I rather than Group II.

\section{CONDUCT OF THE TRIAL}

From an early phase of the study, there was an unfavourable trend in mortality from all causes. By the end of 1972, this came near to the 10 per cent significance level on a sequential basis and the principal investigators were informed. During 1973, the figures improved somewhat, but by the end of 1974 the unfavourable trend in overall mortality was resumed though still not reaching the 10 per cent level. Because of this, and the fact that an interim assessment suggested that there were disappointing benefits in terms of the main objectives of the study-reduction of the incidence of all IHD events-the possibility was seriously considered in 1975 that the trial should be terminated prematurely and the findings reported.

It was agreed, however, that an intensive study should first be made into the deaths from cancer, as there was a suggestion at that time of an excess in the mortality figures in Group I. This involved a major investigation into available information on morbidity as well as mortality of men in the trial, and men who had left the trial, including reviews of all relevant clinical and necropsy records, searches of national and local cancer registers, and reappraisal of all the death certificate data. The results of this inquiry reported in Tables 12 and 13 and Fig. 6 are reassuring.

The investigators were agreed that premature closure of the trial and release of results was inadvisable until the special study of cancer was complete. Meanwhile, the adverse overall trend of mortality in Group I had continued and it neared the 5 per cent significance level late in 1976. By this time, the trial was already being closed and this process was accelerated.

These developments presented the investigators with difficult and anxious decisions and they emphasise that it is mandatory in such long-term trials to apply rigorous monitoring of all supposedly therapeutic regimens. 


\section{OTHER PRIMARY PREVENTION TRIALS}

The results of our study are in some accord with those of the only other published trial of the primary prevention of ischaemic heart disease using clofibrate. But this was an incompletely randomised study, not conducted 'blind', and the first report (Krasno and Kidera, 1972) has been severely criticised (Feinstein, 1972). The greater reduction in incidence of non-fatal myocardial infarction was associated with a reduction in serum cholesterol of $40 \mathrm{mg} / 100 \mathrm{ml}$ (L. R. Krasno, 1978, personal communication). This was achieved by a high degree of rapport between the physicians and the subjects, who were fully aware of their individual cholesterol levels.

The results of the only other large long-term primary prevention trial (Miettinen et al., 1972) are relevant to the findings of the present trial. Mean serum cholesterol reduction in middle-aged men and women in two mental hospitals, given a diet with polyunsaturated/saturated $(P / S)$ ratio of 1.42 to 1.73 on a cross-over design, ranged from 12 to 18 per cent compared with the control periods when they received a normal hospital diet. When the results for the treated groups were pooled, there was a significant reduction in IHD mortality $(P<0.02)$ : no data are available concerning morbidity. There are, however, weaknesses in the design and conduct of the Helsinki Mental Hospital Study and the authors refer carefully to some of these. Others have been emphasised by Halperin et al. (1973), who concluded that the data 'may not be of sufficient strength ... to establish the diet hypothesis and to draw the authors' conclusions'.

Another relevant carefully controlled long-term prevention trial is the Los Angeles Veterans Administration Study (Dayton et al., 1969). This used a double-blind design but was not exclusively a primary prevention study and included, as a minority, patients with pre-existing complications of atherosclerosis. It was conducted in an elderly male population and the effects of a diet high in polyunsaturated fats and low in saturated fats were compared with a control diet comprising fat calories mostly of animal origin. The difference in serum cholesterol between the treated and control groups was 12.7 per cent. There was no difference in the incidence of fatal events, whether sudden or not, but there was a 31 per cent decrease in nonfatal myocardial infarction. This was not statistically significant, but pooling of the data in all subjects (primary and secondary prevention) for all other vascular events, particularly cerebral infarction, showed significant reduction in the 8-year incidence rates in the diet group $(P=0.01)$. There were 85/424 deaths resulting from non-athero- sclerotic causes in the diet group and 71/422 in the control group.

\section{SECONDARY PREVENTION TRIALS USING CLOFIBRATE}

The results in terms of IHD of secondary prevention diet and drug trials are not directly relevant to those of this trial and to the primary prevention trials briefly described above, because the natural history of the development of IHD has probably already been determined by the occurrence of myocardial infarction and because of the inevitable selection of the populations studied. But brief mention is made of non-cardiovascular deaths in the only two which used clofibrate.

In the Coronary Drug Project (1975), the percentages (based on 5-year rates) who died from a non-cardiovascular event was $2 \cdot 1$ in the clofibratetreated group, 2.1 in the nicotinic acid-treated group, and 1.5 in the placebo group. Cancer deaths were equally distributed, giving a slight excess of non-cardiovascular and non-cancer deaths in the treated groups $(1.5 \%$ and $1.5 \%)$ over the placebo group $(0.9 \%)$; the slight and non-significant excess in the clofibrate group only became evident during the seventh year of treatment.

The secondary prevention trials using clofibrate (Physicians of the Newcastle-upon-Tyne Region, 1971; Research Committee of the Scottish Society of Physicians, 1971) did not give any data concerning non-cardiovascular deaths.

\section{GENERAL COMMENTS}

Clofibrate produced only a modest reduction in the mean serum cholesterol level and this was matched by a similarly modest but significant reduction in the number of IHD events, confined to non-fatal myocardial infarcts. There are a number of factors which might have militated against a more striking preventive effect than shown by this trial.

(1) Reduction of plasma lipids might have been too small.

(2) The partial control of one risk factor might not be expected to produce a significant yield in the face of persistence of other risk factors.

(3) The duration of lipid lowering might not have been long enough to influence long-standing coronary artery disease.

(4) Reduction of plasma lipids might have been started too late in life.

(5) Adherence to treatment might have been incomplete, though plasma levels of clofibrate do not suggest this. It is widely assumed and is part of the basis of many national health education campaigns that a greater reduction in serum cholesterol would be associated with a greater effect on IHD incidence. 
But this is difficult to achieve. Unfortunately, there is a sharp division in experience between those who treat patients or individuals through the aegis of a major hospital or lipid clinic, where it is possible to achieve good control of raised plasma lipids, and those who have attempted to control them over long periods in the community. Perhaps it is realistic to conclude that only partial control is readily obtainable in any setting other than one where there is close and regular surveillance, and that this may not be enough.

The excess in total mortality has much concerned us. The mortality from diseases of the liver, biliary tract, and intestines may be a fortuitous association, and, indeed, the number of deaths involved is small, but it could also be due either to clofibrate itself or relate to the effects of the drug in promoting excretion of sterols by way of these tissues. If this speculation is true, the implications for other lipidlowering regimens are plain. Attention should be paid, therefore, to the possiblity of pathology arising in these tissues with the long-term administration of other regimens that promote excretion of bile sterols.

The investigators are grateful to the men who have participated in this long trial for their willing and patient co-operation.

The trial has been supported in all centres by the World Health Organisation. Additional support came, in Budapest and Prague, from the respective Ministries of Health, and, in Britain, from the Medical Research Council (through the Social Medicine Unit), the University of London (through the London School of Hygiene and Tropical Medicine and the Royal Free Hospital School of Medicine), the University of Edinburgh, the British Heart Foundation, and the Albert D. Lasker Foundation of New York City. The capsules containing the drug and the placebo were manufactured, supplied and distributed free by Imperial Chemical Industries, Pharmaceutical Division, Macclesfield, England.

We also thank the examining physicians and the technical, computing, and clerical staff in each centre. Examining physicians, other than the investigators listed earlier, were: Budapest-A. Fejér, A. Jánosi, A. Káli, A. Kucsera, P. Ofner, Z. Tarján; Edinburgh-M. Cooke, A. Davidson, M. Fulton, A. Hall, A. McDonald, D. C. Macmillan, M. Smith, G. Vaughan; Prague-K. Andrýsová, O. Balcarová, B. Bedriněc, M. Dvorák, J. Janda, M. Jeř́ábek, Z. Petržílková, H. Pistulková, M. Santruček, H. Schneibergová, I. Stolz.

The names of technical, computing, and clerical ..staff are available on request (Addendum $F$ ).

\section{References}

Armitage, P. (1957). Restricted sequential procedures. Biometrika, 44, 9-26.

Barnett, D., Craig, J. G., Robinson, D. S., and Perenna Rogers, M. (1977). Effect of clofibrate on glucose tolerance in maturity onset diabetes. British fournal of Clinical Pharmacology, 4, 455-458.

Barrett, A. M., and Thorp, J. M. (1968). Studies on the mode of action of clofibrate. British fournal of Pharmacology and Chemotherapy, 32, 381-391.

Berkowitz, D. (1971). Long-term treatment of hyperlipidemic patients with clofibrate. Fournal of the American Medical Association, 218, 1002-1005.

Blackburn, H., Keys, A., Simonson, E., Rantaharju, P., and Punsar, S. (1960). The electrocardiogram in population studies. A classification system. Circulation, 21, 1160-1175.

Breslow, N. E. (1975). Analysis of survival data under the proportional hazards model. International Statistical Review, 43, 45-58.

Brown, D. F., Kinch, S. H., and Doyle, J. T. (1965). Serum triglycerides in health and in ischaemic heart disease. New England fournal of Medicine, 273, 947-952.

Carlson, L. A., and Böttiger, L. E. (1972). Ischaemic heart disease in relation to fasting values of plasma triglycerides and cholesterol. Lancet, 1, 865-868.

Cooper, J., Geizerova, H., and Oliver, M. F. (1975). Clofibrate and gallstones. Lancet, 1, 1083.

Coronary Drug Project Research Group (1975). Clofibrate and niacin in coronary heart disease. Fournal of the American Medical Association, 231, 360-381.

Cox, D. R. (1972). Regression models and life-tables. fournal of the Royal Statistical Society, Series B, 34, 187-220.

Dayton, S., Pearce, M. L., Hashimoto, S., Dixon, W. J., and Tomiyasu, U. (1969). A controlled clinical trial of a diet high in unsaturated fat in preventing complications of atherosclerosis. Circulation, 39 and 40, Suppl. II, 1-63.

Dewar, H. A., and Oliver, M. F. (1971). Secondary prevention trials using clofibrate: a joint commentary on the Newcastle and Scottish trials. British Medical fournal, 4, 784-786.

Ederer, F., Leren, P., Turpeinen, O., and Frantz, I. D., Jr. (1971). Cancer among men on cholesterol-lowering diets. Lancet, 2, 203-206.

Einarsson, K., Hellström, K., and Leijd, B. (1977). Bile acid kinetics and steroid balance during nicotinic acid therapy in patients with hyperlipoproteinemia types II and IV. Fournal of Laboratory and Clinical Medicine, 90, 613-622.

Enger, S., Johnsen, V., Samuelsen, A., and Laws, E. A. (1977). The effect of clofibrate on glucose tolerance, insulin excretion, triglycerides and fibrinogen in patients with coronary heart disease. Acta Medica Scandinavica, 201, 563-566.

Feinstein, A. R. (1972). Clinical biostatistics XVIII. The clofibrate trials: another dispute about contratrophic therapy. Clinical Pharmacology and Therapeutics, 13, 953-968.

Frederickson, D. S., Levy, R. I., and Lees, R. S. (1967). Fat transport and lipoproteins-an integrated approach to mechanisms and disorders. New England fournal of Medicine, 276, 34-44; 94-103; 148-156; 215-225; 273-281.

Grundy, S. M., Ahrens, E. H., Salen, G., Schreibman, B. H., and Nestel, P. F. (1972). Mechanisms of action of clofibrate on cholesterol metabolism in patients with hyperlipidemia. Fournal of Lipid Research, 13, 531-551.

Halperin, M., Cornfield, J., and Mitchell, S. C. (1973). Effect of diet on coronary heart disease mortality. Lancet, 2 , 438-439.

Heady, J. A. (1973). A co-operative trial on the primary prevention of ischaemic heart disease using clofibrate: design, methods and progress. Bulletin of the World Health Organization, 48, 243-256. 
Heady, J. A. (1974). Management of studies in chronic disease. In Proceedings of the 8th International Biometric Society Conference, Constanza, Romania, pp. 245-255. Editura Academiei Republicii Socialiste România, Bucharest.

Hill, M. J. (1977). Bacterial metabolism. In Topics in Gastroenterology, 5, pp. 45-64. Ed. by S. C. Truelove and E. Lee. Blackwell, Oxford.

Hill, M. J., Drasar, B. S., Williams, R. O., Meade, T. W., Cox, A. G., Simpson, J. E. T., and Morson, B. C. (1975) Faecal bile acids and clostridia in patients with cancer of the large bowel. Lancet, 1, 535-538.

Kannel, W. B., Dawber, T. R., Friedman, G. D., Glennon, W. E., and MacNamara, P. M. (1964). Risk factors in coronary heart disease: an evaluation of several serum lipids as predictors of coronary heart disease. Annals of Internal Medicine, 61, 888-899.

Kannel, W. B., Doyle, J. T., MacNamara, P. M., Quickenton, P., and Gordon, T. (1975). Precursors of sudden death. Factors related to the incidence of sudden death. Circulation, 51, 606-613.

Kessler, G., and Lederer, H. (1965). Automation in Analytica Chemistry, p. 341. L. T. Skeggs, New York.

Keys, A., Aravanis, C., Blackburn, H., van Buchem, F. S. P. Buzina, R., Djordjevik, B. S., Fidanza, F., Karvonen, M., Menotti, A., Puddu, V., and Taylor, H. L. (1972). Probability of middle-aged men developing coronary heart disease in five years. Circulation, 45, 815-828.

Krasno, L. R., and Kidera, G. J. (1972). Clofibrate in coronary heart disease: effect on morbidity and mortality. Fournal of the American Medical Association, 219, 845-851.

Leijd, B., Angelin, B., and Einarsson, K. (1978). Biliary lipid composition during treatment with hypolipidaemic drugs. In Proceedings of 6th International Symposium on Drugs Affecting Lipid Metabolism. Ed. by D. Kritchevsky and W. Holmes. Plenum Press, New York (in press).

Lithell, E., Boberg, J., Hedstrand, H., Hellsing, K., Ljunghall, S., and Vessby, B. (1977). Effect of clofibrate on glucose tolerance, serum insulin, serum lipoproteins and plasma fibrinogen. European fournal of Clinical Pharmacology, 12, 51-57.

Mantel, N. (1966). Evaluation of survival data and two new rank order statistics arising in its consideration. Cancer Chemotherapy Reports, 50, 163-170.

Medalie, J. H., Kahn, H. A., Neufeld, H. N., Riss, E., Goldbourt, U., Perlstein, T., and Oron, D. (1973). Myocardial infarction over a five-year period-I. Prevalence, incidence and mortality experience. Fournal of Chronic Diseases, 26, 63-84.

Miettinen, M., Turpeinen, O., Karvonen, M. J., Elosuo, R., and Paavilianen, E. (1972). Effect of cholesterol-lowering diet on mortality from coronary heart disease and other causes. A 12 year clinical trial in men and women. Lancet, 2, 835-838.

Oliver, M. F. (1962). Reduction of serum-lipid and uric-acid levels by an orally active androsterone. Lancet, 1, 1321-1323.

Pertsemlidis, D., Panveliwalla, D., and Ahrens, E. H., Jr. (1974). Effects of clofibrate and of an estrogen-progestin combination on fasting biliary lipids and cholic acid kinetics in man. Gastroenterology, 66, 565-573.

Physicians of the Newcastle-upon-Tyne Region (1971). Trial of clofibrate in the treatment of ischaemic heart disease. British Medical Fournal, 4, 767-774.

Research Committee of the Scottish Society of Physicians (1971). Ischaemic heart disease: a secondary prevention trial using clofibrate. British Medical fournal, 4, 775-784.

Rose, G. A., and Blackburn, H. (1968). Cardiovascular survey methods. World Health Organization. Monograph Series, No. 56.

Sturdevant, R. A. L., Pearce, M. L., and Dayton, S. (1973). Increased prevalence of cholelithiasis in men ingesting a serum cholesterol lowering diet. New England fournal of Medicine, 288, 24-27.

Symposium on Atromid (1963). Fournal of Atherosclerosis Research, 3, 341-755.

Thorp, J. M. (1962). Experimental evaluation of an orally active combination of androsterone with ethyl chlorophenoxyisobutyrate. Lancet, 1, 1323-1326.

Thorp, J. M., and Waring, W. S. (1962). Modification of metabolism and distribution of lipids by ethyl chlorophenoxyisobutyrate. Nature, 194, 948-949.

Walker, S. H., and Duncan, D. B. (1967). Estimation of the probability of an event as a function of several independent variables. Biometrika, 54, 167-179.

World Health Organization (1961). Chronic Cor Pulmonale, Report of an Expert Committee. World Health Organization. Technical Report Series, No. 213.

World Health Organization (1962). Arterial Hypertension and Ischaemic Heart Disease: Preventive Aspects, Report of an Expert Committee. World Health Organization. Technical Report Series, No. 231.

World Health Organization (1968). Exercise Tests in Relation to Cardiovascular Function, Report of a WHO meeting. World Health Organization. Technical Report Series,. No. 388.

World Health Organization (1970). Classification of hyperlipidaemias and hyperlipoproteinaemias. Bulletin of the World Health Organization, 43, 891-915.

Requests for reprints to Professor M. Oliver, Department of Cardiology, The Royal Infirmary, Edinburgh EH3 9YW. Requests for Addenda ${ }^{1}$ to $\mathrm{Dr}$ J. A. Heady, Department of Clinical Epidemiology, The Royal Free Hospital, 21 Pond Street, London NW3 2PN.

\section{${ }^{1}$ LIST OF ADDENDA AVAILABLE ON REQUEST:}

A. Clinical data forms and questionnaires

B. Serum cholesterol methods

C. Centre differences

D. Population at risk by 5-year age-group and centre

E. Deaths more than one year out of trial

F. List of technical, computing, and clerical staff 


\section{LIST OF APPENDICES}

1. Criteria for rejection and withdrawal

2. Statistical methods

3. Definition of end-points

4. Centre differences

5. Drug adherence

6. Conditions not necessarily causing withdrawal but recorded as possible side-effects

\section{APPENDIX 1}

CRITERIA FOR REJECTION AND WITHDRAWAL

\section{Rejection from Entry into the Trial}

1. History of treated myocardial infarction with ECG signs (see $2 \mathrm{a}$ and $\mathrm{b}$ below) and/or enzyme changes (using local methods and standards). Previous ECG and hospital records must be examined. An unsubstantiated history of myocardial infarction is not a cause for rejection.

2. ECG evidence of heart disease (Minnesota code system):

(a) ECG evidence of myocardial infarction or widespread myocardial ischaemia; i.e. category 1-1, 1-2, 4-1, 5-1, 6-1 or 9-6 (as defined).

(b) Complete left bundle branch block: 7-1.

(c) "Lone" atrial fibrillation or flutter.

(d) Multiple (more than 4 in 12 complexes) or bifocal ventricular extrasystoles.

3. Systemic hypertension:

(a) A diastolic blood pressure of 120 or greater on any one occasion.

(b) A diastolic blood pressure of 110-119 on any two occasions.

(c) A diastolic blood pressure of 110-119 on any one occasion if accompanied by ECG signs of left ventricular hypertrophy, or strain; i.e. 3-1, or $3-3+5-2$ or $+5-3$.

(d) If the diastolic blood pressure is within the accepted limits but only on account of treatment with antihypertensive drugs and the ECG shows signs of left ventricular hypertroply or strain; i.e. $3-1$, or $3-3$ $+5-1$ or $+5-2$ or $+5-3$.

4. Clinical evidence of rheumatic heart disease.

5. Congenital heart disease.
6. Pulmonary heart disease - as defined by the World Health Organisation (1961). Chronic bronchitis, emphysema or kyphoscoliosis when associated with ECG signs of right ventricular hypertrophy or strain $2-2,3-2,7-2$ and $7-3$.

7. Other heart disease associated with cardiomegaly or heart failure.

8. Diabetes mellitus requiring drug treatment.

9. Co-existing disease with an unfavourable prognosis reducing likelihood of completion of trial:

(1) Malignant disease.

(2) Residual paralysis due to cerebral damage with or without hypertension.

(3) Chronic advanced renal disease with systemic manifestations.

(4) Cirrhosis of liver with systemic manifestations.

A positive answer to the effort chest pain questionnaire alone or coronary insufficiency (as defined) are not indications for rejection.

Withdrawal after Admission to the Trial

1. Myocardial infarction - see "Definition of end-points" in Appendix 3.

2. Hypertension - as for the criteria for rejection, until November 1973. Thereafter hypertensive men were kept in the trial and treated where necessary.

3. Other heart disease - which has previously not been recognised - as defined under rejection criteria 5 , 6 and 7.

4. Diabetes mellitus - requiring drug treatment.

5. Contraindications for taking capsules :

(a) Side-effects which cannot be tolerated by individual.

(b) Infective hepatitis and cirrhosis.

(c) Advanced renal disease.

(d) Agranulocytosis or thrombocytopenic purpura. 
APPENDIX 2

STATISTICAL METHODS

Incidence and Mortality Rates are expressed per 1000 per annum i.e. as

$$
\frac{\text { the number of new events (or deaths) }}{\text { man-years of exposure }} \times 1000
$$

Man-years of exposure were calculated separately, for each man, as the time, in years and fractions of a year, from admission to withdrawal from the trial for in-trial rates, and from admission to withdrawal +1 year for rates of events occurring in the trial or within one year after withdrawal.

Date of Withdrawal was defined as the date of the last trial visit for men who were in the trial when it stopped, but otherwise as the date of the event which removed the man from the trial - e.g. death, myocardial infarction, withdrawal for medical reasons, or of explicitly "opting out". For men who were "lost to follow-up" the date was taken as 9 months from the date of the last trial visit, during the period when visits were at 6-monthly intervals, and as $1 \frac{1}{2}$ years from the date of the last trial visit in the period when visits were at 12-monthly intervals. As stated in the text, a similar principle was adopted for deciding whether a death occurred "in the trial" or "out of the trial".

Age-standardisation was by simple averaging of the death-rates in five-year age-groups. "Al1-centre" rates were standardised over the range 40-59 years, but because there were only 57 men aged 54-59 on admission in Prague (Addendum D), indiviciual centre rates were standardised over the range 40-54 years, thus enabling them to be compared.

This method of standardisation was adopted, after much discussion, as the simplest and clearest way of dealing with a situation made difficult by the difference in age-structure of the trial populations in the several centres. The use of equal weights for the 5-year age-groups corresponded reasonably closely with the age-distributions of the populations from which the men were drawn (as opposed to the trial populations) in each centre. Any more detailed weighting system (e.g. by centre and age distributions of the trial population) would have produced very variable rates in the individual cells and thus high standard errors. This also was one of the main reasons for excluding from the age- standardisation deaths in the range 30-39. The other reason was the absence of any men in Prague in this age-range.

Life Table The life-table data are calculated by standard methods, using intervals of 1 year from admission. The tests of significance between survivorship curves is a $X^{2}$ test with 1 degree of freedom and follows the approach of Mantel (1966) and Cox (1972), using a constant hazard rates model. That is to say it tests the difference between the shapes of the entire curves rather than the percentage surviving at a particular period after admission. In this it is similar to the log-rank test but uses grouped intervals rather than precise times.

The following tables give the percentages free from various events at different stages in the study, calculated on a 1 ifetable basis and shown in Figures 2 and 5 or mentioned in the text, togetiner with the standard errors of these rates and the results of the overall tests of significance.

Significance tests . The significance of the difference between the numbers of events in Groups I and II were calculated by the binomial formula on the expectation that they should be equal. Slight differences in numbers exposed to risk were ignored.

In comparing standarised rates the variance of the standardised rate was assumed to be the sum of the variances in the separate 5-year age-groups, appropriately weighted. Thus, for standardisation at ages 40-59, let $r_{i}$ be the rate and $d_{i}$ the number of events in age-group $i$, where $i=1,2,3,4$, corresponding to ages $40-44,45-49,50-54,55-59$, respectively. The variance of $r_{i}$ was taken to be approximately $r_{i}{ }^{2} / d_{i}$. The standardised rate is, thus, $\frac{1}{4} \sum_{i=1}^{k} r_{i}$

and its variance $\frac{1}{16} \sum r_{i}{ }^{2} / d_{i}$

Formulae for Cholesterol Change Let $c_{1 X}$ indicate the serum cholesterol level of a man in Group I at the xth visit, and $C_{\text {2p }}$ the mean of his pre-treatment cholesterol levels. Let $c_{2 x}$ and $c_{2 p}$ be the corresponding values for a man in Group II. Let $\bar{c}_{2 x}$ be the mean of the serum cholesterol levels at the $x$ th visit for all men in Group II in the same centre, and $\bar{c}_{2 p}$ the corresponding mean of pre-treatment cholesterol levels. 
Life Table. "Survivorship" Data

The figures are percentages free of the event indicated \pm the standard error of this percentage.

\begin{tabular}{|c|c|c|c|c|c|c|c|c|c|}
\hline \multirow{3}{*}{$\begin{array}{c}\text { Years } \\
\text { in } \\
\text { Trial }\end{array}$} & \multicolumn{9}{|c|}{ IN-TRIAL } \\
\hline & \multicolumn{3}{|c|}{ A11 I.H.D. } & \multicolumn{3}{|c|}{ Fatal I.H.D. } & \multicolumn{3}{|c|}{ Non-fatal I.H.D. } \\
\hline & I & II & III & I & II & III & I & II & III \\
\hline 0 & 100 & 100 & 100 & 100 & 100 & 100 & 100 & 100 & 100 \\
\hline 1 & $99.5 \pm 0.10$ & $99.4 \pm 0.11$ & $99.9 \pm 0.05$ & $99.9 \pm 0.05$ & $99.9 \pm 0.03$ & $99.9 \pm 0.03$ & $99.6 \pm 0.08$ & $99.5 \pm 0.10$ & $99.9 \div 0.04$ \\
\hline 2 & $98.9^{+}-0.15$ & $98.7+0.16$ & $99.6 \pm 0.09$ & $99.7 \pm 0.07$ & $99.8 \pm 0.06$ & $99.9 \pm 0.04$ & $99.1 \pm 0.13$ & $98.8 \pm 0.15$ & $99.6 \pm 0.09$ \\
\hline 3 & $98.3^{+}-0.19$ & $98.2 \pm 0.19$ & $99.3 \div 0.12$ & $99.6-0.09$ & $99.7 \pm 0.08$ & $99.9 \pm 0.05$ & $98.7 \pm 0.16$ & $98.5 \pm 0.18$ & $99.5 \pm 0.11$ \\
\hline 4 & $97.9 \pm 0.21$ & $97.3 \div 0.24$ & 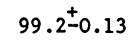 & $99.6 \pm 0.10$ & $99.6 \pm 0.10$ & $99.8 \pm 0.07$. & $98.3 \pm 0.19$ & $97.8 \pm 0.22$ & $99.4 \div 0.12$ \\
\hline 5 & $97.3 \pm 0.24$ & $96.7 \pm 0.27$ & $99.0 \pm 0.15$ & $99.5-0.11$ & $99.4 \pm 0.11$ & $99.7 \pm 0.08$ & $97.9 \pm 0.22$ & $97.2 \pm 0.24$ & $99.3 \pm 0.13$ \\
\hline 6 & $96.8 \pm 0.27$ & $95.7 \pm 0.31$ & $98.8 \pm 0.17$ & $99.3 \pm 0.13$ & $99.3 \pm 0.13$ & $99.7 \pm 0.08$ & $97.4 \pm 0.24$ & $96.4 \pm 0.29$ & $99.0 \pm 0.15$ \\
\hline 7 & $95.8 \pm 0.35$ & $94.8 \pm 0.37$ & $98.3 \pm 0.23$ & $99.0 \pm 0.17$ & $99.2 \pm 0.16$ & $99.5-0.14$ & $96.7 \pm 0.31$ & $95.6 \pm 0.35$ & $98.8 \pm 0.19$ \\
\hline 8 & $95.1 \pm 0.46$ & $94.0 \pm 0.50$ & $98.1 \pm 0.28$ & $99.0 \pm 0.17$ & $99.0 \pm 0.21$ & $99.5 \pm 0.14$ & $96.0 \pm 0.44$ & $94.9 \pm 0.46$ & $98.6 \pm 0.24$ \\
\hline $\begin{array}{c}\text { Comparison } \\
\text { of } \\
\text { Groups }\end{array}$ & \multicolumn{2}{|l|}{$x^{2}$} & P & \multicolumn{3}{|c|}{$x^{2}$} & \multicolumn{3}{|c|}{$x^{2}$} \\
\hline$I \& I I$ & \multicolumn{2}{|c|}{4.583} & & \multicolumn{2}{|c|}{0.056} & 0.05 & \multicolumn{2}{|c|}{6.173} & $<0.05$ \\
\hline I \& III & \multicolumn{2}{|c|}{52.787} & .01 & \multicolumn{2}{|c|}{7.280} & 0.01 & \multicolumn{2}{|c|}{46.522} & $<0.01$ \\
\hline II \& III & \multicolumn{2}{|c|}{94.363} & .01 & & 45 & 0.05 & 94. & $<$ & 0 \\
\hline
\end{tabular}

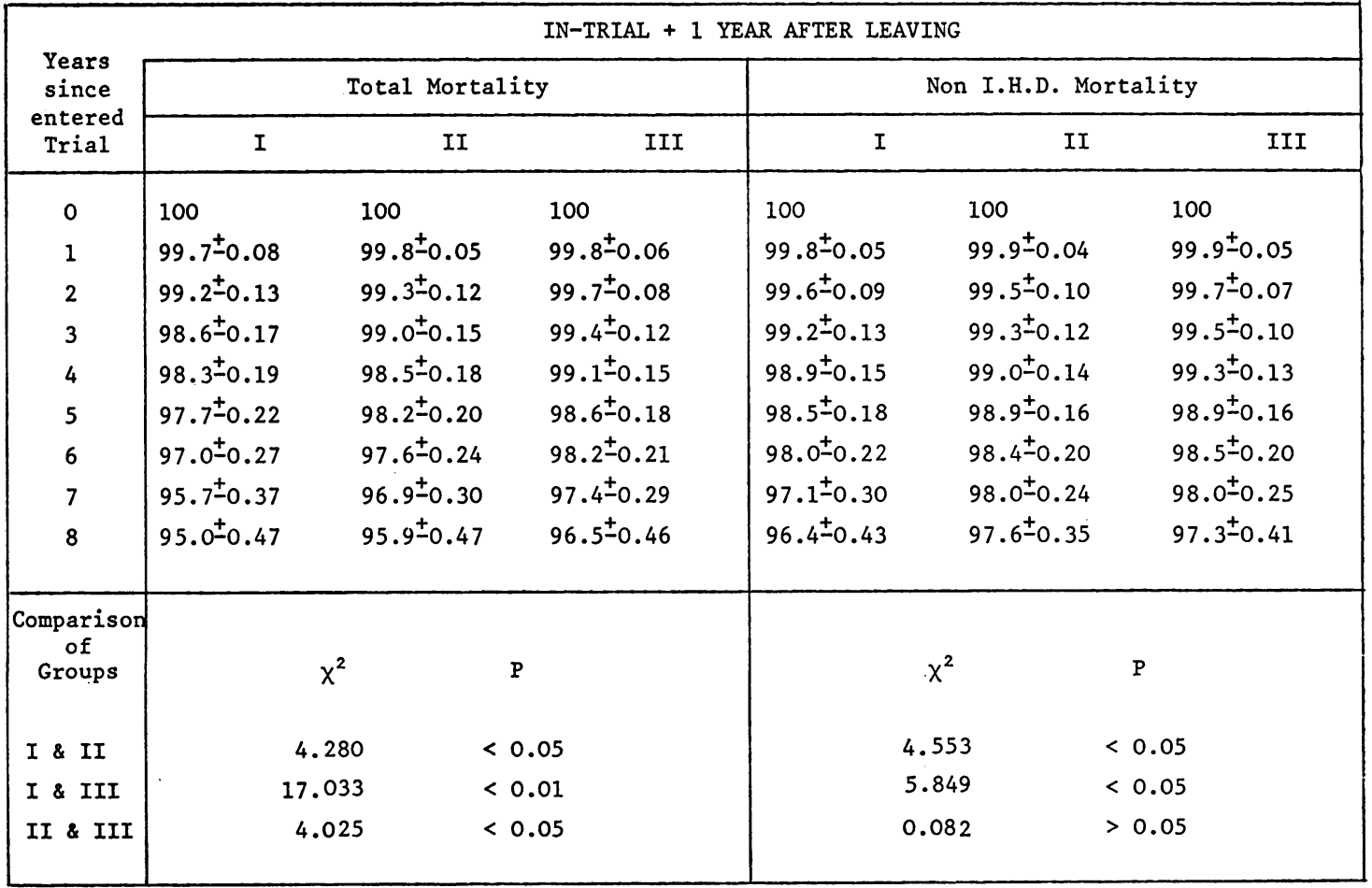


Then the mean percentage change at the $x$ th visit in all the men in that centre in Group II is

$$
\frac{\bar{c}_{2 p}-\bar{c}_{2 x}}{\bar{c}_{2 p}} \times 100,
$$

and the cholesterol change at the xth visit of an individual in Group $I$ is

$$
\frac{c_{1 p}-c_{1 x}}{c_{1 p}} \cdot \times 100
$$

Thus the man's cholesterol change at visit $\mathrm{x}$ as defined in the text is

$$
\left[\frac{c_{1 p}-c_{1 x}}{c_{1 p}}-\frac{\bar{c}_{2 p}-\bar{c}_{2 x}}{\bar{c}_{2 p}}\right]
$$

or

$$
\left[\frac{\bar{c}_{2 x}}{\bar{c}_{2 p}}-\frac{c_{1 x}}{c_{1 p}}\right] 100
$$

The man's mean cholesterol change (or response) is the mean of this function for all the man's visits from the second onwards.

Individual changes in Groups II and III, similarly defined in terms of the mean change in Group II are:-

$$
\left[\frac{\bar{c}_{2 x}}{\bar{c}_{2 p}}-\frac{c_{2 x}}{c_{2 p}}\right] 100 \text { and }\left[\begin{array}{c}
\bar{c}_{2 x} \\
\frac{c_{3 x}}{\bar{c}_{2 p}}
\end{array}\right]
$$

by obvious extension of the notation to Group III.

Sjmilarily mean changes (over all men at a given centre, at visit $x$ ) in Groups I and III were defined as

$$
\left[\frac{\bar{c}_{2 x}}{\bar{c}_{2 p}}-\frac{\bar{c}_{1 x}}{\bar{c}_{1 p}}\right] 100 \text { and }\left[\begin{array}{l}
\bar{c}_{2 x} \\
\frac{\bar{c}_{2 p}}{\bar{c}_{3 x}} \\
\bar{c}_{3 p}
\end{array}\right] 100
$$

respectively.

\section{Mean In-trial Cholesterol Level The mean level (for all men} in a treatment Group at a given centre and visit) in Groups I and III was derived by applying to the mean pre-treatment level the mean percentage change figure, derived as above to allow for changes in the average-value of cholesterol levels from time to time in Group II. For Group II the observed levels were used.
These values were then averaged over all visits to give a mean in-trial cholesterol level for that Group and centre.

In order to be able to use the same scale of cholesterol values a further correction was made to adjust for initial differences between centres in the pre-treatment cholesterol levels. (As has been stated, the results of the exchange of serum samples shows that differences between centres in observed values were mainly methodological.)

This correction was made as follows:-

A single factor, $f$, was derived for each of the two centres (Budapest and Prague) relating its mean values to those for Edinburgh.

$$
f=\frac{2 x_{1}+x_{3}}{2 y_{1}+y_{3}}
$$

where $x_{1}, y_{2}=$ are the mean pre-treatment levels, at ages 4059 for the combined Groups I and II for the centre $\left(x_{1}\right)$ and for Edinburgh $\left(y_{1}\right)$

and $x_{3}, y_{3}=$ are the mean pre-treatment levels, at ages 4059 for Group III for the centre $\left(x_{3}\right)$ and for Edinburgh $\left(y_{3}\right)$

The values of $f$ were 0.948 for Budapest and 0.874 for Prague and were used throughout to convert centre values to a common scale where this was required - e.g. in Figure 4, or in the multivariate analysis. These figures were also used to denote the "all.centres" figures in the bottom line of Table 7 .

\section{Sequential Scheme for Monitoring of Results It was agreed} that the results of the trial should be released to the principal investigators if, according to the sequential diagram in Appendix 2, Figure 1, a path crossed the line SVX indicating a result in favour of the treatment: or if one crossed the line $M N$, the early warning line, indicating a result against the treatment or if a line crossed $\mathrm{NX}$ representing a nonsignificant result. Any of these would be reported in the first instance to the Committee of Principal Investigators who would decide, on the basis of this and other information, whether the result should be further divulged and whether the trial should be stopped. This scheme applied to any class of event - e.g. all deaths, deaths from ischaemic heart disease, I.H.D., or any adverse side-effect. 


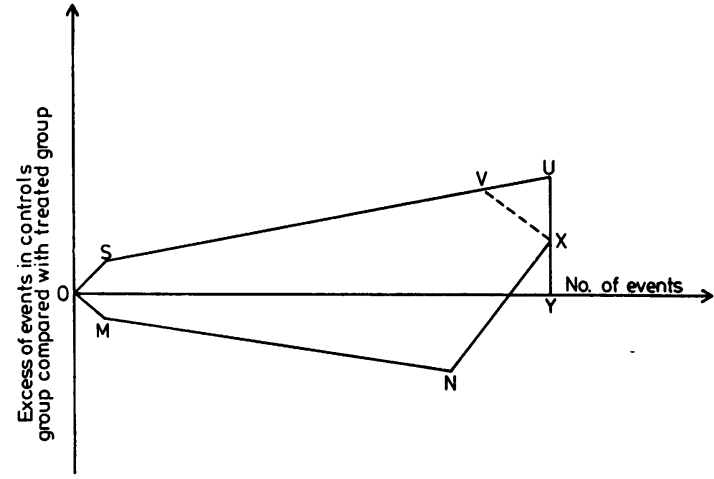

Appendix 2: Fig. 1 Excess of events in control group compared with treated group.

The line SVU is taken from Armitage's set of closed sequential designs (Armitage, P. 1957, Biometrika, 44, 9-26) with $2 \alpha=$ $0.01, \beta=0.90$ and set to detect a 1.5:1 difference. The line MN is taken from the same set of designs, but with $2 \alpha$ $=0.10, \beta=0.90$ and set to detect the same difference. The point $Y$ is set at 400 events, chosen to give a fixed sample result with $2 \alpha=0.01$ and $\beta=0.90$ and able to detect a 1.5:1 difference and $X$ is the point on the line $Y U$ such that any path which cuts $\mathrm{YU}$ above $\mathrm{X}$ gives a significant result. $V X$ is at $45^{\circ}$ to the vertical so that any path which cuts VX must cut YU above $X . \quad X N$ is also at $45^{\circ}$ to the vertical so that no path which cuts $\mathrm{NX}$ can cut $\mathrm{YU}$ above $\mathrm{X}$ (and thus give a significant result).

The characteristics of this scheme are as follows:

(1) Effective (two-sided) significance level for a favourable result - 1.4\% (347).

(2) Effective (two-sided) significance level for an unf avourable result -9.47 (347).

(3) Power to detect an actual reduction of $33 \%$ in incidence in the treated group - 93\% (218).

(4) Power to detect an unfavourable result of the same magnitude $-91 \%$ (110).

The figures in brackets are the median number of events required before a decision is reached (Heady, 1974).

Multivariate Analysis

The multiple logistic model was used (Walker \& Duncan, 1967) the end-points being either any episode of major I.H.D., of non-fatal myocardial infarction or of fatal I.H.D., or death from causes other than I.H.D.

The following variables were used in the equations:$$
\begin{aligned}
& \text { Var } \\
& \text { Log } \\
& \text { Smo } \\
& \text { Tre }
\end{aligned}
$$ \\ Fat}


of the different units used in comparing results with other studies and in assessing the relative importance of the variables in any one equation standardised $\beta^{\prime}$ 's should be used. They are derived by multiplying the $\beta$ 's by the standard deviation of the variables. In Tables 8 and 10, comparisons (e.g. between different sub-groups of high and low levels of 'risk' factors) have been based on the 'expected' incidence of events for a given set of baseline characteristics using the data derived from GroupII. Thus, for example, the expected probability of an individual experiencing (over the duration of the study) a given event (e.g. any I.H.D.), based on the data from Group II, would use the coefficients and intercept shown at No. 1 of the Table. The sum of such 'risk scores' for each individual in any group or sub-group, provides an estimate of the total number of specified events to be expected from the independent contributions of each of the baseline characteristics. This figure, because of the exponential distribution of individual risk scores, (and the iterative fitting procedure), overestimates (by $3-5 \%$ ) the true incidence, and derived values have been corrected accordingly.

In the example quoted above, the calculated 'risk score' for I.H.D. of two individuals with the following baseline characteristics:

\begin{tabular}{|c|c|c|c|c|c|}
\hline & Age & Smoking & Father & Systolic BP & Cholesterol \\
\hline A: & 40 & 0 & Alive & 125 & 220 \\
\hline B: & 55 & + & Dead & 160 & 260 \\
\hline
\end{tabular}

$$
\text { would be:- } \begin{aligned}
p(A) & =0.0072 \\
p(B) & =0.1324
\end{aligned}
$$

Where $p=$

$$
=\frac{1}{1+e^{-\left(\alpha+\sum \beta_{i} x_{i}\right)}}
$$

$x_{i}=$ value for each of $i$ baseline characteristics

$B_{i}=$ regression coefficient for baseline characteristic $x_{i}$

$\alpha=$ Intercept
In this (very limited) example the sum of the risk scores (which should be multiplied by the appropriate factor) gives the (uncorrected) expected total number of events (0.1396) expected to occur if there had been no effect of intervention.

\section{Results from other studies}

The unstandarised coefficients $(\beta)$ for serum cholesterol in multivariate equations for the "prediction" of ischaemic heart disease from three other published studies are given below. In each study, men previously free of ischaemic heart disease have been followed for a number of years. These coefficients should be compared with the corresponding value from the first line of the. Table in this Appendix. i.e, 0.008 .

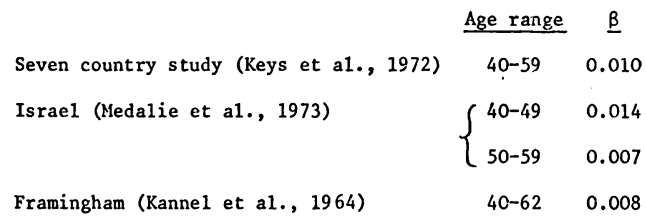

A cholesterol reduction of $9 \%$ (the mean value observed in this study) would correspond to a reduction of $20 \%$ in the incidence of I.H.D. if $\beta$ is 0.10 , to $16 \%$ if $\beta$ is 0.008 , and to $24 \%$ if $\beta$ is 0.014 .

It will be seen that the range of values of $\beta$ quoted above is similar to the range seen in the first 7 lines of the Table in this Appendix where the equations for different combinations of treatment groups and variables included in the equations are shown.

\section{Acknowledgement}

The help and advice of Mr. David Clayton lately of the Department of Clinical Epidemiology and Social Medicine of the Royal Free Hospital School of Medicine in connection with the technical aspects of the life-table and multivariate analysis is gratefully acknowledged. The test of significance in the life table analysis was developed by him, and he wrote the associated computer programme as well as the programme to handle the multivariate analysis. In both respects his statistical advice was also invaluable. 


\begin{tabular}{|c|c|c|c|c|c|c|c|c|c|c|}
\hline No. & End-point & Group (s) & $\begin{array}{l}\log _{e} \text { (Age) } \\
(\log (y r s))\end{array}$ & $\begin{array}{c}\beta,(t-v \\
\text { Smoking } \\
(0 / 1)\end{array}$ & $\begin{array}{c}\text { 1ue) and } \\
\text { Father } \\
\text { History } \\
(0 / 1) \\
\end{array}$ & $\begin{array}{c}\text { tandardis } \\
\text { Systolic } \\
\text { BP } \\
(\mathrm{mmHg})\end{array}$ & 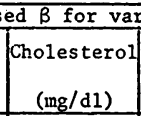 & $\begin{array}{c}\text { iables } \\
\text { Cholesterol } \\
\text { Change } \\
(\%) \\
\end{array}$ & $\begin{array}{c}\text { Treatment } \\
(1 / 2)\end{array}$ & Intercept \\
\hline 1 & Al1 I.H.D. & II & $\begin{array}{r}2.76 \\
(4.4) \\
0.40\end{array}$ & $\begin{array}{r}0.87 \\
(5.3) \\
0.43\end{array}$ & $\begin{array}{r}0.48 \\
(2.1) \\
0.21\end{array}$ & $\begin{array}{r}0.014 \\
(3.7) \\
0.25\end{array}$ & $\begin{array}{r}0.0084 \\
(3.4) \\
0.22\end{array}$ & & & -18.707 \\
\hline 2 & Al1 I.H.D. & III & $\begin{array}{r}5.21 \\
(4.4) \\
0.85\end{array}$ & $\begin{array}{r}1.08 \\
(3.6) \\
0.54\end{array}$ & $\begin{array}{l}-0.03 \\
(-0.1) \\
-0.01\end{array}$ & $\begin{array}{r}0.018 \\
(2.8) \\
0.31\end{array}$ & $\begin{array}{r}0.017 \\
(1.6) \\
0.21\end{array}$ & & & -29.416 \\
\hline 3 & Al1 I.H.D. & I & $\begin{array}{r}3.32 \\
(4.5) \\
0.48\end{array}$ & $\begin{array}{r}0.79 \\
\cdot(4.3) \\
0.39\end{array}$ & $\begin{array}{r}0.88 \\
(3.0) \\
0.38\end{array}$ & $\begin{array}{l}0.0064 \\
(1.4) \\
0.11\end{array}$ & $\begin{array}{r}0.011 \\
(4.6) \\
0.29\end{array}$ & & & -21.042 \\
\hline 4 & All I.H.D. & II/III & $\begin{array}{r}3.40 \\
(6.1) \\
0.53\end{array}$ & $\begin{array}{r}0.94 \\
(6.5) \\
0.47\end{array}$ & $\begin{array}{r}0.35 \\
(1.8) \\
0.16\end{array}$ & $\begin{array}{l}0.0153 \\
(4.6) \\
0.23\end{array}$ & $\begin{array}{l}0.012 \\
(8.1) \\
0.51\end{array}$ & & & -22.292 \\
\hline 5 & All I.H.D. & I/II & $\begin{array}{r}3.09 \\
(6.1) \\
0.44\end{array}$ & $\begin{array}{r}0.83 \\
(6.5) \\
0.41\end{array}$ & $\begin{array}{r}0.67 \\
(3.6) \\
0.29\end{array}$ & $\begin{array}{l}0.0126 \\
(4.2) \\
0.22\end{array}$ & $\begin{array}{l}0.010 \\
(5.1) \\
0.27\end{array}$ & $\begin{array}{l}0.023 \\
(3.9) \\
0.24\end{array}$ & & -20.430 \\
\hline 6 & All I.H.D. & I/II & $\begin{array}{r}3.00 \\
(6.3) \\
0.44\end{array}$ & $\begin{array}{r}0.83 \\
(6.8) \\
0.41\end{array}$ & $\begin{array}{r}0.64 \\
(3.6) \\
0.28\end{array}$ & $\begin{array}{l}0.011 \\
(3.7) \\
0.19\end{array}$ & $\begin{array}{l}0.0095 \\
(5.6) \\
0.26\end{array}$ & & $\begin{array}{r}-0.32 \\
(-2.9) \\
0.16\end{array}$ & -19.282 \\
\hline 7 & All I.H.D. & I/II & $\begin{array}{r}3.09 \\
(6.1) \\
0.22\end{array}$ & $\begin{array}{r}0.84 \\
(6.5) \\
0.21\end{array}$ & $\begin{array}{r}0.67 \\
(3.6) \\
0.29\end{array}$ & $\begin{array}{c}0.013 \\
(4.2) \\
0.22\end{array}$ & $\begin{array}{l}0.0099 \\
(5.0) \\
0.26\end{array}$ & $\begin{array}{r}0.019 \\
(3.0) \\
0.20\end{array}$ & $\begin{array}{l}-0.18 \\
(-1.4) \\
-0.09\end{array}$ & -20.145 \\
\hline 8 & $\begin{array}{l}\text { Non-fatal } \\
\text { M.I. }\end{array}$ & II & $\begin{array}{r}2.02 \\
(3.0) \\
0.29\end{array}$ & $\begin{array}{r}0.89 \\
(4.9) \\
0.44\end{array}$ & $\begin{array}{r}0.71 \\
(2.8) \\
0.31\end{array}$ & $\begin{array}{l}0.014 \\
(3.3) \\
0.24\end{array}$ & $\begin{array}{c}0.0072 \\
(2.6) \\
0.19\end{array}$ & & & -15.875 \\
\hline 9 & Fatal I.H.D. & II & $\begin{array}{r}7.46 \\
(4.1) \\
1.07\end{array}$ & $\begin{array}{r}0.80 \\
(2.1) \\
0.40\end{array}$ & $\begin{array}{l}-0.64 \\
(-1.4) \\
-0.28\end{array}$ & $\begin{array}{l}0.015 \\
(1.7) \\
0.26\end{array}$ & $\begin{array}{c}0.013 \\
(2.5) \\
0.33\end{array}$ & & & -39.128 \\
\hline 10 & $\begin{array}{l}\text { Non-I.H.D. } \\
\text { Deaths (in- } \\
\text { and }<1 \text { yr ex- } \\
\text { trial) }\end{array}$ & III & $\begin{array}{c}6.79 \\
(5.8) \\
1.11\end{array}$ & $\begin{array}{r}0.72 \\
(2.8) \\
0.36\end{array}$ & $\begin{array}{r}0.28 \\
(0.8) \\
0.13\end{array}$ & $\begin{array}{l}0.010 \\
(1.6) \\
0.17\end{array}$ & $\begin{array}{l}-0.012 \\
(-1.8) \\
-0.23\end{array}$ & & & -30.347 \\
\hline 11 & $\begin{array}{l}\text { Non-I.H.D. } \\
\text { deaths (in- } \\
\text { and<l yr ex- } \\
\text { trial) }\end{array}$ & III & $\begin{array}{r}6.88 \\
(6.1) \\
1.13\end{array}$ & $\begin{array}{r}0.70 \\
(2.7) \\
0.35\end{array}$ & & $\begin{array}{l}0 . \operatorname{cog} 9 \\
(1.5)\end{array}$ & & & & -32.472 \\
\hline 12 & $\begin{array}{l}\text { Non-I.H.D. } \\
\text { deaths (in- } \\
\text { and<l yr.ex- } \\
\text { trial) }\end{array}$ & III & $\begin{array}{r}7.10 \\
(6.4) \\
1.16\end{array}$ & & & & & & & -31.576 \\
\hline
\end{tabular}




\section{APPENDIX 3}

\section{DEFINITION OF END-POINTS OF VASCULAR DISEASES}

\section{Ischaemic heart disease}

The term ischaemic heart disease (I.H.D.) as used in the trial comprises major and minor events defined as follows:

\section{A. Major Events}

(1) Fatal events - these include deaths from myocardial infarction (as defined below) and deaths where it is not possible with certainty to diagnose myocardial infarction, but surrounding circumstances suggest that this is the cause.

Fatal events have been sub-divided into those occurring within 3 hours of the onset of symptoms, and those occurring between 3 hours and 28 days of the onset of symptoms

(2) Non-fatal myocardial infarction (see below) surviving more than 28 days.

(3) Acute coronary insufficiency (see below) surviving more than 28 days. These were classified with non-fatal myocardial infarction in the final analysis.

\section{B. Minor Events}

(1) Angina pectoris (see below) with an abnormal ECG (Minnesota codes $4.1,4.2,5.1,5.2,6.1,6.2,7.1,8.3$, $11.1,12.1,14.1)$.

(2) Angina pectoris without one of the above codable abnormalities.

(3) An abnormal ECG (as defined above) developing during the course of the trial without symptoms of chest pain to warrant classification by questionnaire as angina pectoris.

\section{Myocardial infarction}

Myocardial infarction was considered to have occurred when:

(1) The resting ECG developed Q-wave changes, classified by the Minnesota code as 1.1 or 1.2 , or 9.6 (a new category defined as follows: ST junction (J) and ST segment elevation of $1 \mathrm{~mm}$ or more with an upward sloping ST segment and a negative or diphasic $T$ wave, with the negative phase of at least $1 \mathrm{~mm}$. These changes must be present in at least two leads from $v_{2}-v_{6}$ and last for at least 3 days. The changes described were regarded as indicating recent intramural anterior myocardial infarction).

$\underline{\mathrm{OR}}$

(2) The resting ECG developed equivocal Q-wave changes (codable as 1.3) with elevated serum enzymes or with classical symptoms (prolonged chest pain of $\frac{1}{2}$ hour or more, acute breathlessness or syncope).

$\underline{\text { OR }}$

(3) There was a typical clinical picture with classical symptoms (see above) and elevated serum enzymes, but without definite ECG evidence. Consensus had to be reached on these cases at the Annual Review Meeting.

\section{Elevated serum enzymes}

These were interpreted in each centre according to the locally accepted ranges of normal and. abnormal.

\section{Acute coronary insufficiency}

This was defined as classical chest pain lasting more than $\frac{1}{2}$ hour at rest, with ECG abnormalities codable as 4.1 , 5.1 or 7.1 , but without elevation of serum enzymes.

\section{Angina pectoris}

This was said to be present when appropriate positive answers were given to item 23, "effort chest pain", on the follow-up form. (It was notifiable as newly arising in the trial only if the corresponding questions on the admission form were negative.) The answers to question 23 were said to be positive when positive answers were given to the first or second questions, "Have you ever had any pain or discomfort in your chest?" or "Have you' ever had any pressure or heaviness in your chest?" and the third question, "Do you get any of these when you walk uphill or hurry?" In addition the following questions must have been completed in the manner shown below:-

(1) What do you do if you get it while you are walking? Answer: stop or slow down.

(2) If you stand still what happens to it? Answer: relieved.

(3) How soon?

Answer: 10 minutes or less.

(4) Will you show me where it is/was?

Answer: 'sternum (upper middle), sternum lower, left anterior chest plus left arm. 


\section{Exercise ECG}

This was conducted on a bicycle ergometer using graded work loads of 50,100 and 150 watts, each of 4 minute duration, according to W.H.O. standards.

An exercise test was done in all cases of angina (positive effort chest pain questionnaire) with normal resting ECG. An intra-exercise ECG was said to be positive if the horizontal or downward sloping segment was depressed $2 \mathrm{~mm}$ or more; a post-exercise ECG was considered positive when codable as $11-1,12-1$ or $14-1$ at any time in the period of 1 to 10 minutes after the test had been stopped. Intra- or post-exercise ECG's were also considered positive if extrasystoles appeared exceeding $10 \%$ of the number of observed complexes (based on all ECG readings during the exercise test).

\section{Intermittent claudication}

This was said to be present when appropriate positive answers were given to item 24 , "leg pain", on the follow-up form (Addendum A). (It was notifiable as newly arising in the trial only if the corresponding questions on the admission form were negative.)

\section{Hypertension}

This was defined as:

(a) A diastolic blood pressure of 120 or greater on any one occasion.

(b) A diastolic blood pressure of 110-119 on any two occasions.

(c) A diastolic blood pressure of 110-119 on any one occasion if accompanied by ECG signs of left ventricular hypertrophy or strain (coded as 3.1 , or $3.3+5.2$, or as $3.3+5.3)$.

\section{Cerebrovascular disease}

No trial definitions were specified. Centres used their own conventions. 
APPENDIX 4 CENTRE DIFFERENCES (See Table 3)

Incidence of Major Ischaemic Heart Disease (IHD), Non-fatal and Fatal,

by Age at Entry

Rates per 1000 per annum

Edinburgh

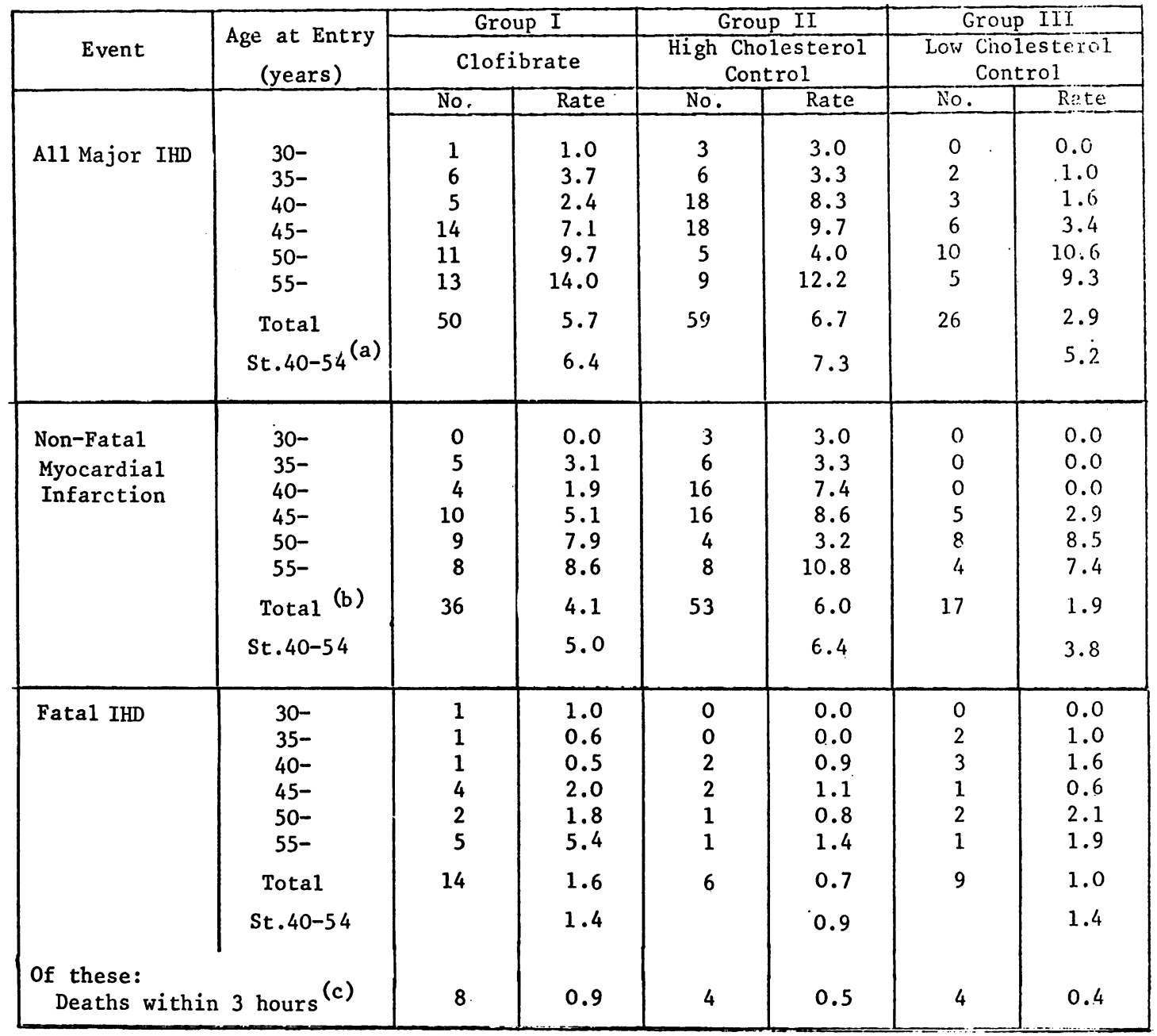

(a) Standardised rates for the three age-groups 40-44, 45-59, 50-54, equal weights being given to each age-group.

(b) Includes 4 with Acute Coronary Insufficiency (Intermediate Coronary Syndrome), 2,2 and 0 in Groups I, II and III respectively.

(c) The numbers of IHD deaths occurring from 3-12 hours were $1, .1$, 2, in the three Groups respectively. 
APPENDIX 4 CENTRE DIFFERENCES (See Table 3)

Incidence of Major Ischaemic Heart Disease (IHD), Non-fatal and Fatal, by Age at Entry

Rates per 1000 per annum

Budapest

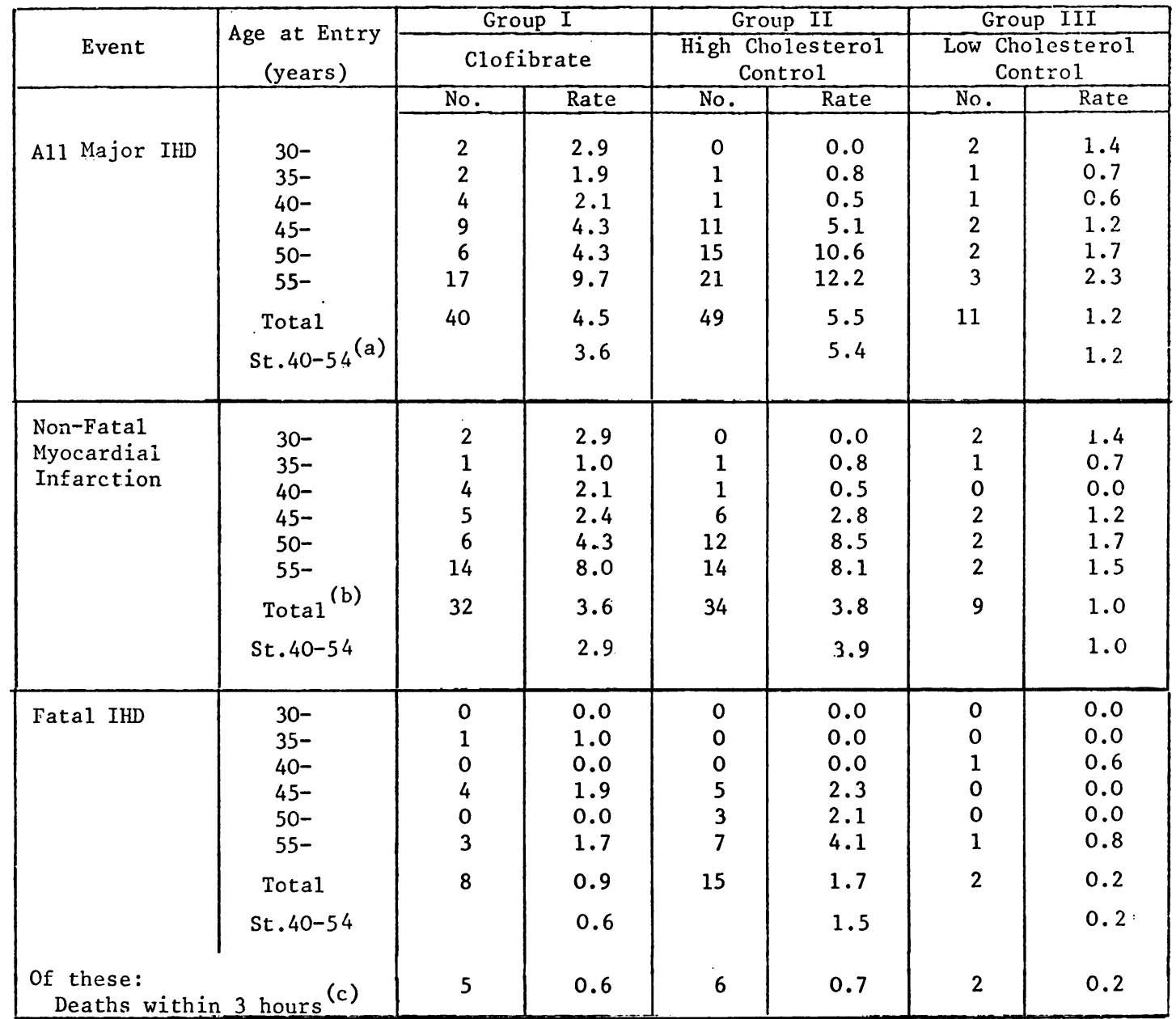

(a) Standardised rates for the three age-groups 40-44, 45-49,50-54, equal weights being given to each age-group.

(b) Includes 7 with Acute Coronary Insufficiency (Intermediate Coronary Syndrome) 2,4 and 1 in Groups I, II and III respectively.

(c) The numbers of IHD deaths occurring from 3-12 hours were $1,3,0$, in the three Groups respectively. 
APPENDIX 4 CENTRE DIFFERENCES (See Table 3)

Incidence of Major Ischaemic Heart Disease (IHD), Non-fatal and Fatal by Age at Entry

Rates per 1000 per annum

Prague

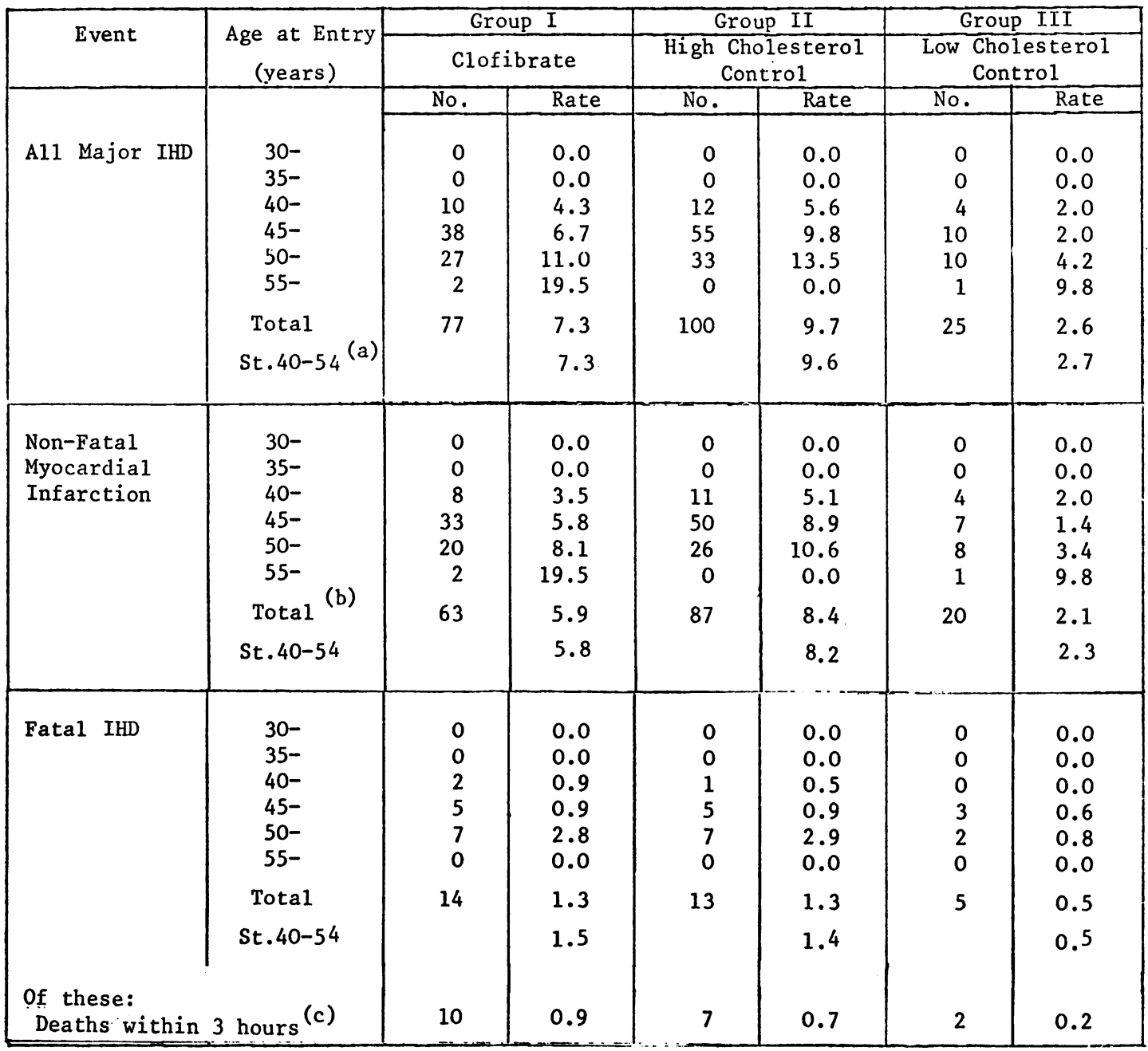

(a) Standardised rates for the three age-groups $40-44,45-49,50-54$, equal weights being given to each age-group.

(b) Includes 27 with Acute Coronary Insufficiency (Intermediate Coronary Syndrome) 14, 10 and 3 in Groups I, II and III respectively.

(c) The numbers of IHD deaths occurring from 3-12 hours were 2, 2, 1 in the three Groups respectively. 
APPENDIX 4 CENTRE DIFFERENCES (See Table 12)

Deaths in the Trial and within 1 year of leaving it

Main Cause Groups. Numbers of Deaths at Ages 30-59 and

Age-standardised Rates per 1000 per annum at ages 40-54

\begin{tabular}{|c|c|c|c|c|c|c|c|}
\hline \multirow{3}{*}{ Cause of Death } & \multirow{3}{*}{ Centre } & \multirow{2}{*}{\multicolumn{2}{|c|}{$\frac{\text { Group I }}{\text { Clofibrate }}$}} & \multicolumn{2}{|c|}{ Group II } & \multicolumn{2}{|c|}{ Group III } \\
\hline & & & & \multicolumn{2}{|c|}{$\begin{array}{c}\text { High Cholesterol } \\
\text { Control }\end{array}$} & \multicolumn{2}{|c|}{$\begin{array}{c}\text { Low Cholesterol } \\
\text { Control }\end{array}$} \\
\hline & & $\begin{array}{c}\text { Number } \\
\text { (A11 ages) }\end{array}$ & $\begin{array}{c}\text { Rate } \\
(40-54)\end{array}$ & $\begin{array}{c}\text { Number } \\
\text { (A11 ages) }\end{array}$ & $\begin{array}{c}\text { Rate } \\
(40-54) \\
\end{array}$ & $\begin{array}{c}\text { Number } \\
\text { (Al1 ages) }\end{array}$ & $\begin{array}{c}\text { Rate } \\
(40-54) \\
\end{array}$ \\
\hline \multirow{3}{*}{$\begin{array}{l}\text { Ischaemic Heart } \\
\text { Disease }\end{array}$} & Edinburgh & 18 & 1.6 & 12 & 1.4 & 9 & 1.2 \\
\hline & Budapest & 13 & 1.0 & 18 & 1.3 & 5 & 0.7 \\
\hline & Prague & 23 & 2.0 & 18 & 1.5 & 6 & 0.5 \\
\hline \multirow[t]{3}{*}{ Other Vascular } & Edinburgh & 1 & 0.0 & 6 & 0.5 & 1 & 0.2 \\
\hline & Budapest & 7 & 1.0 & 3 & 0.2 & 5 & 0.6 \\
\hline & Prague & 6 & 0.4 & 5 & 0.6 & 3 & 0.2 \\
\hline \multirow[t]{3}{*}{ Neoplasm: malignant } & Edinburgh & 12 & 1.5 & 12 & 1.0 & 9 & 0.6 \\
\hline & Budapest & 24 & 2.9 & 14 & 1.1 & 14 & 1.8 \\
\hline & Prague & 22 & 1.9 & 16 & 1.2 & 18 & 1.5 \\
\hline \multirow[t]{3}{*}{ Neoplasm: benign } & Edinburgh & 1 & - & - & - & 1 & - \\
\hline & Budapest & - & - & - & - & - & - \\
\hline & Prague & 2 & - & - & - & - & - \\
\hline \multirow[t]{3}{*}{ Other Medical Causes } & Edinburgh & 2 & 0.0 & 1 & 0.1 & 0 & 0.0 \\
\hline & Budapest & 8 & 0.5 & 2 & 0.2 & 1 & 0.2 \\
\hline & Prague & 6 & 0.6 & 2 & 0.2 & 6 & 0.5 \\
\hline \multirow[t]{3}{*}{ Accidents \& Violence } & Edinburgh & 5 & 0.4 & 1 & 0.1 & 1 & 0.0 \\
\hline & Budapest & 8 & 0.9 & 6 & 0.8 & 9 & 1.3 \\
\hline & Prague & 4 & 0.3 & 11 & 1.0 & 5 & 0.4 \\
\hline \multirow{3}{*}{$\begin{array}{l}\text { All causes other than } \\
\text { I.H.D. }\end{array}$} & Edinburgh & 21 & 2.0 & 20 & 1.8 & 12 & 0.8 \\
\hline & Budapest & $47 * *$ & 5.3 & $25 * *$ & 2.3 & 29 & 3.9 \\
\hline & Prague & 40 & 3.4 & 34 & 3.0 & 32 & 2.8 \\
\hline \multirow{3}{*}{$\begin{array}{l}\text { All cause other than } \\
\text { I.H.D., Vascular and } \\
\text { Accidents \& Violence }\end{array}$} & Edinburgh & 15 & 1.6 & 13 & 1.2 & 10 & 0.6 \\
\hline & Budapest & $32 *$ & 3.4 & $16 *$ & 1.3 & 15 & 2.0 \\
\hline & Prague & 30 & 2.7 & 18 & 1.5 & 24 & 2.1 \\
\hline \multirow[t]{3}{*}{ TOTAL ALL CAUSES } & Edinburgh & 39 & 3.6 & 32 & 3.2 & 21 & 2.0 \\
\hline & Budapest & 60 & 6.3 & 43 & 3.5 & 34 & 4.6 \\
\hline & Prague & 63 & 5.4 & 52 & 4.5 & 38 & 3.2 \\
\hline
\end{tabular}

* Significant difference between Groups I and II $(P<0.05)$.

** Significant difference between Groups I and II $(P<0.01)$. 


\section{APPENDIX 5}

Drug Adherence Group I

(i) Average concentrations of Clofibrate (CPIB) ( $\mu \mathrm{g} / \mathrm{ml})$

\begin{tabular}{|l|c|c|c|c|c|}
\hline \multirow{2}{*}{ Centre } & \multicolumn{5}{|c|}{ Years in trial } \\
\cline { 2 - 6 } & 1 & 2 & 3 & 4 & 5 \\
\hline \multirow{2}{*}{ Edinburgh } & 142 & 141 & 151 & 157 & - \\
Budapest & 132 & 141 & 134 & 129 & 1.24 \\
Prague & 156 & 165 & 159 & 171 & 171 \\
\hline
\end{tabular}

(ii)

\begin{tabular}{|l|c|c|}
\hline \multirow{2}{*}{ Centre } & \multicolumn{2}{|c|}{ Percentage of negative estimates in: } \\
\cline { 2 - 3 } & $\begin{array}{c}\text { Men with a major } \\
\text { I.H.D. event }\end{array}$ & All men \\
\hline Edinburgh & $\%$ & $\%$ \\
Budapest & 3 & 6 \\
Prague & 12 & 6 \\
& 13 & 9 \\
\hline
\end{tabular}

(iii) Average concentrations of clofibrate (CPIB)

\begin{tabular}{|l|l|r|r|r|r|r|r|r|}
\hline & \multicolumn{1}{|c|}{ Centre } & \multicolumn{6}{|c|}{ Visit number } \\
\cline { 2 - 8 } Men with a major & Edinburgh & 172 & 145 & 158 & 132 & 154 & 145 & 150 \\
IHD event & Budapest & 128 & 135 & 116 & 160 & 144 & 114 & 91 \\
(value at visit & Prague & 148 & 145 & 156 & 159 & 141 & 166 & 164 \\
imediate1y \\
preceding IHD \\
event).
\end{tabular}


APPENDIX 6

Conditions not necessarily causing withdrawal from the trial but recorded as possible side effects

\begin{tabular}{|c|c|c|c|c|c|c|c|c|c|c|c|c|c|}
\hline \multirow{2}{*}{ Condition } & \multicolumn{3}{|c|}{ Edinburgh } & \multicolumn{3}{|c|}{ Budapest } & \multicolumn{3}{|c|}{ Prague } & \multicolumn{4}{|c|}{ A11 Centres } \\
\hline & I & II & III & I & II & III & I & II & III & I & II & III & Total \\
\hline Endocrine, Metabolic Diseases & & & & & & & & & & & & & \\
\hline Weight gain & $66 * x$ & $24 * x$ & 36 & 25 & 15 & 13 & 8 & 2 & 1 & $99^{\circ} \times$ & $41^{* *}$ & 50 & 190 \\
\hline Mental Disorders & & & & & & & & & & & & & \\
\hline Impotence & 13 & 7 & 14 & 18 & 16 & 7 & $27^{* *}$ & $10^{* * *}$ & 10 & $5 S^{* i}$ & $33^{* *}$ & 31 & 122 \\
\hline Diseases of Circulatory Sys. & & & & & & & & & & & & & \\
\hline Cardiac Arrhythmia & - & - & 2 & - & - & - & - & - & - & - & - & 2 & 2 \\
\hline Diseases of Respiratory Sys. & & & & & & & & & & & & & \\
\hline Catarrh, coryza & 2 & 2 & 2 & - & - & - & - & - & - & 2 & 2 & 2 & 6 \\
\hline Diseases of Digestive System & & & & & & & & & & & & & \\
\hline Aggravation of peptic ulcer & - & - & 1 & - & - & - & - & - & - & -1 & - & 1 & 1 \\
\hline Indigestion, abdom. symptoms & 168 & 163 & 119 & $43 *$ & 23 * & 21 & $10 \%$ & $55 * x$ & 59 & $1320 * \frac{1}{4}$ & $241^{* *}$ & 199 & 760 \\
\hline Constipation & 20 & 19 & 24 & 5 & 4 & 1 & 3 & 3 & 2 & 26 & 26 & 27 & 81 \\
\hline Intestinal hurry & $130 * x$ & $90 * *$ & 121 & 9 & 16 & 13 & 31 & 20 & 23 & $170^{*}$ & $120^{*}$ & 157 & 453 \\
\hline Diseases of the Skin & & & & & & & & & & & & & \\
\hline Pruritus & 2 & - & - & 6 & 5 & 4 & 4 & - & 3 & 12 & 5 & 7 & 24 \\
\hline Alopecia & 2 & 2 & 1 & 1 & 1 & 1 & - & - & - & 3 & 3 & 2 & 8 \\
\hline Hirsutism & 1 & - & - & - & - & - & - & - & - & 1 & - & - & 1 \\
\hline Symptoms \& I11-defined & & & & & & & & & & & & & \\
\hline Conditions & & & & & & & & & & & & & \\
\hline Dizziness & 7 & 6 & 7 & 6 & 4 & 12 & 3 & 7 & 5 & 16 & 17 & 24 & 57 \\
\hline Sleep Disturbance & 6 & 2 & 4 & 7 & 7 & 6 & 8 & 11 & 4 & 21 & 20 & 14 & 55 \\
\hline Ocular symptoms & - & 2 & - & - & - & - & - & - & - & - & 2 & - & 2 \\
\hline Dental symptoms & 1 & 1 & - & - & - & - & - & - & - & $\mathbf{i}$ & 1 & - & 2 \\
\hline Paraesthesia & 2 & 6 & 5 & 6 & 7 & 12 & 6 & 5 & 8 & 14 & 18 & 25 & 57 \\
\hline Epistaxis & 15 & 18 & 21 & 1 & 3 & 1 & $\epsilon$ & 2 & 2 & 22 & 23 & 24 & 69 \\
\hline Chest discomfort & 1. & 2 & - & - & - & - & - & - & - & 1 & 2 & - & 3 \\
\hline Anorexia & 1 & 1 & $?$ & - & - & -- & - & - & - & 1 & 1 & 2 & 4 \\
\hline Nausea & 2 & - & 1 & - & - & - & - & - & - & 2. & - & 1 & 3 \\
\hline Urinary symptoms & 3 & 1 . & 3 & 6 & 3 & - & 1 & - & 1 & 10 & 4 & 4 & 18 \\
\hline Muscular cramps & 10 & 7 & 5 & 4 & 5 & 4 & 3 & 2 & - & 17 & 14 & 9 & 40 \\
\hline Arthralgia & 1 & 7 & 5 & - & - & 1 & 3 & 3 & 2 & 4 & 10 & 8 & 22 \\
\hline Hyperhidrosis & $24 * *$ & $7 * k$ & 7 & 4 & 7 & 3 & 1 & 3 & - & 29 & 17 & 10 & 56 \\
\hline Rash & 29 & 24 & 21 & 9 & 12 & 5 & 16 & 12 & 17 & $54^{\circ}$ & 48 & 43 & 145 \\
\hline Increased appetite, thirst & 7 & 3 & 2 & 8 & 2 & 10 & 7 & 2 & 2 & 22 & 7 & 14 & 43 \\
\hline Fatigue, depression & 31 & 30 & 24 & 7 & 5 & 5 & 13 & 13 & 11 & 51 & 48 & 40 & 139 \\
\hline Headache & 4 & 4 & 6 & 9 & 6 & 1 & 2 & 3 & 11 & 15 & 13 & 18 & 46 \\
\hline Coldness & 8 & 10 & 6 & 2 & 3 & - & - & 1 & - & 10 & 14 & 6 & 30 \\
\hline $\begin{array}{l}\text { Reduced tolerance to } \\
\text { alcohol }\end{array}$ & 2 & 6 & 6 & - & 1 & 2 & - & - & - & 2 & 7 & 8 & 17 \\
\hline Other & - & - & - & - & 1 & - & - & - & - & - & 1 & - & $?$ \\
\hline
\end{tabular}

* Significant difference between Groups $I$ and II $(P<0.05)$.

** Significant difference between Groups. I and II $(P<0.01)$. 